\title{
HOW HAS ACCESS TO GENERAL PRACTITIONER SERVICES CHANGED SINCE THE PRIMARY HEALTH CARE STRATEGY 2001?
}

BY

MICHAEL THOMSON

A thesis submitted to Victoria University of Wellington in fulfilment of the requirements of PUBL 591 for the degree of Master of Arts in Public Policy

VICTORIA UNIVERSITY OF WELLINGTON 
Abstract

With a governmental review of the health system impending, it is timely to examine whether the universal capitation-based subsidies engendered by the 2001 Primary Health Care Strategy have achieved and maintained their strategic goal of expanding access to general practitioners and reducing inequities. Prior scholarship finds evidence of reduced fees and increased consultation numbers and rates during the roll-out period, but the long-run picture remains unexplored, and there are multiple hitherto unexamined sources of endogeneity to unravel. This thesis addresses these gaps by examining New Zealand Health Survey data between 2002/03 and 2015/16. I examine the distribution of co-payments, utilisation and unmet need due to cost using regression modelling, accounting for endogenous self-reporting errors and selection effects through instrumentation and Heckman modelling, respectively. I propose a novel instrument to account for selection bias in self-reported fees, applicable in contexts where general practitioners play 'gate-keeping' roles for tertiary services.

I find that the expanded universal subsidies were associated with improved access for Māori and more preventive visits as intended. However, patients with the greatest health need made far fewer doctors' visits per annum than before. After providing universal subsidisation, the fees paid by high- and low-income groups also converged, and low-to-middle-income earners made more use of services but high-income earners did not. The higher rates of utilisation for both the whole population and for Māori have not survived in recent years. I discuss a range of possible explanations for these developments, with particular attention paid to the role of both the capitation subsidies and the subsequent Very-Low Cost Access pricecapping scheme.

This research contributes evidence to international scholarship on the link between universal healthcare subsidisation and equity of access, with attention to local nuances. It further provides domestic policymakers with an understanding of the contemporary scope and correlates of poor healthcare access ahead of the health system review. 


\section{Acknowledgements}

I would like to extend gratitude to my supervisor, Professor Jackie Cumming, for giving me the opportunity to work and study at Health Services Research Centre. The Centre has trusted me to undertake independent research and develop myself at my own pace. I have particularly enjoyed joining the team each morning for a coffee and quiz break to clear my head of capitation funding and Heckman selection modelling.

A special acknowledgement deserves to be given to Dr. Thomas Stubbs for continuing to mentor me from the other side of the world. I'm indebted to you for the time and effort you have invested in my development, the opportunities you have offered me, and the belief you've demonstrated in my ability.

I was privileged to explore the inner workings of policy-making during my time as an intern at Treasury, and I believe this experience significantly strengthened the quality of my thesis. Thank you to Andrew, Jennie, Richard, Abbas, Kate, Margaret, Nic, Victoria, Amarind, and everyone else who helped to make my time as an intern deeply fulfilling. I am excited to have returned recently as a graduate analyst.

Writing a thesis can be an existential task, and I'm particularly grateful to my flatmates and the warm community of friends I have made in Wellington for keeping me grounded and relaxed. Special thanks to my mother Mary-Ann, sister Kelsey, and girlfriend Laura for lending me undue patience whenever I excitedly describe improvements to my research design. I promise I'll find better conversation topics once my thesis is submitted.

I dedicate this thesis to my father who very suddenly passed away shortly before I could complete this work. I owe my love of learning to you, which is in my view the highest compliment a teacher can receive. I know you would have been proud to see what I've accomplished. 


\section{Contents}

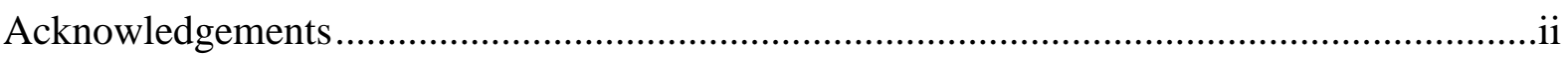

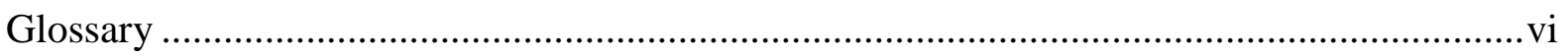

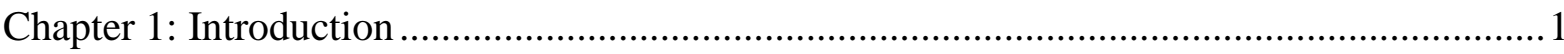

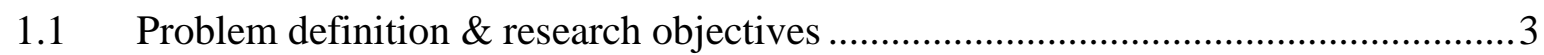

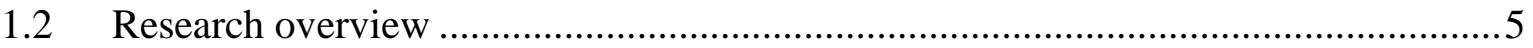

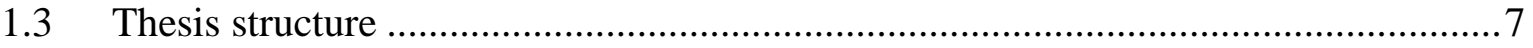

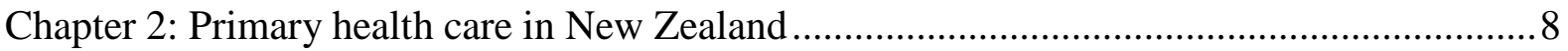

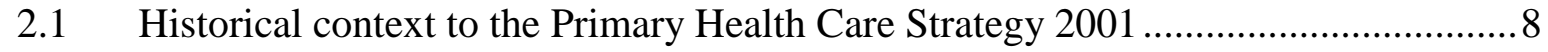

2.2 The Primary Health Care Strategy and the current primary health system................9

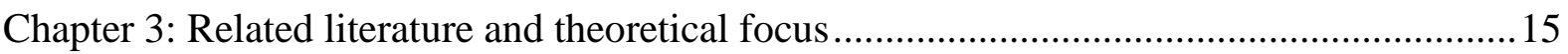

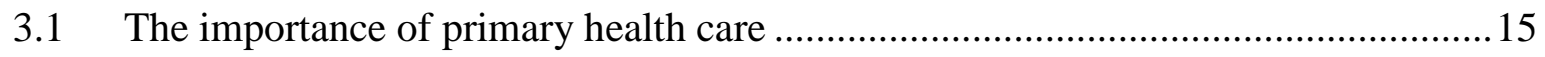

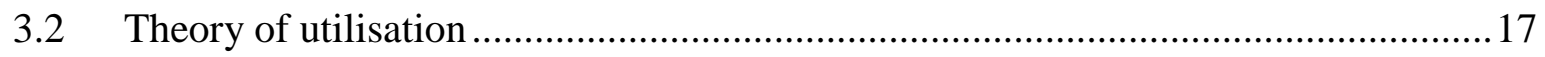

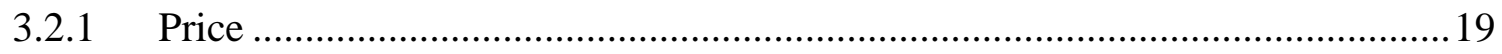

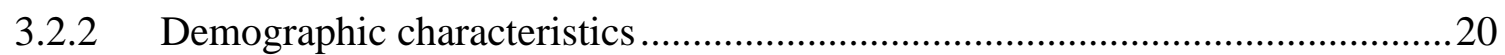

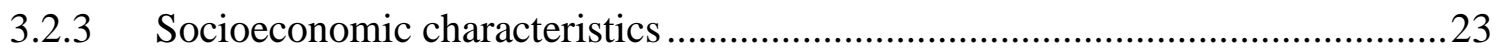

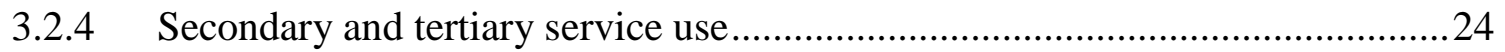

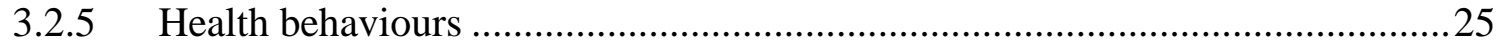

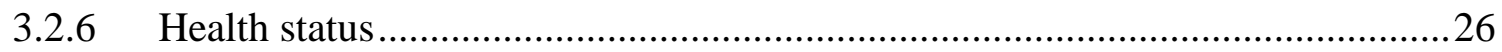

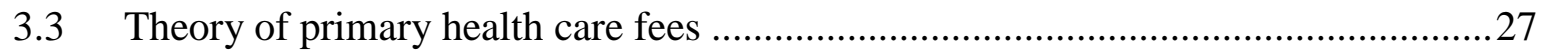

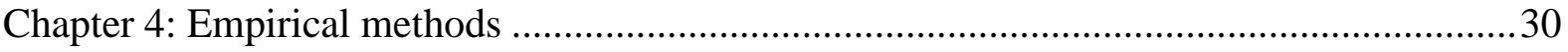

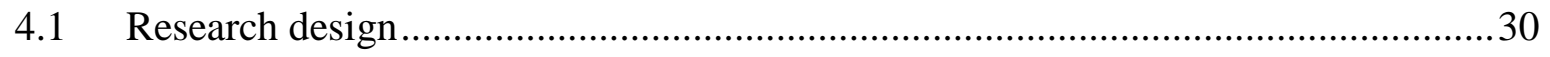

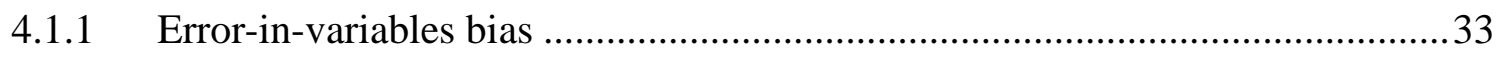

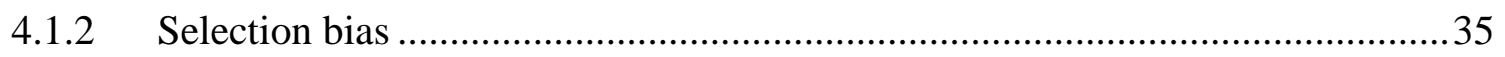

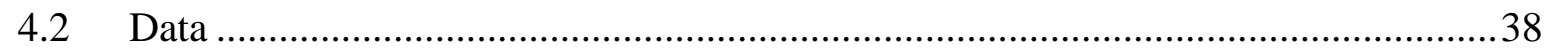

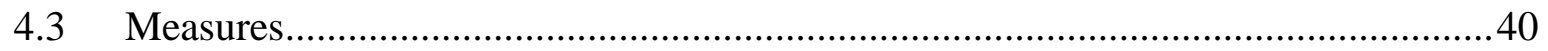

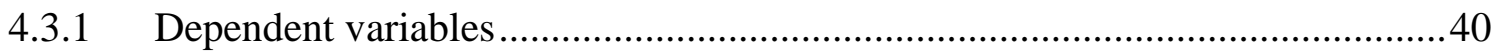




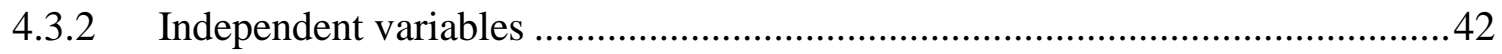

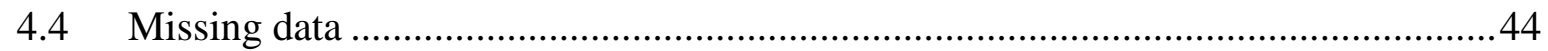

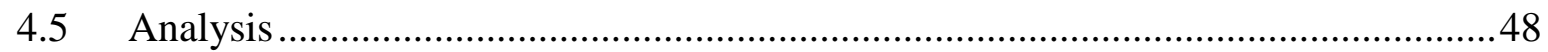

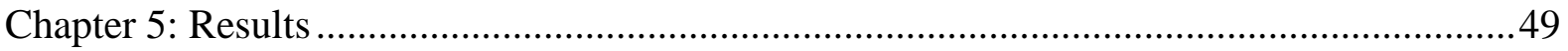

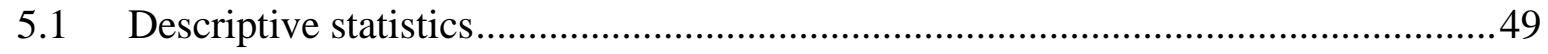

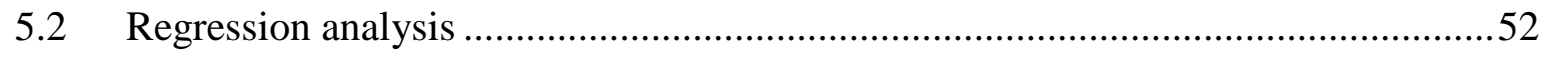

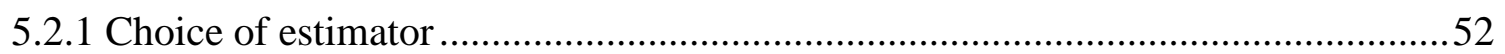

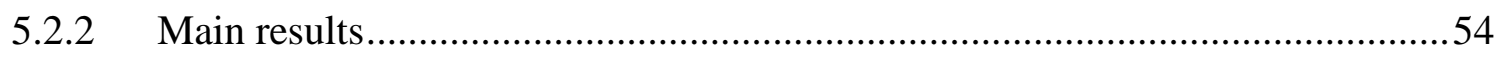

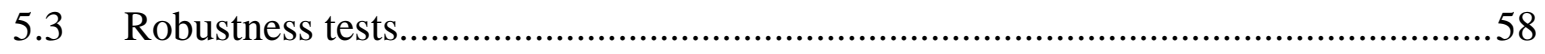

5.3.1 Chronic conditions, simultaneity, and error-in-variables bias ...........................58

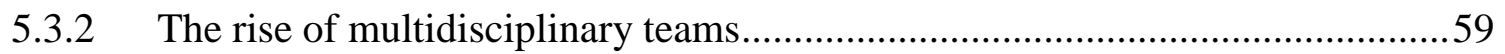

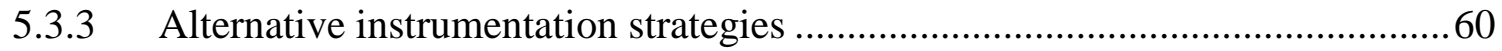

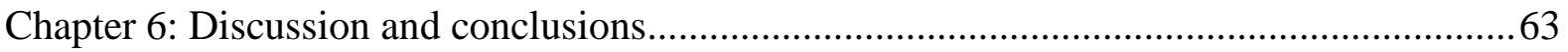

6.1 How have fees for and access to GPs changed since the PHCS was adopted?........63

6.2 How has the distribution of co-payments and access changed over time? ..............67

6.2.1 Distribution prior to roll-out of First-Contact subsidies ................................. 67

6.2.2 Distribution following First-Contact subsidy expansion ................................69

6.2.3 Distribution following the establishment of VLCA .......................................... 70

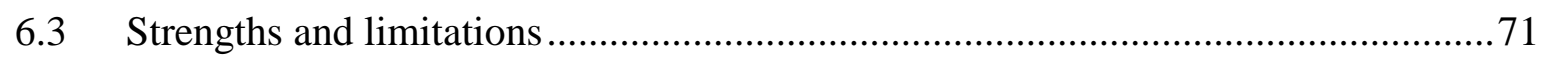

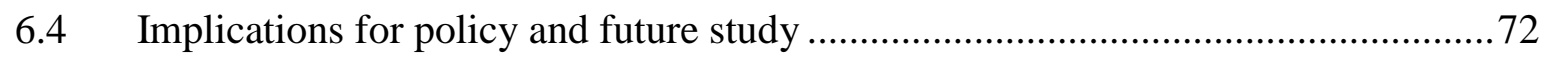

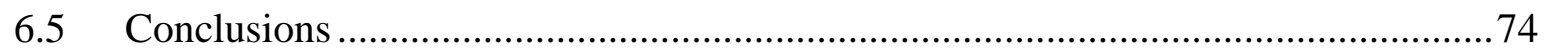

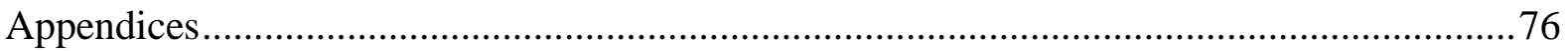

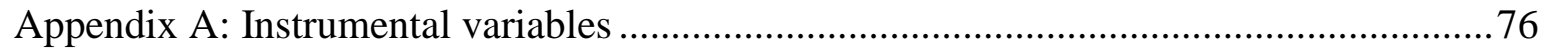

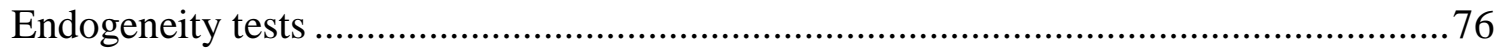

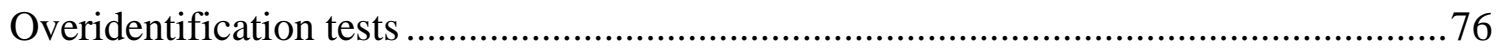

Appendix B: Validity of self-reported fees............................................................. 77

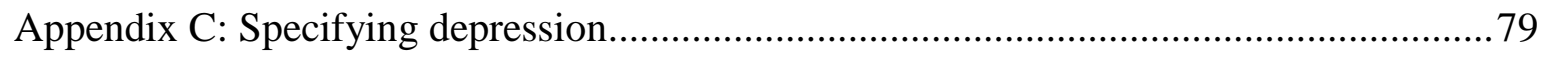




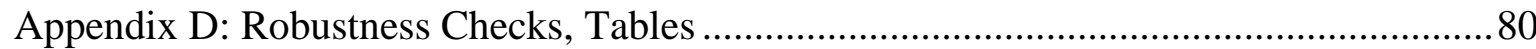




\section{Glossary}

BMI - Body Mass Index

CSC - Community Services Card

DHB - District Health Board

ED - Emergency department

GP - General practitioner

HUHC - High Use Health Card

MAR - Missing at random

MCAR - Missing completely at random

MNAR - Missing not at random

NZD - New Zealand Dollars

NZDep - New Zealand Deprivation Index

NZHS - New Zealand Health Survey

PHC - Primary health care

PHCS - Primary Health Care Strategy

PHO - Primary Health Organisation

VLCA - Very-Low Cost Access 


\section{Chapter 1: Introduction}

The Primary Health Care Strategy (PHCS) of 2001 produced some of the country's most significant healthcare reforms in recent history, entailing an historical return from a targeted model of healthcare subsidies to a universal model [1]. The reforms paid intellectual homage to the First Labour Government's (1935-1949) vision of a comprehensive universal health system and the 1978 Declaration of Alma Ata's conceptualisation of primary health care (PHC) as the focal point for effective population health intervention [2, 3]. PHC is defined in the Declaration as a universally accessible point of first contact for individuals in their communities to receive essential healthcare (pp. 1-2), and generally refers to services provided by community-based health centres and, in New Zealand, general practices. Comprehensive and well-integrated PHC systems are associated with more equitable access to and outcomes resulting from health care, and reduced mortalities and morbidities, in comparison to systems with greater reliance on specialists [4-6].

While PHC subsidies in New Zealand were directed primarily at populations of interest such as low-income earners and children in the 1990s [7], some contemporary commentators worried the system was particularly difficult to access for Māori, Pasifika, low-income earners, and those with high health needs [8-11]. In response, the PHCS promised to substantially increase funding for PHC in an attempt to reduce co-payments and enable the development of Primary Health Organisations (PHOs) to co-ordinate and develop PHC services. The PHCS also sought to shift the financial incentives for general practitioners (GPs) away from maximising consultations and toward effectively managing the drivers of population health, by subsidising services via a formula derived from population characteristics at the PHO level rather than by reimbursing fees for service at the GP level [12]. While universal subsidies were restored to meaningful levels, significant co-payments remained at rates determined by individual general practitioners [12]. These residual costs, comprising an estimated 30 percent balance-billing payment for service users on average [13], are the subject of ongoing policy attention. Indeed, both major political parties campaigned on increases in health spending intended to improve GP access in the 2017 election, with the incumbent National Party targeting fee caps at low-income Community Services Card (CSC) holders, and the Labour Party proposing \$10 co-payment reductions across the board $[14,15]$. Since taking office, the Labour-led government has announced 
intention to conduct a comprehensive health system review incorporating its previous plans to review PHC funding [15-17].

International literature on determinants of access suggests reductions in co-payments are associated with increases in both appropriate and inappropriate utilisation of services [1820]. However, access commonly remains asymmetrically distributed across population groups even after expansion of subsidies. Previous studies in jurisdictions with universal healthcare coverage find unmet health need to be most prevalent among, inter alia, women, younger age-groups, minority ethnicities, low-income earners, those not enrolled with a PHC provider, those without medical insurance, and those with chronic conditions [21-26].

In New Zealand, early evaluations of the PHCS provide evidence of reduced costs and increased consultation numbers, particularly for groups that received priority in the rollout of new funding such as those aged 65 and over, and those enrolled in practices with high-needs populations [7, 12, 27, 28]. However, both earlier and more recent studies suggest inequities in access are ongoing, particularly for younger women, Māori and Pacific Peoples, and people living with chronic conditions [23, 26, 29]. Furthermore, the roll-out of PHC subsidies does not appear to have directly substituted ambulatory-sensitive demand for hospitals as hoped, and instead may play a more complex complementary role [30].

The existing evidence base could be strengthened with attention to a number of present shortcomings. First, while prior studies have covered the immediate roll-out period of subsidies, examining longer-term trends is desirable to discount the possibility of transient effects such as the relief of pent-up demand following expectations of lowered fees. Second, no studies of access in New Zealand currently control for systematic differences in the way different social groups self-report their health, which artificially reduces the observed difference in utilisation between healthier and less healthy groups [31, 32]. For example, more educated respondents have been found to self-report more negatively due to better selftriaging of health conditions and self-comparisons to healthier peers, amongst other reasons [32]. Relatedly, no existing studies on the price paid for GP visits in New Zealand explore the extent to which selection bias affects the estimated relationships. The research presented in this thesis builds upon earlier evaluations with specific focus on addressing the shortcomings in the present literature body. 


\subsection{Problem definition \& research objectives}

This study seeks to infer how access to GPs has changed following the expansion of universal subsidisation associated with the PHCS in 2001. For access to be equitable, it should not differ by health need or social characteristics such as ethnicity and income, after holding all other characteristics equal. Moreover, there should be more equitable access over time if the PHCS has met its objectives unhindered.

To investigate whether this is the case, I establish two guiding research questions:

1. How have fees for and access to GPs changed since the PHCS was adopted?

2. How has the distribution of these variables changed over time?

Answering these questions in a robust manner involves overcoming a number of key empirical challenges. The following characteristics of the field of study have underpinned my selection of methods and interpretation of results:

- Access is unobservable: Access refers to the potential to visit health services when needed, and hence is inherently unobservable. Inferences into access therefore rely upon careful examination of proxy measures such as likelihood of making a visit, number of visits made per year, and likelihood of reporting unmet need.

- Associative inference: The most comprehensive source of PHC data in New Zealand is a cross-sectional household survey, which inhibits the ability to draw causal inferences and instead lends itself to associative interpretation of the relationships between variables. Causal claims commonly (but not always) rest upon the validation that the 'cause' preceded the 'effect' [33]. Because each survey wave consists of a sample of different individuals, it is not possible to take before-and-after measurements. Cross-sectional data is not suited to controlling for unobserved timeconstant effects specific to each individual, such as their propensity to self-report a given way, or their biological predisposition toward illness.

- Simultaneity bias: Relatedly, cross-sectional data warrants limited conclusions about whether an observed increase in utilisation reflects better access to services or poorer population health, because health and health service use simultaneously influence each other. Conceptually, unhealthy individuals self-select into visiting doctors, and subsequently receive a service which can be expected to improve both their health and 
their accuracy in self-evaluating their health status. Without first separating out the confounding simultaneous effect of health on utilisation, inferences into access are subject to bias.

- Endogenous measurement error: The way in which people self-report their health status in household surveys is asymmetric across population groups [31]. In particular, more educated groups have been found to report their health more negatively for any given level of objective health, due to greater ability to self-triage and self-comparisons against a healthier peer group, amongst other reasons [32]. This is expected to narrow observed differences between groups if left unadjusted.

- Sample selection bias: Data sources are only able to record fees data for those who, by definition, have been able to pay for services. Hence, there is a classic sample selection problem as described in the seminal work of Heckman [34]. Failure to observe the very participants who are least likely to be able to afford health services is expected to reduce differences observed between groups.

- Missing data: Substantial portions of data are missing on some variables, most notably household income. If the likelihood of having missing data is systematically related to the values of other covariates or the missing values themselves, then estimates will be biased.

- Lack of randomised treatment: It is difficult to directly measure the independent effect of universal subsidies because there is no meaningful 'control group' with which to observe the counterfactual non-adoption of the PHCS. Other studies have observationally reported the differential impacts on population groups who received early rollout of increased subsidies against those who did not [7]; however, selection into these 'treatment' groups was non-random, being selected by age-group and population need as determined via Access/Very-Low Cost Access (VLCA) funding formulae. Without a meaningful control group, it is not easy to distinguish the effects of the PHCS from contemporary historical events that may have influence over practice fees and utilisation, including government programmes targeting rheumatic fever and home insulation, the introduction of Working For Families tax credits, and the Global Financial Crisis [35]. 
In short, the challenge is to infer changes in access to GPs, controlling for potential sources of bias in the data. I will now describe the empirical approach adopted to achieve this goal and briefly summarise the key findings.

\subsection{Research overview}

In this study, health service demand is conceptualised using a utility maximisation framework in which individuals invest in their 'stock' of health by paying for health services [36]. Health is 'purchased' by combining time spent on producing health (for example, exercise) with the consumption of goods that affect health (for example, doctor's visits). The price an individual is willing to pay for healthcare will vary with the unobserved value they place on their own health, which is expected to rise with the 'depreciation' on health stock associated with age and fall with the improved efficiency in producing health associated with education. Individuals will access health services only when their 'reservation price' - the highest price they would be willing to pay for healthcare - is at or above the market price for health services.

Using seven waves of New Zealand Health Survey (NZHS) data, I examine how proxies of access and their determinants have changed since the PHCS has come into force. Access is inferred by observing relationships between population characteristics and the fees paid for consultation, the likelihood of utilising services, the number of visits made, and the likelihood of reporting unmet need due to cost. Careful examination of patterns across these variables can yield inference that may help to disentangle the simultaneous relationship between health and service use, and therefore provide insight into access. For example, if Māori ethnicity is associated with a lower likelihood of making at least one past-year GP visit, but a higher overall average number of visits per year and a greater likelihood of reporting unmet need due to cost, the results would support prior evidence finding Māori face a greater intensity of health need alongside poorer access to services compared to NZ Europeans/Other ethnicities [23, 26, 37, 38]. Changes over time are assessed by comparing how the dependent variables were distributed prior to the roll-out of new subsidies, following the roll-out of subsidies, and in recent years characterised by the VLCA system of low-cost access.

This study's econometric methods help to address some of the aforementioned empirical challenges. I use regression modelling to estimate the association between proxies of access and a range of social and health characteristics. I follow the example of previous 
studies by identifying and correcting for systematic differences in how various groups selfreport their health by using an objective health instrument $[31,32]$. Simultaneity between health and health service use (and prices) are assessed in two ways: firstly, by examining patterns across models using different proxies of access as outcome variables as described above; and secondly by examining differences in coefficients when health variables are included or omitted. To address the sample selection issue in the estimation of fees, I adjust for the probability of each participant having their data observed using a novel excludable instrument. Missing data for household income was modelled as a distinct variable level, while various types of missingness for the objective health instrument were controlled for with survey-wave-interacted dummies. Results are interpreted with appropriate attention to their associative nature, which limits inferences into causality and does not fully control for contemporary historical influences.

My analysis shows that the targeted subsidies prior to new funding successfully distributed co-payments largely on the basis of income and health status, the latter finding contrasting an earlier analysis which did not instrument out the self-reporting errors in the global health status variable [27]. With the roll-out of the majority of new capitation funding by $2006 / 07$, utilisation rates increased for most patients. As the policy intended, Māori utilisation increased and people visited doctors while still in good health as part of a 'preventive' transition. However, the highest income earners also now paid similar fees to the lowest earners without making any additional doctors' visits and the highest-need patients made far fewer visits per year.

These trends have mostly held steady through the more recent VLCA era, but Māori no longer have improved utilisation rates. Fees for some typically-healthy groups such as Asians have fallen substantially without any accompanying increase in service use. Unmet need due to cost remains more common among women, 25-44 year olds, Māori, low-income earners, people in more deprived areas, and people with poor health, chronic conditions, and depressive feelings.

The study is significant for a number of reasons. From a policy perspective, it informs the government's review of the health system by identifying ongoing price barriers to PHC access for specific population groups and exploring the distributional changes associated with previous subsidies. The study can also help to disentangle the influence of the later VLCA scheme of price-capping. Methodologically, it proposes a novel excludable instrument to 
account for selection bias in self-reported fees, applicable in contexts where general practitioners play 'gate-keeping' roles for tertiary services. It is also the first study in the New Zealand context to correct biases in self-rated health status using an objective health instrument. Finally, this study contributes to the broader state of knowledge by providing a case-study in the long-term distributional changes associated with universal subsidy expansions and subsequent practice-level price-capping.

\subsection{Thesis structure}

This thesis is structured to provide the reader with general context before narrowing its scope to the empirical investigation of focus. It begins by contextualising the PHCS within the history of PHC reforms in New Zealand in Chapter Two. Understanding the rationale and impetus for the PHCS is essential to evaluating its success. In Chapter Three, I review the literature on PHC and discuss how theory suggests utilisation and PHC fees are determined. The discussion of prior literature motivates the empirical methods used to investigate access to GPs in this study, outlined in Chapter Four. Chapter Five presents the results and checks their robustness against alternative methodological choices. Finally, Chapter Six interprets the outcomes in light of the study's strengths and weaknesses and draws conclusions for policy and further study. 


\section{Chapter 2: Primary health care in New Zealand}

Universal access to PHC subsidies has expanded and contracted considerably over the course of New Zealand's history as different groups and ideologies have come to power. The universal subsidies established by the democratic socialist First Labour Government are sharply contrasted by the exclusively targeted subsidies accompanying the neoliberal reforms of the early 1990s. This ideological tug-of-war forms the backdrop for the adoption of the PHCS. In this chapter, I orient the reader with the history of New Zealand's PHC system. Having a clear understanding of the rationale behind the PHCS in context will allow better understanding of how to evaluate its success.

\subsection{Historical context to the Primary Health Care Strategy 2001}

Reforms enacted by the First Labour Government (1935-1949) established many ongoing features of New Zealand's health system, including the first subsidies for PHC [3]. The government envisaged a comprehensive and integrated public health care system with universal access to tax-payer funded services. This vision was partially recognised through the Social Security Act 1938, which introduced free hospital treatment and medicines, and subsidised other services for children under 16 [39]. However, efforts to extend these arrangements to PHC were met with opposition from the British Medical Association (representing New Zealand GPs at the time), who argued that user fees efficiently managed service demand, and that practitioners preferred to remain independent business owners [27, 29]. After protracted negotiations, the government compromised by introducing a fee-forservice partial subsidy model. Subsidies initially covered around $66 \%$ of the total fee charged by GPs [40], and GPs were still permitted to charge patients directly for general care in addition to the subsidy payments. Hence, the government's comprehensive and integrated national public health system was never fully realised [41].

This lack of integration was noted as a key challenge for the health system in a 1975 Department of Health white paper entitled "A Health Service for New Zealand” [40], alongside the need for more equitable needs-based provision of services. By the 1970s, inflation had eroded the static value of government subsidies for GP services to just a third of the fees charged by GPs [40].

As in other parts of the economy, the health system of the 1980s and 1990s was remodelled to allow greater subjection to market forces through deregulation, privatisation, 
and increased competition [29]. The governing National Party of the early 1990s divided authority over funding and provision of services with four Regional Health Authorities (RHAs) responsible for the former and 23 profit-driven Crown Health Enterprises (CHEs) responsible for the latter [3, 42]. These reforms entailed a pronounced shift toward the present capitation funding arrangements and rearranged the organisation of primary health care for the first time in decades [43]. RHAs were now responsible for purchasing primary health care in place of the central government [44], while GPs were also permitted to collectively contract their services to RHAs through Independent Practitioner Associations [45]. Greater funding was made available for government subsidies, but for adults these were now available exclusively through the use of entitlement cards [27, 46]. The Community Services Card (CSC) was available to low income households, with roughly $50 \%$ of the population entitled [47]. The High Use Health Card (HUHC) was made available to an estimated $5 \%$ of the population who regularly consulted with health practitioners for an ongoing medical condition [27]. Uptake for both cards was less than perfect, with an estimated $21 \%$ of individuals eligible for the CSC failing to hold the card in practice in the late 1990s [12].

The unpopularity of the market-based approach to healthcare led to swift reversals. Following the nation's first Mixed-Member Proportional (MMP) election in 1996, the Coalition Agreement on health between the National and New Zealand First Parties signalled a shift away from the quasi-market model, with the four RHAs abolished in 1997 and a singular Health Funding Authority formed to purchase services in January of the following year [3]. These reforms proved short-lived as a mounting body of academics and policymakers took aim at the poor state of PHC access and developed alternate models to improve service access [9, 48-52]. The Labour-Alliance coalition government elected in 1999 promptly took hold of these suggestions with a discussion paper entitled 'The Future Shape of Primary Health Care' [53] and enacted comprehensive and enduring reforms over the following years.

\subsection{The Primary Health Care Strategy and the current primary health system}

The Primary Health Care Strategy was part of a broader reform agenda mandated under the Public Health and Disability Act 2000. The Act was purposed with improving population health, reducing health disparities (particularly for Māori), increasing inclusivity and participation for those with disabilities, and providing communities with voice. It did so 
through the establishment of 21 locally elected and geographically-based District Health Boards, revisions to funding and provisional arrangements, and changes to the duties of key agents and agencies. Responsible Ministers are statutorily required under the Act to develop health and disability strategies to guide national health provision, which presently include the New Zealand Health Strategy [54, 55], the New Zealand Disability Strategy [56, 57], He Korowai Oranga: Māori Health Strategy [58, 59], and the PHCS [1].

The impetus for reform was opposition to the market-oriented health system of the 1990s, with the newly established District Health Boards (DHBs) intended to give ownership of health care back to communities [29]. Another aspect of the Strategy's motivation was to restore universal access to health care subsidies, closer to the First Labour Government's initial intentions. The Strategy notes "New Zealand is unusual among developed countries in only funding about 40 percent of first-contact services through Vote Health, in what is otherwise a predominantly publicly funded system" [1, p. 15]. Under the PHCS, all New Zealanders were once more eligible for at least some level of PHC subsidisation, as had been the case prior to the neoliberal health system reforms $[46,60]$. The strategy also makes substantial reference to reducing health disparities for Māori and Pacific populations and people from lower socioeconomic groups through increased access, provision of appropriate services, and reduced financial barriers, amongst other mechanisms [1]. A key principle in managing the roll-out of additional subsidy funding was that they should first reach those with the greatest health needs. Table 2.1, adapted from the PHCS, summarises how the Strategy's authors conceptualised the key changes to the system.

The PHCS and broader health system reforms led to substantial changes in PHC's funding and organisation. The Public Health and Disability Act 2000 established 21 locallyelected DHBs with responsibility for funding health and disability services across designated geographical areas $[3,27]$. In 2002, the government encouraged the establishment of local non-governmental Primary Health Organisations (PHOs) to co-ordinate primary health care services and improve the health of their enrolled populations. By 2008, there were 80 PHOs with enrolled populations ranging between 3,000 and 350,000 people [60]. In subsequent years governments have sought to amalgamate these organisations, with 32 PHOs currently co-ordinating services nation-wide [3]. Patients are incentivised to enrol at a GP of their choosing to access lower-cost services, while practitioners are incentivised to contract with PHOs to receive government funding. In this way, PHOs develop an enrolled population 
Table 2.1: Summary of changes conceptualised in the PHCS

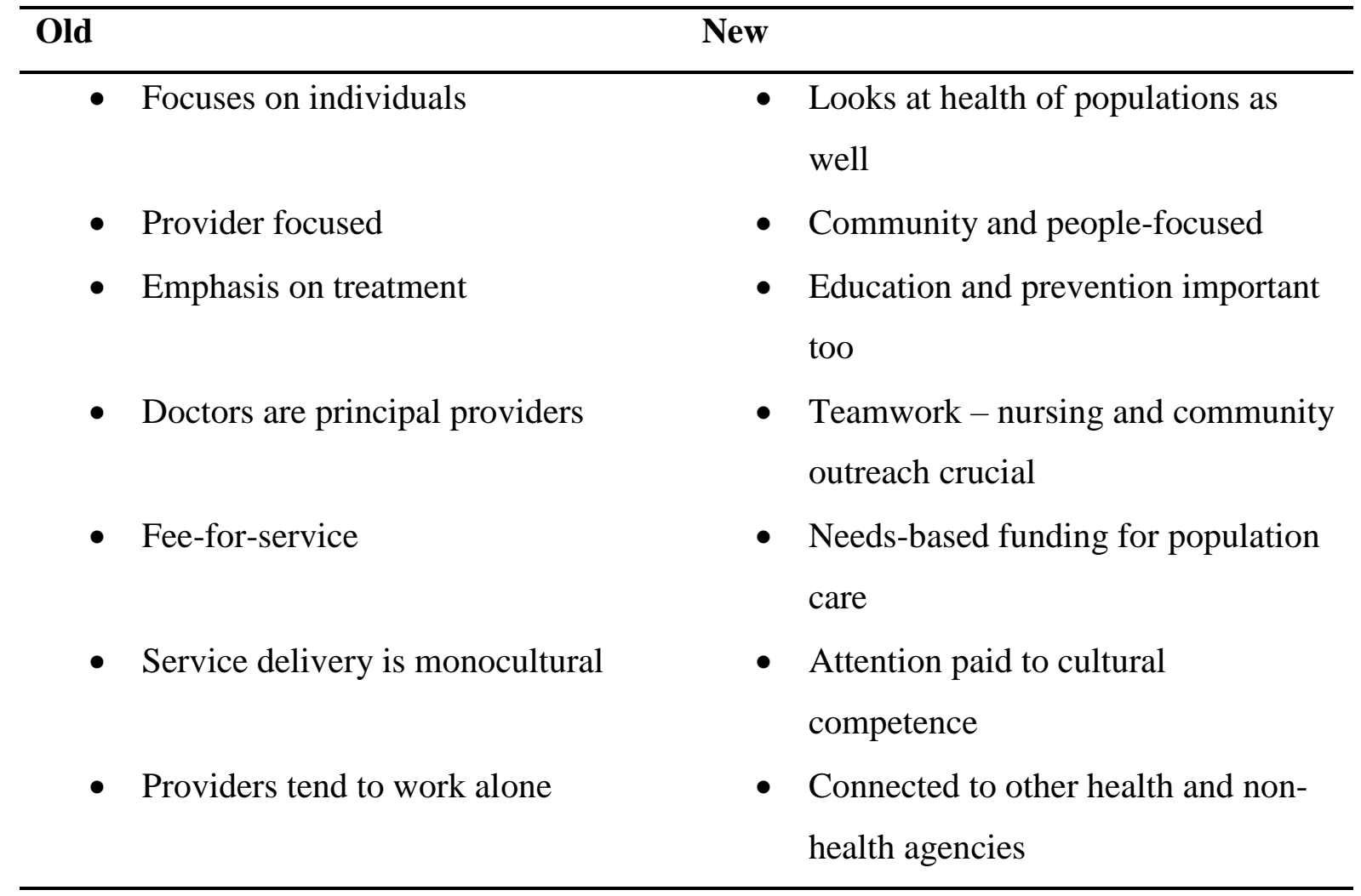

Source: PHCS 2001

whose health needs and inequalities in health they are responsible for addressing. Each organisation contracts with a lead DHB to provide primary health services in their area.

PHOs are central to the remodelled funding structure in primary healthcare following the PHCS. Where practitioners had previously claimed subsidy payments from the government after providing services to targeted individuals, in the present system PHOs receive fixed funding amounts according to the expected service use of their enrolled populations. Funding rates are determined through a formula considering the gender, agegroup, and HUHC entitlement for enrolled populations [61]. Because these so-called 'capitation payments' provide payments per head of population rather than per visit, the financial incentives for practitioners are shifted away from maximising the number of visits or treatments given and toward effectively managing the drivers of health service demand [62]. The Strategy's architects believed this shift would improve health inequalities through ensuring funds are distributed according to population need rather than density of services [1]. Capitation funding was also seen to be conducive to encouraging a multidisciplinary approach to delivering services, where service demand can be met by practice nurses and other allied services, rather than exclusively doctors [63]. A fee-for-service element remains 
in the General Medical Subsidies (GMS) made to GPs in return for consultations with minors and subsidy card holders.

The PHCS also prompted a substantial funding increase for PHC intended to reduce over-the-counter fees and improve access to services, as well as expand the range of services available [29]. Over $\$ 2.2$ billion was committed over seven years for implementing the PHCS in 2002/03 [64]. While the government was committed to universal access to subsidies, it also sought to ensure new funds reached vulnerable populations first. To achieve this, the government initially prioritised early funding for'Access' PHOs, where more than $50 \%$ of the enrolled population are Māori, Pacific Peoples, or live in an area belonging to the most deprived socioeconomic quintile (defined by the New Zealand Deprivation Index, or NZDep) $[1,60]$. This was motivated on the assumption that these populations have poorer health on average than the general population, and that greater funding would reduce consultation fees. Between 2004 and 2007, capitation funding was rolled out to all other PHOs (so-called 'Interim' PHOs) successively by age-group (see Table 2.2). Funding rates for Access and Interim PHOs have been almost identical since July 2007, with only minor differences for those under $15[60,61]$.

Due to ongoing concerns about the affordability of consultation fees, the government introduced a further subsidy scheme in 2006 which granted access to higher capitation payments for practices voluntarily agreeing to limit consultation fees for adults and eliminate fees for children under six [29]. Initially, all practices were eligible to participate in this Very Low Cost Access (VLCA) scheme. However, in 2009 the criteria were adjusted to restrict eligibility to PHOs and contracted practices where greater than $50 \%$ of the enrolled population were considered vulnerable, in the same vein as the previous Access PHO

Table 2.2: Date of First-Contact funding roll-out to Interim PHOs by age-group

\begin{tabular}{ll}
\hline 1 October 2003: & $6-17$ year olds \\
1 July 2004: & $65+$ year olds \\
1 July 2005: & $18-24$ year olds \\
1 July 2006: & $45-64$ year olds \\
1 July 2007: & $25-44$ year olds \\
\hline
\end{tabular}

Source: Ministry of Health (cited in Barnett et al., 2009) 
requirements [3]. The current maximum fee for adults in VLCA practices is $\$ 18$ [65]. Other funding sources in the new system include Services to Improve Access (SIA) funding, which is purposed with improving access for high-needs patients or financing new services [66]; Health Promotion funding, which is intended to support preventative community initiatives [67], and CarePlus funding, intended to reduce fees for patients with high service use [68].

Overall, most observers consider the Strategy successfully implemented. The prompt establishment of PHOs and almost comprehensive enrolment of all New Zealanders into these PHOs is attributable to initial broad sectoral and public support for the Strategy's general approach, as well as the alignment of financial incentives with PHO membership [69, 70]. However, some remain concerned that the PHCS was not able to be implemented in a manner consistent with its objectives. Firstly, while the public was promised that new funding would greatly reduce consultation fees, the government became concerned during rollout about the extent to which additional funds were genuinely translating to lowered user fees [12]. To this end, it progressively required more stringent targets to be set by DHBs and PHOs detailing the extent to which new funds should translate into lower fees, as well as tightening the conditions which would trigger a formal review of patient fees to better align with the government's objectives. For Access PHOs, fees for adults were generally seen to be low if they were around $\$ 15-\$ 20$, while in Interim PHOs, fees were assessed against both changes in cost pressures and the extent to which subsidy payments corresponded with actualised fee reductions [7]. Observing general practice information systems from a sample of 99 practices, Cumming et al. [28] find that while fee reductions between 2001/02 and 2004/5 for Access practices generally proceeded as government intended, fees increased at roughly the rate of inflation in Interim practices, with the exception of fees for patients over 65. The most likely explanation for this is that the subsidies replaced pre-existing discounts provided by practices in the previously competitive healthcare market, thereby resulting in raised incomes for GPs and no benefit in reducing patient fees.

More recently, some observers within government, academia and clinical practice have levelled claims of chronic PHC sector underfunding against the previous government, leading particularly non-VLCA PHC providers to increase consultation fees [29, 71-73]. If substantiated, this would comprise a failure of implementation limiting improvements in service access and health inequities. In support of this argument, Core government health spending as a share of GDP has been in decline since 2008, following a period of increase over the roll-out of the PHCS [71]. Investigating claims of sectoral underfunding using 
administrative data, Downs [29] finds that between 2008 and 2017, fees have significantly increased for non-VLCA practices but not for VLCA practices, with most increases occurring before 2012. However, with the exception of Pacific Peoples, the proportion of New Zealanders reporting cost to be a barrier has not increased in recent years, and instead there is growth in the proportion of respondents reporting inability to get an appointment within 24 hours. These findings suggest that any inadequacies in funding are likely to have hit Pacific Peoples and those without access to VLCA practices hardest.

During the 2017 elections, both major political parties promised to increase PHC subsidies to improve access. The National Party targeted its proposed subsidies at CSC holders, while the Labour Party proposed a universal \$10 reduction in co-payments, in tandem with significant remedial investment in health infrastructure in response to perceived underfunding $[14,15]$. The new Labour-led government plans to undertake a comprehensive review of the health system, incorporating previous arrangements for a review of the funding model for PHC $[16,17]$. It is crucial that this review is informed about which population groups currently bear the brunt of structural shortcomings. This requires theoretically sound modelling of associations between access and population characteristics. The following chapter explores the theoretical and prior empirical basis for examining PHC access, in order to motivate the empirical modelling. 


\section{Chapter 3: Related literature and theoretical focus}

Public health analysts are commonly interested in whether access is equitable - that is, whether it is distributed evenly across population groups after accounting for differences in health status. However, such inferences are hindered by the imprecise controls available for health status in household survey data and by the simultaneous relationship between service use and health status. Making inferences about access requires a well-justified theoretical framework to motivate the selection of variables and the way they are conceptualised to relate to one another and to the model error term. This chapter motivates the study's theoretical and empirical frameworks by synthesising prior literature on the determinants of access. Before doing so, however, I first address a more rudimentary concern - why does access to PHC matter?

\subsection{The importance of primary health care}

The Alma Ata Declaration of 1978 was a striking moment in the history of global health. Drawing together government officials and public health experts from across the divides of East and West, developed and developing, the Declaration engendered an unprecedented consensus that social justice norms should underwrite public health initiatives, and championed PHC as a means to achieve equity, multidisciplinary co-operation, and community participation $[74,75]$.

Taking as its starting point the World Health Organisation's (WHO) aspirational definition of health as a state of complete physical, mental and social, rather than the mere lack of disease or infirmity, the Declaration affirms health as a human right warranting the sustained policy attention of governments [2]. PHC is advocated as the most effective means through which governments are able to promote equitable health outcomes for their populations. Article 6 of the Declaration defines PHC as "essential health care based on practical, scientifically sound and socially acceptable methods and technology made universally accessible to individuals and families in the community through their full participation and at a cost that the community and country can afford to maintain" [2; pp. 12]. PHC is seen as a first point of contact in a continuing health care process taking place within the patient's community.

The bold assertions made about the expected impact of PHC in the Declaration generated a broad corpus of literature studying the effectiveness, equity, and efficiency of 
PHC. The most prolific author in this field has been the US-based Barbara Starfield. In a review of the evidence linking PHC to better health outcomes, Starfield et al. [4] identifies three successively convincing lines of evidence. First, health is better in areas with a greater density of PHC physicians. Secondly, people who generally receive care from PHC physicians rather than other professionals, such as specialists, are healthier. Finally, receiving care that more closely aligns with the characteristics of PHC is associated with better health. In a comparison of 18 OECD countries, Macinko et al. [76] find that stronger PHC systems are associated with improved performance on a wide range of health measures, including lower all-cause mortality, potential years of life lost from all causes, and life expectancy. Hsieh et al. [77] find that low- and middle-income countries with broader coverage of PHC are associated with longer life expectancy and downward trends in infant and under-5 mortality rates, controlling for GDP per capita.

PHC is also shown to improve equity of outcomes. A review by Starfield [78] demonstrates that investments in PHC are associated with greater improvements in equity than investments in the general health system. Another finding was that interventions aimed at improving the average level of health commonly did not tend to improve equity. Several studies find that $\mathrm{PHC}$ is associated with improved racial equity $[79,80]$. The pro-equity effects of PHC can also be seen in self-reported measures of health. In areas of the US with higher income inequality, the share of people reporting poor or fair health is one-third larger when the area has a low density of PHC physicians than in high-density areas [81]. Conceptually, the pro-equity effects of PHC are thought to occur by expanding accessibility and availability of health services particularly for those who would have been least likely to access private or specialist care [77].

PHC may also draw support from an efficiency viewpoint. Numerous studies find that PHC is associated with better health outcomes for lower levels of health expenditure $[77,82$, 83]. Scholars theorise that expanded access associated with PHC's low cost and local availability increases preventive health-seeking behaviours, allowing patients to have symptoms checked before they develop into more costly and complex conditions [84-86]. PHC coverage can significantly reduce the strain on public hospitals and emergency departments by treating low-urgency conditions in the patient's community, therefore allowing a more efficient use of physical and human capital in the secondary health sector $[30,87,88]$. However, recent associational evidence from Europe contests the idea that primary care is less expensive, finding greater expenditure alongside better health outcomes 
in countries with stronger PHC systems, which the authors suggest might be due to the greater cost of maintaining decentralised administrative structures [89].

\subsection{Theory of utilisation}

Through its associated reforms, the PHCS seeks to improve access to PHC. Individuals are said to have access to PHC if their circumstances allow them to use health services should the need arise. Such a potential is often unobserved in data. Instead, analysts commonly make inference on access based on actualised service use, or utilisation [90]. This distinction is important, because access and utilisation are likely to differ in crucial ways. For example, higher income might predict greater access and simultaneously predict lower utilisation of services, because wealthier people also tend to be healthier and hence have less need to seek medical advice. A better proxy for access is unmet need, which results when an individual has a perceived health need but fails to visit a doctor for some reason. Unlike utilisation, this measure inherently controls for health status, notwithstanding error associated with differences in perception of 'health need' across population groups [32].

The literature provides numerous social scientific models illustrating how access is determined and how it might be improved. Some focus predominantly on interventionamenable supply side characteristics like scheduled fees and labour supply, with the characteristics of individuals treated as confounding factors [91-93]. Others describe the fit between the accessibility of services and the ability to access of individuals [90, 94, 95]. From the latter perspective, services are considered accessible if they are approachable, culturally and socially acceptable, geographically accessible, have capacity for more patients, affordable, and appropriate for their populations. For a given individual to have access, the barriers resulting from dearth in any of these characteristics must be outweighed by their own ability to identify, seek, reach, pay for, and engage with the service. The influential Behavioural Model of Health Services Use conceptualised the decision to use health services as dependent on predisposing characteristics (such as health beliefs), enabling resources (such as income), and perceived or evaluated need for health services (such as chronic illness) [96].

While these models are helpful in developing a conceptual understanding of health demand, statistical modelling of health-seeking behaviour is best operationalised using an economic utility maximisation framework in which individuals invest in health to receive both direct utility from being healthy, and indirect utility through increased productivity [36, 97-99]. A model of 'health capital' was first developed by Grossman [36], following in the 
footsteps of Becker's [100] broader conceptualisation of human capital as an individual's stock of characteristics contributing to their ability to produce economic (and non-economic) value. Healthcare is not a direct input into the utility function; rather, it is a service that individuals purchase in order to produce good health. This conceptualisation therefore relies upon a household production function model to explain the transformation of goods and services indirectly related to the utility function, into commodities directly related to the utility function $[36,101]$. Better educated people will more efficiently transform health advice into better health outcomes, due to greater comprehension of doctors' advice and greater non-market productivity $[36,102]$.

The structural form model stipulates that individuals maximise utility, which is a function of the consumption of goods, leisure time, health, and preferences. Each individual is endowed with a stock of health that depends on genetic and environmental factors and seeks to increase this stock of health due to its effects on utility. Health status at any point in time depends on the previous period's health status, depreciation of health status over time (i.e. aging), recent 'purchases' of health, and unexpected shocks to health such as illness or injury. Health is 'purchased' by combining time spent on producing health (for example, by exercising or going to the doctor) with the consumption of goods that affect health (these include positive goods such as fruits/vegetables, medicines, and doctor visits; and negative goods such as fatty foods and cigarettes). Individuals acquire income, which they can spend on consumption goods or save, by working (at a given wage rate), receiving non-labour income (such as social benefits or investment income), and by drawing from their savings. An individual's health status directly affects their ability to earn income by changing the number of productive hours they can work and how productive they are when they are working.

The structural form model suggests healthcare utilisation is a consumption good which is purchased to increase an individual's stock of health. Like all consumption goods, the demand for health care depends on the price of all different types of health care, the price of all other consumption goods, an individual's wage rate (i.e. the cost of their time), nonlabour income, and characteristics that influence preferences for consumption versus health (such as education or ethnicity). The model also demonstrates that the 'shadow price' of health (so-called because there is no direct market for it) depends on not just the price of health services, but also on other factors such as the 'depreciation' of health stock associated with age and efficiency in producing health associated with education. 
To motivate the model specification in subsequent analyses, prior conceptual and empirical understandings of the determinants of access and utilisation are reviewed. Determinants reviewed in the literature include the price of service use, demographic characteristics, socioeconomic characteristics, use of secondary and tertiary services, healthrelated behaviours, and health status.

\subsubsection{Price}

Associations between price and access form the chief rationale behind the PHCS's expansion of subsidies, and therefore it is useful to explore the extent to which prior empirical work would suggest co-payment reduction is effective. The gold standard of evidence in the broader field of health-seeking behaviour comes from a seminal large-scale experimental study undertaken by RAND Corporation in the US [18, 19]. A sample of 5809 people were randomly assigned to receive varying levels of fee-for-service subsidy payments for health services (not limited to PHC), ranging from no subsidisation to $95 \%$ subsidisation. Participants remained in the study for between three and five years to control for potential transient effects in demand following stimulus. The study demonstrated that reducing or eliminating co-payments for health increases both necessary and non-urgent or inappropriate service utilisation and estimates a price elasticity of demand for healthcare of between -0.1 and -0.2 .

Price may influence PHC utilisation to a different degree than the more general healthcare demand explored in the RAND study. Investigating the effect of different levels of subsidy coverage on GP utilisation, an Irish study finds significantly higher utilisation rates when GP services are free [20]. However, unlike the RAND experiment, the cross-sectional data used in this study are unable to account for a priori differences in the characteristics of groups selected to receive free access to GP services, and is also unable to account for the possibility of transient increases in utilisation resulting from pent-up demand in expectation of free services.

The price elasticity of demand for healthcare, however, is likely to be much higher than the RAND study suggests, given recent empirical developments. A study estimating the price elasticity of medical care expenditure for different conditional levels of expenditure finds considerable differentiation in the effect of price at different levels of healthcare expenditure claimed from an insurance company in the US, with price elasticity estimates ranging from -0.76 to -1.49 across conditional quantiles [103]. The intuition behind this 
finding is that individuals with varying levels of health need are likely to differ in both the amount they spend on health care and their ability to defer treatment when the price is too high, which results in considerable downward bias in traditional estimates of price elasticity. A similar study found that low-intensity health expenditure such as PHC was more significantly curtailed during the Global Financial Crisis than more serious, non-deferrable and expensive procedures [35]. The recession reduced low-intensity spending for minority ethnicities more than White Americans. Linking these results to the literature on the benefits of PHC suggests GP services may help to divert low-intensity service demand away from secondary services, where they may more appropriately be dealt with $[84,85,87,88]$.

In New Zealand, previous analysis of NZHS data found that approximately $14 \%$ of adults report deferring GP visits due to cost, with relatively little recent change in this figure between 2011/12 and 2015/16 save for a significant increase for Pacific Peoples [29]. Māori also remain significantly more likely to have unmet need. These cost barriers may extend to other less commonly studied groups in New Zealand, with one qualitative study finding cost to be the greatest barrier to GP service utilisation among Thai New Zealanders [104].

A complication in assessing the relationship between price and utilisation in economic modelling is that the fees individuals pay for health services reflect both the underlying cost of those services and the quality of services purchased. Thus, the actual fee paid by an individual is a choice variable.

Collectively, the results suggest price is an important predictor of both desirable and undesirable health service use, but its effect depends on the intensity of health need faced by patients, and inequities among social groups.

\subsubsection{Demographic characteristics}

Men and women may have distinct utilisation patterns due to differences in health need, self-triaging, and predisposition toward health-seeking. Women have greater health need on average due to higher rates of chronic illness, longer life-spans, and the additional burden of reproductive health needs $[10,105,106]$. Women also typically self-evaluate their health more strictly and are more likely to engage in help-seeking behaviour [107-109]. While most studies of access find women are more likely than men to have unmet health needs controlling for other factors [21, 23, 26, 110, 111], this finding is not universally supported $[25,112,113]$. Often, women are more likely to report both having visited a doctor's office and having unmet need $[21,23]$. However, the higher utilisation rate 
disappears when excluding reproductive health services $[114,115]$. This suggests unadjusted utilisation rates may provide misleading inference into whether gendered parity of access has been achieved.

Access can differ based on the unique circumstances associated with each stage of the life-course. While youth are typically seen to be healthy [116], empirical studies commonly find that younger age is related to both lower utilisation and higher unmet health need [22, $23,25,26]$. Difficulties in access for youth can arise due to less familiarity with health resources, more difficulties finding a health professional perceived to be suitable [117], and greater financial, social, and geographical instability than older age-groups [118]. For older adults, utilisation is commonly higher and unmet need lower [23], with the latter predominantly psychosocial in nature [119]. Grossman's [36] model suggests age is associated with a depreciation in an individual's stock of health, which decreases the quantity of health demanded, and increases the quantity of health care demanded. In other words, older individuals may invest more to maintain a lower level of health.

Gender and age are two key determinants of the capitation formula determining general subsidy payments awarded to PHOs [61]. Women and older age groups are associated with higher subsidy payments by virtue of their expected greater need for health services. If the PHCS has successfully balanced service use with service need consistent with this study's working definition of access, then being a woman and belonging to an older agegroup should be associated with greater odds and frequency of utilisation but not greater odds of unmet need.

Ethnicity often predicts different patterns of health service utilisation due to associations with income and deprivation but can continue to exert an independent effect controlling for these factors. Prior to the PHCS, Māori were less likely to visit GPs than other ethnicities [23, 37, 120], despite evidence of poorer health [10, 37]. Asians were also 18\% less likely to use GP services, and made 1.8 fewer GP visits per year than Pakeha and nonMāori/Pacific Peoples [23], but unlike Māori this is likely to reflect lower health need [121]. More recently, unmet need for GP services has been found to be greatest for Māori and Pacific Peoples before adjusting for factors like income and deprivation [29], while a study controlling for these factors found that Māori and Asians are significantly less likely than Pakeha to defer doctor's visits [26]. One possible explanation for the independent ethnic effect is the role of government strategy and interventions explicitly seeking to boost access 
among Māori and Pacific Peoples in particular [1, 54]. Another explanation is the role of culture, which may influence care-seeking behaviours through resource-sharing, beliefs about health care, differing cultural expectations and health care requirements, and language-related barriers to access [122-127].

Education level may affect health service utilisation independently of its association with higher income, however present evidence is conflicted about whether higher education causes better health, better health causes better education outcomes, or whether an omitted third variable accounts for their common direction [102]. As outlined earlier, highly educated people are more efficient at translating medical advice into good health [36]. Highly educated people are more likely to recognise and triage their own symptoms, and may furthermore hold higher standards for their own health due to comparisons with healthier peer groups [32]. Once this bias in self-rated health is removed from the effect of education, Bago d'Uva et al. [32] find that significant pro-educated inequities exist in the distribution of doctors' visits in a cross-national dataset. Another study finds that people with higher levels of education visit GPs and are admitted to hospital less frequently, but also finds less educated people are less likely to receive preventive care [128]. In New Zealand, a study of utilisation prior to the PHCS found no differentiation by education level [23], while a study of unmet need for GP services after the PHCS' roll-out found that post-school education was counterintuitively associated with unmet need, controlling for income and other factors [26]. This may be explained by the endogeneity described by Bago d'Uva et al. [32], in which more educated people perceive health need more acutely at any given objective level of health.

Immigrants may have distinct patterns of service utilisation. Studies commonly find that immigrants utilise PHC services less than native-born citizens $[129,130]$. This could reflect unique barriers to access including language and cultural appropriateness of services $[122,123]$. Another explanation is the so-called "healthy immigrant effect", where individuals self-selecting into migration have healthier morbidity profiles on average than the general population of the host country [131]. In support of the latter explanation, a Spanish study found that differences in GP utilisation by migration status disappeared among adults after adjusting for morbidity profiles [130]. Immigrants may also adjust their health-seeking behaviours the longer they stay in a host country, with one study finding immigrants to Norway increased their odds of use, but not rate of use, the longer they remained in the country [129]. 
Enrolment with a regular PHC provider improves the likelihood of service use and health outcomes, particularly when the patient has a relationship with a single practitioner [132]. Identification with a place and person who will provide PHC has been shown to improve problem recognition, increase accuracy and timeliness of diagnoses, improve appointment keeping, reduce hospitalisations and emergency department use, and reduce unmet need, among other things [132]. International studies show having a regular source of PHC is significantly associated with lower odds of deferring healthcare treatment [25] and receiving preventive care, outperforming resource variables such as health insurance and income [133]. In a New Zealand study of unmet need, respondents with a regular PHC provider were counterintuitively more likely to defer doctors' visits than those who did not [26]. While the study is unable to resolve why this occurred formally, the authors suggest patients enrolled in PHC practices are more aware of the cost of receiving PHC.

\subsubsection{Socioeconomic characteristics}

Income represents an important enabling resource in Andersen's [96] utilisation framework. Although we would expect income to increase access in general, it is also common for health policy subsidies and interventions to target low-income earners, meaning the association between income and access may not necessarily be linear. For example, the CSC targets low-income households. If implemented successfully, low income should be associated with greater odds and frequency of utilising services, but not greater likelihood of unmet need, assuming that low income predicts greater health need. Prior empirical work in New Zealand supports this hypothesis, finding that middle income earners, but not lowincome earners, are significantly more likely than high income earners to defer doctors' visits [26]. Studies exploring the period prior to the PHCS reforms are mixed, however; with some finding low-income earners less likely to utilise GPs than high-income earners [37, 134], and others finding no income effect [23]. Internationally, estimates of the income elasticity of demand for health care demonstrate that health care is a necessity rather than a luxury good (meaning demand increases proportionately less than income), once country and year specific effects are taken into account $[135,136]$. Empirical evidence of the relationship between income and doctor visits among 18 OECD nations shows higher income earners are more likely to consult doctors than lower income earners [24]. Notably, the greatest inequities in GP visits among the countries sampled in this study were found in New Zealand, while inequities tended to be much smaller in countries with fully subsidised PHC. 
Access might differ for similar income-earners at the community level. In New Zealand, place-based variation is most usefully captured by a geographical index of deprivation known as NZDep. More deprived areas are likely to have populations with greater health needs and lower incomes [137, 138], but are also likely to have access to lower-cost health services through higher capitation payments and practices participating in the VLCA scheme [3, 29]. Empirical studies examining pre-PHCS primary care access found that people from more deprived communities paid less for PHC [27], and community deprivation did not relate to use, frequency, or failing to visit GPs in the presence of unmet need [23], suggesting the targeted subsidies were adequate in reducing socioeconomic (but not ethnic) disparities. In contrast, a study after the PHCS found that unmet need is most prevalent among those from middling socioeconomic communities rather than those at the bottom [26].

\subsubsection{Secondary and tertiary service use}

PHC was earlier propounded for its ability to improve health system efficiency by substituting secondary service use, but the service-seeking decision process deserves a more thorough examination here. Conceptually, individuals select a primary or secondary provider for health care on the basis of the perceived severity of their health need, their (potentially limited) knowledge of available primary and secondary options, and an assessment of the benefits and barriers associated with each service to the best of their knowledge [87]. In their qualitative exploration of inappropriate emergency department (ED) use, Shaw et al. [87] found that some participants used emergency departments despite knowing of PHC alternatives for a range of reasons, including issues with transportation, perceived racial discrimination, and facing difficulties accessing their usual health provider. The lattermost reason is supported by cross-sectional evidence from England which suggests that inability to access a GP within two days is associated with self-referral to ED [88].

In New Zealand, previous analysis has approximated the substitution between primary and secondary care by examining how preventable hospitalisations changed as PHC subsidy coverage was progressively expanded under the PHCS [30]. Using administrative hospital data on ambulatory sensitive hospitalisations (ASH), the study finds that reductions in ASH rates did not neatly fit the direction of PHC subsidy rollouts, and disparities between more and less deprived communities widened over the study period. These findings suggest that expansion of PHC coverage is not sufficient to reduce the absolute level or inequities in ASH 
rates and may mean primary and secondary services are not used as perfect substitutes for one another. However, the study is not able to comment on whether ASH rates are lower than the counterfactual had the PHCS not expanded PHC subsidy coverage.

\subsubsection{Health behaviours}

Health behaviours are considered investment inputs into health stock in Grossman's [36] model. Health insurance is a clear example of this, where the individual invests resources in an asset expected to increase health service utilisation by reducing point-of-use costs. Health insurance was introduced to the Grossman model by Liljas [139]. Unlike the original Grossman model, Liljas incorporates the understanding that individuals are uncertain about their current and future level of health, and that private insurance is purchased to manage this risk. Liljas finds that private insurance reduces the effect of income on marginal valuation for an expected improvement in health.

Evidence from the US suggests that an absence of health insurance significantly increases the odds of having unmet health need [25]. Private insurance is likely to have a modest effect on utilisation in New Zealand where it plays a markedly smaller role in the health system, particularly following the expansion of universal PHC subsidies. Individuals can choose to insure against some or all of the residual co-payments on services after government subsidies, including GP services [3]. Before the reintroduction of universal subsidies, health insurance was associated with greater utilisation and reduced likelihood of unmet need $[23,140]$. It is likely that the effect of private insurance coverage has subsequently diminished.

Health-affecting behaviours are not always beneficial. In a utility maximisation framework, individuals who smoke or drink heavily may be inferred to perceive lesser gains in utility from good future health than in enjoying health-damaging substance consumption in the present. Accordingly, heavy smokers and drinkers may be expected to utilise services less even after adjusting for differences in health need. This difference in preferences may also lead to endogenous differences in the way health status is self-reported. Studies of periods prior to the PHCS reforms find that regular smokers pay slightly less for GP services than non-smokers, but drinkers pay significantly more [27]. Smokers were less likely to visit a GP and more likely to report failing to visit a doctor despite health need than non-smokers, while drinkers were both more likely to visit a GP and more likely to have unmet need [23]. A 
study subsequent to the PHCS also found that smokers were more likely to defer doctor's visits [26].

\subsubsection{Health status}

PHC exists to serve health need, and in turn, many conceptions of equitable access seek to ration health care on the basis of health need alone. In practice, this ideal is invariably unattained, with one US studying finding that just over a quarter of variation in utilisation is attributable to health status, after controlling for endogenous measurement of patient health [141]. Health status is commonly measured in terms of burden of physical or mental health morbidity, either indicated through dummy variables or aggregated into morbidity indices. Another measure common to household surveys is a global self-reported health metric asking respondents to rate their health on a scale from one to five. As previously discussed, this measure is associated with endogenous measurement error, due to systematic differences in the way respondents perceive their own health and respond to the question [32]. Another source of endogeneity is the simultaneous relationship between health status and service utilisation, discussed in the next chapter.

Health status may affect service utilisation in a number of ways. Poorer health increases the need for health care but may also reduce the individual's productivity and hence the resources available for accessing services [36]. In New Zealand, people with long-term high health need are subsidised through the HUHC and through CarePlus, which may ameliorate some of the resource strain associated with repeated service use [12]. If these interventions are perfectly successful, then health status should be associated with greater odds of utilisation, but not greater odds of unmet need.

Empirical evidence in New Zealand prior to universal subsidisation finds lowered fees for people living with diabetes but not asthma or high blood pressure [27]. Accordingly, people with chronic conditions were 8-12\% more likely to visit a GP and made 1.1-1.4 more visits per year, but only those with asthma were more likely to report deferring a doctor's visit despite health need [23]. The same study found that people self-reporting poor health were $15 \%$ more likely than those in excellent health to visit a GP and made 5.3 more visits per year but were also more likely to report failing to visit a GP despite having health need. However, the study did not account for self-reporting bias associated with health status. A study following the introduction of the PHCS found that people with two or more comorbid conditions were significantly more likely to defer doctor's visits than those without chronic 
conditions [26], suggesting access remains a problem for this group despite existing policy interventions. While self-rated health was not found to be significantly related to unmet need in this study, the study design did not account for measurement error in this variable.

\subsection{Theory of primary health care fees}

In competitive markets, price reflects the value placed upon a good. As previously discussed, health services are only valued indirectly as an input into the production of health, which is directly related to utility [36]. Hence the value attached to health services is dependent on the value individuals place on health. Because health is not directly purchased, we can only indirectly observe the 'shadow price' of health through the markets for inputs to health.

The Grossman model contains a number of insights into the shadow price of health which affect the interpretation of the price paid for GP services. For example, the shadow price of health is expected to rise with the depreciation on health stock associated with age and fall with the improved efficiency in producing health associated with education. The Grossman model suggests that a rising value placed on health can be associated with both a reduced quantity of health demanded (ie, people accept worse health) and increase quantity of care demanded (ie, people seek to increase their investment in health more because it's more valuable). This suggests that unmet need will decrease with age and rise with education, while utilisation will rise with age and fall with education, all else equal. The model also implies that the price paid for health care reflects the quality of services (including the human and physical capital contributing to care) and is therefore a choice variable. This means a higher price may not always be associated with less access to services and might instead signal a greater willingness to pay for the commodity of health.

Models of the price paid for PHC can be usefully informed by the concept of reservation prices. On the demand side, an individual's reservation price is the highest possible price they would be willing to pay to consume a commodity [142]. Individuals will utilise health services when the market price is at or below their personal reservation price. We observe fees for individuals only when they visit a doctor, and hence we omit individuals whose reservation price is lower than the market price - for example, low-income earners who cannot afford healthcare, or people who have little health need and therefore do not wish to pay for services. Observing the price paid by only those who utilised health services will not allow us to estimate unbiased relationships with population characteristics if there are 
systematic differences in reservation price between those who do and do not utilise services, as seems likely. This problem is a classic example of a sample selection problem described by Heckman [34], and is explored in detail in the main analysis.

Prior to the PHCS, GP fees for adults in New Zealand were entirely unsubsidised for individuals not holding either a CSC or a HUHC and were determined in a competitive market environment. A study of the price paid for GP services at this time examined differences between individuals with differing individual, household, and community characteristics [27]. In their final multivariate model specification, they find lower fees are associated with male gender, younger age, Māori and Pacific ethnicity, single parent households, households with more people, lower household income, non-employment, not holding health insurance, having diabetes, not drinking, living in a rural area, and living in a more deprived area. Outside of diabetes, fees did not seem to differ by health status, meaning the HUHC arrangements may not have been sufficiently subsidising those with ill health. However, the study did not account for self-reporting bias associated with the measure for global health status. While the relationship with household income was weak, the level of community deprivation was strongly associated with lower fees, which may reflect either successful subsidisation through the CSC or market adjustment to lower-income markets by allocating lower quality services to areas where they will be affordable and demanded.

Following the introduction of universal capitated subsidies, prices for all adults are predominantly determined by two sources: government funding and the market for GP services in the local area. Government funding is in turn allocated through two main mechanisms: a capitated universal payment, and targeted payments [3]. The capitation formula generally allocates higher funding rates to PHOs for enrolled women, older agegroups, and HUHC holders. The formula assumes that these groups have greater health need and will therefore require greater use of health services. Targeted payments include the CSC for low-income earners and the HUHC for individuals with high health need. If the capitated and targeted subsidies are successfully fulfilling their purpose, then the aforementioned characteristics should be associated with lower fees, controlling for other factors.

This chapter has reviewed the theoretical determinants of PHC utilisation and fees in the framework of a stock model of health. The goal of observing these variables is to provide insight into access, an unobservable attribute of individuals who can utilise services whenever they have health need. Prior literature enables theoretical and empirical predictions 
of the relationship between variables, which can assist this study's model building. The following chapter describes the research design and methods employed to investigate GP access. 


\section{Chapter 4: Empirical methods}

In the previous chapter, I noted that health service use can be explained as an investment in health and reviewed literature on how a range of population characteristics might be related to access and its component parts. The next step is developing an empirical research design which is able to usefully comment on the statistical relationships between these population characteristics and some measurable indicator/s of access. This chapter justifies the chosen research design, describes the data used for analysis, and outlines how I accounted for potential sources of bias.

\subsection{Research design}

To motivate the research design, it is worth returning to the study's core objective. The study seeks to infer how access to GPs for individuals with varying population characteristics has changed over the period following the adoption of the PHCS. While I noted in the previous chapter that access is inherently unobservable, it is helpful to conceptualise what a hypothetical 'ideal' research design would look like if all relevant information was observed. The in-practice design should approximate the ideal as closely as possible by paying attention to the features which make the ideal research design attractive and adjusting for biases resulting from deviation from this ideal.

Access is commonly conceptualised in simple terms as the ability to visit a GP when health need arises, or more formally as health service use qualified by health need [90]. For access to be perfectly equitable, it should not be conditional on personal characteristics such as ethnicity or income. For example, the PHCS states that equitable access should not depend on ability to pay [54]. Mathematically, this can be expressed by the conditional expectations function (CEF):

$$
\operatorname{cov}\left(E\left[Y_{i} \mid H_{i}=1\right], X_{i}^{\prime}\right)=0
$$

(Equation 1)

where $Y_{i}$ denotes access for individual $i, X_{i}^{\prime}$ represents a vector of $i$ 's characteristics, and $H_{i}$ is a Bernoulli-distributed variable indicating health need. The equation states that the expected level of access for individuals with health need is not related to personal characteristics. 
Similarly, the aforementioned definition of access implies that it is proportional to health need, and hence equitable access should not be predicted by health need. Mathematically:

$$
\operatorname{cov}\left(E\left[Y_{i} \mid X_{i}^{\prime}=x\right], H_{i}\right)=0
$$

(Equation 2)

where $x$ is a particular expression of $i$ 's personal characteristics. In other words, expected access for individual $i$ with characteristics $x$ does not differ by health status.

The CEF is approximated by regression analysis, allowing for random error. To begin with, let access to general practice be represented by the following simple linear regression equation:

$$
Y_{i t}^{*}=\alpha+\rho^{\prime} X_{i t}+\delta^{\prime} H_{i t}+\gamma_{t}+\varepsilon_{i t}
$$

(Equation 3)

In this model, $Y_{i t}^{*}$ is person $i$ 's access to GP services, $\alpha$ is the constant, $X_{i t}$ is a vector of person $i$ 's personal characteristics, $H_{i t}$ is a vector of person $i$ 's health characteristics, $\gamma_{t}$ is a set of survey wave dummies, and $\varepsilon_{i t}$ is the error term. The CEF Equations $1 \& 2$ imply that the coefficient vectors $\rho^{\prime}$ and $\delta^{\prime}$ should equal zero if access is equitable, conditional on their independence.

For Equation 3 to allow causal interpretation, the ideal research design would (i) randomly assign differing individual and health characteristics to participants, (ii) observe changes in access before and after a one-unit change in the variables of causal interest, (iii) directly observe all relevant variables, and (iv) observe variables without error. Departure from (i) is associated with selection bias, (ii) with simultaneity bias, (iii) with omitted variables, and (iv) with error-in-variables biases.

In New Zealand, the most comprehensive source of GP utilisation and fees data (the NZHS) is observational, precluding random assignment of conditions and before-after comparisons for the same individuals. This means coefficients $\rho^{\prime}$ and $\delta^{\prime}$ are likely to be a function of both the intended independent relationship and a term denoting selection bias, unless all covariates explaining self-selection of conditions are included. In addition, the data are cross-sectional and hence limited in determining whether poor access causes poor health or vice versa, because we cannot see which preceded the other. In econometric analysis, the 
theoretical joint determination of variables is termed simultaneity bias. Health and GP service use are simultaneous because unhealthy individuals are expected to self-select into visiting doctors and receive a service which should improve both their health and their accuracy in self-evaluating their health status [31]. Finally, self-reported household survey questions are commonly associated with measurement error, particularly for self-reported health status [31]. These empirical challenges inform the selection of empirical methods, as discussed shortly.

Equation 3 ignores the unobservability of access, and empirical study of course requires an observable dependent variable. In this study, I observe four proxies of access: fees paid on the participant's last visit (FEES), probability of having visited a GP in the past 12 months (VISPROB), the number of visits to a GP in the past 12 months (VISNUM), and the likelihood of reporting unmet need for a GP due to cost in the past 12 months (UNMET). I argue that comparison of trends between these variables offers a useful inference into access, particularly with regard to disentangling simultaneity.

To understand why, recall that the earlier definition of access contains two parts: (i) potential to use services, qualified by (ii) need for services. Each of the four dependent variables relate to these two components in distinct ways. For example, FEES are expected to be inversely related to potential service use but should not relate to need for services after controlling for health variables (which may entitle individuals to high-use health card discounts) and other confounds. VISPROB and VISNUM measure actualised access to doctors, and while the former does not allow insight into the intensity of health need, high values of the latter are indicative of high (real or perceived) health need. UNMET is intended to measure failure to actualise access given perceived health need. To elucidate how these results operate when taken together, imagine that a population characteristic such as highincome is associated with (i) paying a greater-than-average fee, (ii) high likelihood of service utilisation, (iii) a low number of visits per year, and (iv) low odds of reporting unmet need due to cost. While (i) and (iii) may suggest poor access in isolation, by observing these in tandem with (ii) and (iv) it appears much more likely that high-income earners have good access to services but relatively low health need.

Borrowing from Equation 3, each dependent variable is assumed to take the form:

$$
Y_{i t}=\alpha+\rho^{\prime} X_{i t}+\delta^{\prime} H_{i t}+\gamma_{t}+\varepsilon_{i t}
$$


where $Y_{i t}$ represents each proxy of latent access $Y_{i t}^{*}$.

Recall the research questions from Chapter 1. To assess how fees for and access to GPs has changed since the PHCS was adopted, I begin with a descriptive analysis tabulating the average (or prevalence) of each variable by selected one-way population characteristics in three time periods: the period prior to widespread rollout of subsidies (2002/02), after all Access and most Interim subsidies had been rolled out (2006/07), and the more recent period predominantly characterised by VLCA funding (2011/12-2015/16). The second research question, concerning how the distribution of these variables have changed over time, is answered by comparing regression coefficient vectors $\rho^{\prime}$ and $\delta^{\prime}$ when models are estimated using data for each of the same three time periods. Observation over the three time periods allows observation of the distributional changes associated with each phase of the PHCS' development across the study period. The descriptive models report the predicted (mean) population values, while the regression models report coefficients in relation to baseline categories (ie, the marginal change in service use associated with an undergraduate degree compared with having no qualifications).

Given the deviations from Equation 4 noted above and below, the interpretation of $\rho^{\prime}$ and $\delta^{\prime}$ are unlikely to meet the conditional independence assumption, and hence do not have causal interpretation. This means that even if access were to be perfectly equitable, the coefficients might not equal zero when estimated with the given data. As with all associative inference, the analysis must instead combine clear interpretation of the methodological procedures employed with in-depth theoretical knowledge about how the variables conceptually relate, alongside other strategies to discount alternative explanations. Inference is eased by correction for several key biases, as the following sections elaborate.

\subsubsection{Error-in-variables bias}

A key empirical challenge is the measurement error contained in the coefficient on self-reported health. Health is an important control variable for the effect of other regressors. However, in survey data such as the NZHS we commonly rely on self-reported health status to measure latent health among the sample. This means that the coefficient is a function of both latent objective health and each individual's propensity to (1) accurately self-triage and (2) evaluate their health favourably or negatively. As discussed in Chapter 3, Bago d'Uva et al. [32] show these propensities are likely to systematically differ by education level, but other factors such as temperament and age warrant similar concern. 
The most common solution to endogeneity issues in econometric analysis is to employ instrumental variables regression $[143,144]$. This approach identifies a portion of the variance in the regressor of interest which is assumed to be free of the effects of confounding through use of an 'instrument', a variable which strongly predicts the desired concept (relevance criterion) but is independent of the undesired confounding effect (exclusion criterion). In a study demonstrating how the instrumental variables approach improves estimates of the relationship between self-reported disease morbidity and GP utilisation, Sutton et al. [31] use objective anthropometric health measures such as body mass index (BMI) and forced exhalation volume (FEV) as instruments for self-reported morbidities. The intuition is that objective measures of health are strong predictors of latent health but are independent of the factors which bias self-reporting. An alternative strategy uses anchoring vignettes describing fixed health states to identify and adjust for how each respondent is likely to self-report [32].

This study uses a similar identification strategy to Sutton et al. [31] with available data, using anthropometric measurement of BMI to construct categories representing the World Health Organisation's [145] categories I, II and III of obesity. I differ from Sutton and colleagues in operationalising BMI as classes of obesity, rather than by normalising the variable and including its squared term to capture non-linear effects, in order to allow very clear theoretical expectation and validation of the link between the variable's functional form and the latent concept of health. That is, higher classes of obesity should relate more strongly to latent objective health. The instrument is relevant because obesity is predictive of a wide array of poor health conditions, including all-cause mortality, hypertension, Type II diabetes, heart disease, stroke, and some cancers [146-148]. The measure is valid, too, because there is no reason to expect that anthropometric measurements of obesity are related to each person's self-reporting style after conditioning on potential confounds such as age, education, chronic illness and depression. The relevance of the instruments are validated by Kleibergen-Paap F statistics in the main regression output, and the issues of endogeneity testing and overidentification are discussed in Appendix A. Figure 4.1 displays the hypothesised relationships. Note that no self-reporting endogeneity is hypothesised for the unmet need model. This is because the survey question inherently involves a subjective evaluation of health need, and therefore self-reporting characteristics appear in both the left and right hand side of the equation. 
Figure 4.1: Conceptual model for instrumenting self-rated health to purge selfreporting style

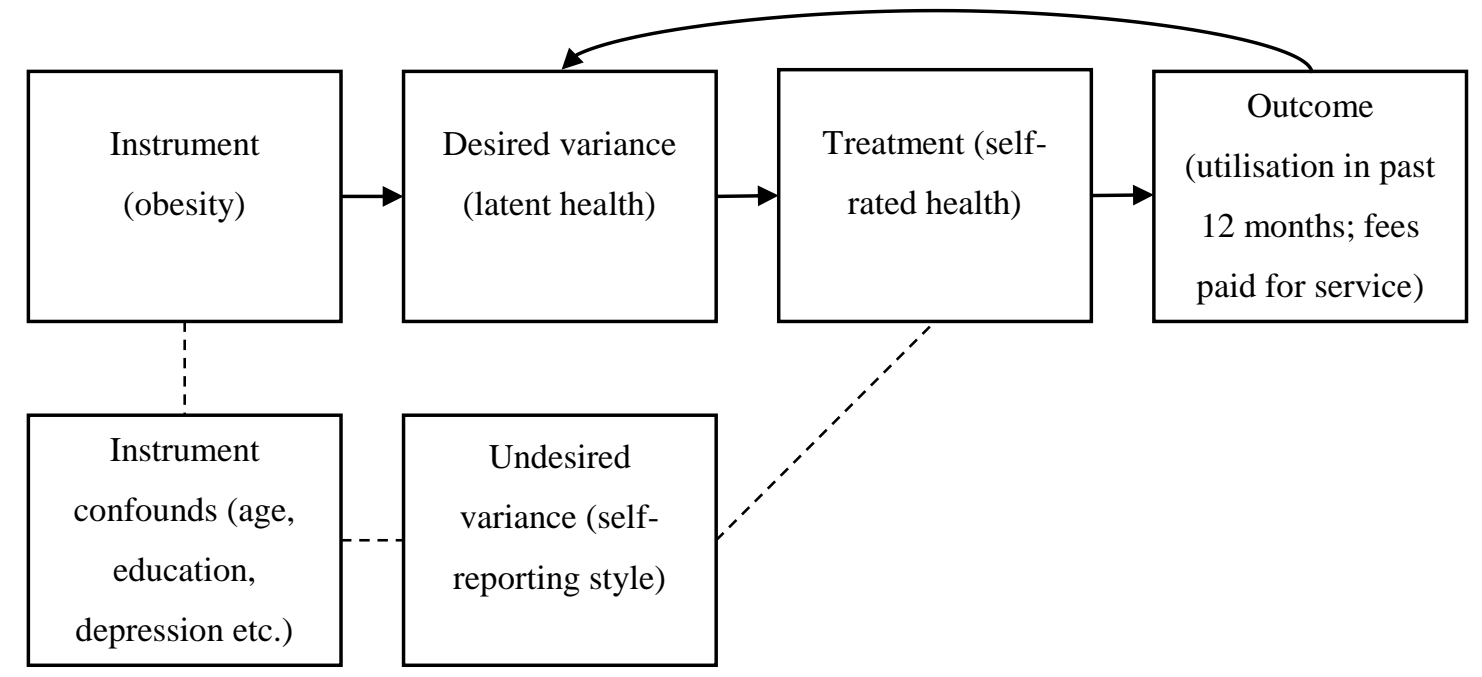

Solid lines represent the causal pathway identified by the instrumentation strategy. Dotted lines represent confounding pathways.

Self-reported health is therefore modelled by the expression:

$$
\delta_{1} H_{i t}^{\text {self }}=\tau+\theta Y_{1 i t}+\varphi Z_{i t}+\pi_{t}+\mu_{i t}
$$

(Equation 5)

where $Y_{1 i t}$ is the dependent variable from Equation 4 denoting proxies of access, $Z_{i t}$ is the set of exogenous instruments indicating classes of obesity, $\tau$ is a model constant, $\pi_{t}$ indexes changes over time, and $\mu_{i t}$ is a random error term.

\subsubsection{Selection bias}

In addition to the error-in-variables bias, the analysis of self-reported fees is subject to a unique selection problem. Fees are only reported for individuals who visited a doctor within the past 12 months. This may bias the estimation of fees if the reasons why people choose to visit doctors relate to the level of fees. For instance, if certain population groups are systematically unable to afford GP services at the market price (or perceive services as unaffordable, rightly or wrongly), ignoring their deselection from observation would lead to downward bias in the estimated differences between groups.

The previous chapter discussed the concept of reservation prices, which provides a useful framework for identifying the selection problem. Conceptually, individuals will only visit doctors (and report fees) when the market price for health care is below their personal 
reservation price - the highest fee they are willing to pay for health care at a given time. This reservation price is a function of the shadow price they place on health, which is in turn dependent on their current health stock, the utility they gain from good health compared to other commodities, and so on.

For the selection problem to be overcome, estimation must first account for the probability of reporting fees. Hence, fees are estimated with a maximum-likelihood Heckman selection model, which simultaneously estimates a first-stage probit model for selection, and a second-stage linear model for fees. The probability of selection calculated in the first stage is incorporated into the cross-equation covariance matrix of the error terms, thereby correcting the selection bias. These results are compared to OLS regression on the sample of individuals who reported fees. Doing so allows inference into the effect of including participants whose reservation price was below the market price.

The performance of estimators in the Heckman correction models depend on identifying a variable or set of variables which strongly relate to the unobserved reservation price (the latent variable hypothesised to increase the odds of accepting the market price), but not the price offered in the market and observed in data [149]. These excludable instruments can partial out variance attributable to selection effects from variance attributable to the direct empirical relationships of interest.

I propose a novel excludable instrument in this study. In the New Zealand health system, GPs act as 'gate-keepers' for subsidised referral to specialist services [3, 24], meaning there is a strong theoretical relationship between visiting a specialist and the person's unobserved reservation price for GP services. This is because people visiting specialists are systematically more likely to have already visited a GP and therefore accepted the market price for GPs.

At the same time, I argue that visiting a specialist cannot cause differences in the price offered by GPs, but price differentials may instead arise from selection effects that affect (1) reservation price, and/or (2) eligibility for different brackets of a GP's scheduled fees or government subsidisation. For example, chronic illness increases an individual's service need, entitles them to discounted GP visits through government subsidies such as HUHC and CarePlus, and incentivises them to visit a GP to receive subsidised tertiary care. All major variables used to set government subsidisation and practice scheduled fees (such as age-group, gender, ethnicity, NZDep, household income) are controlled for in this study, 
leaving the coefficient of interest free to represent the association between probability of observation and specialist visits, rather than with specialist visits and a selection term, hence leaving it conditionally independent of potential observed fees. Figure 4.2 displays the hypothesised relationships.

Preliminary tests support these theoretically predicted relationships, showing that after accounting for all final-model covariates, specialist service use significantly predicts the odds of having missing data for fees, but does not have an independent relationship to fees in a linear model once again taking account of final-model covariates. To test the first assumption, the probability of fees data being missing (indicated by a Bernoulli-distributed variable) was modelled using a probit function and entering all final analytic model covariates as regressors, including specialist utilisation. In this model, specialist utilisation was significantly related to the probability of missingness at the $p<.001$ level, with a coefficient of -0.481 , thereby lending support to the hypothesised assumption. To test the second assumption, the fees paid to visit a GP were estimated using a linear regression model and entering all final analytic model covariates as regressors, including specialist utilisation. In this model, specialist utilisation was not significantly related to fees paid (-0.006; $\mathrm{p}=0.983$ ), similarly lending support to the hypothesised assumption. Fees for individual $i$ are observed if:

$$
\pi+\beta_{1}^{\prime} X_{i t}+\beta_{2}^{\prime} H_{i t}+\beta_{3} I_{i t}+\sigma_{t}+\omega_{i t}>0
$$

(Equation 6)

where $I$ is the excludable instrument indicating visits to a specialist, $\pi$ is a model constant, $\sigma_{t}$ indexes change over time, and $\omega_{i t}$ is a random error term.

Other sources of bias controlled for in this study are the probability of participation in the survey through the use of probability weights, clustering between individuals sampled in the same stratum and cluster, and potentially non-random missingness of BMI data through regression imputation, as discussed further below. 
Figure 4.2: Conceptual model of selection bias in observed fees data.

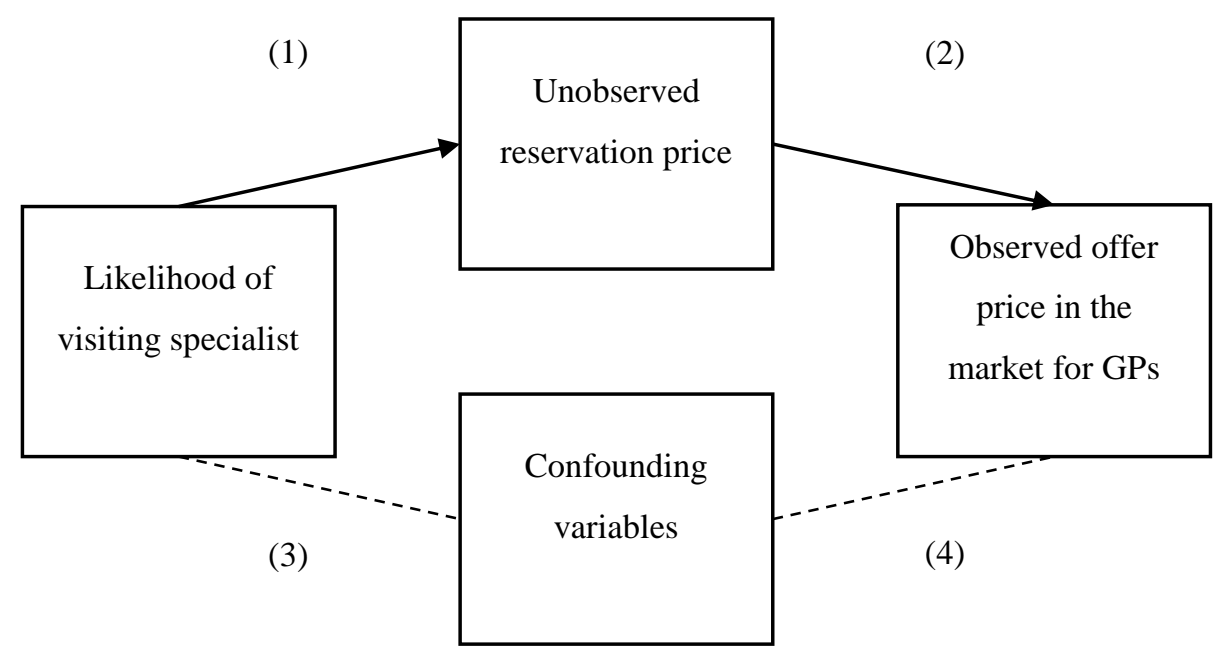

Solid lines represent the causal pathway identified by the selection modelling strategy. Dotted lines represent confounding pathways controlled for by covariates.

(1) People visiting specialists are likely to have a reservation price for GPs above market offer price due to the role of GPs as "gate-keepers" for subsidised tertiary access.

(2) Higher values increase likelihood that reservation price exceeds the offer price.

(3) Health \& socioeconomic variables that select patients into specialist service use.

(4) Government discounting variables and GP scheduled-fee price-setting variables.

\subsection{Data}

The New Zealand Health Survey (NZHS) is a cross-sectional and nationally representative survey. The first NZHS was run in 1992/93, and was iterated in various forms in 1996/97, 2002/03, and 2006/07, before being standardised into a singular survey with continuous operation and annual reporting from 2011/12 onward. This study begins data observation at 2002/03 due to inconsistencies in question wording and variable availability before this point. The 2002/03 wave acts as a baseline in which a large subsidy package had been announced for the next seven years but had not been widely implemented [69]. Early evaluation shows approximately $10 \%$ of the population received new subsidisation by September 2003 [150], and very little change in co-payments occurred at either Access or Interim practices before the year 2003/04 [7], suggesting that 2002/03 data is a defensible baseline. Data for 2006/07 lends insight into the effects of the new capitation subsidies, which had been rolled out to all Access enrolees and patients aged 65+ and 18-24 in Interim practices for over 12 months, and was rolled out to 45-64 year olds a few months before data collection began in October 2006, and was rolled out to 25-44 year olds near the end of data collection. Data from 2011/12-2015/16 is used to track how fees and access have fared in later years, characterised by division between VLCA and non-VLCA practices. The 
distribution of fees between these waves is relatively stable, and the year dummies included in each analysis are non-significant, suggesting it is defensible to pool these data waves.

The core survey consists of cognitively-tested questions covering long-term conditions, health status \& development, health behaviours, service utilisation and experience, and sociodemographic characteristics, and also includes anthropometric measurement of variables such as height, weight, and blood pressure. Data were collected in face-to-face interviews, with field activities contracted out to various specialist survey providers in all waves [151]. Approval for use of Statistics New Zealand's Confidentialised Unit-Record Files (CURF) was gained in June 2017.

All waves employ a three-stage, stratified, probability-proportional-to-size (PPS) sampling design [151]. Estimates are calculated from pooled data, with dummy indicators for each wave of data collection. In line with standard practice outlined by Korn and Graubard [152], Primary Sampling Units (PSUs) and strata in each survey wave are treated as statistically independent, such that the $j^{\text {th }}$ survey wave has $k_{\mathrm{j}}$ PSUs and $L_{\mathrm{j}}$ strata. Although it is technically possible for a given PSU to be sampled in more than one survey wave, the chances are slim (between 1,178 and 1,707 PSUs were sampled in each wave, from a pool of approximately 32,000 ), and the effect of double-sampling on variance estimation is expected to be negligible; hence it is reasonable to assume these units are statistically independent across waves for practical purposes. Treating strata as distinct across years allows differences in the definition of strata to be respected, such as the ethnicity-based groupings in 2002/03 compared to the stratification by DHB in later surveys, or intra-stratum changes across time. However, a limitation to this approach is that the variation within each DHB are likely to be correlated across time. Given that DHBs are not identified in a way that allows linking across survey waves in the data provided, this issue must be accepted as a limitation.

Probability weights are used to adjust for the differential probability of selection, including oversampling of important sub-populations. The survey weights provided for each wave are adjusted such that their sum is the average $\mathrm{N}$ across survey waves, and each wave remains proportional to its original size [152]. Hence, for individual $i$ in survey wave $j$, with weight $w$ and with a sample size $n$, the final weight $W_{i j}^{*}$ is given by the expression:

$$
W_{i j}^{*}=w_{i j}\left(\frac{n_{j}}{n_{j s u m}}\right)
$$


While the NZHS provides an alternative set of weights intended to account for the lowered probability of participation for participants who had anthropometric measurements taken, these were not available for all years of study. Participants of the main survey were ineligible to have their measurements taken if they were pregnant or in a wheelchair, while others refused to participate. In 2015/16, around $95 \%$ of adult participants had anthropometric measurements taken [151]. The solution to this problem is discussed on page 47-48.

Table 4.1 summarises the design characteristics of each wave for comparison. Full details are available in each survey wave's methodology documents [121, 151, 153-157].

\subsection{Measures}

\subsubsection{Dependent variables}

The dependent variables in this study are fees paid at last visit, likelihood of utilisation, number of visits, and unmet need due to cost, in the previous twelve-month period.

Fees were measured through the survey question "Thinking about your last visit to a GP, what were you charged for that visit?" from 2011/12 onwards, with very minor wording differences in the previous waves. Responses to this item are reported in categorical bands in the 2002/03 and 2006/07 waves, and as a continuous variable thereafter. The earlier waves were made continuous by taking the midpoint of each band, and treating top coded variables as though they were a band with the same range as the preceding fee band, following the example of previous research [27]. For example, a value indicating the individual payed between $\$ 40$ and $\$ 50$ for their last visit was coded as $\$ 45$, while a value indicating a fee of “more than $\$ 50$ " was coded as $\$ 55$. Second, fees were adjusted for inflation to 2015 dollars using the CPI in quarter 4 of the year of data collection as a proportion of the CPI in quarter 4 of 2015. Self-reported fees may be biased by recall issues, particularly given that the question may be requiring participants to remember up to 12 months ago. To test the external validity 
Table 4.1: Design characteristics of the New Zealand Health Survey waves 2002/03 to 2015/16

\begin{tabular}{|c|c|c|c|c|c|c|c|}
\hline & $\begin{array}{l}\text { Target pop. } \\
\text { includes } \\
\text { non-private } \\
\text { residents }\end{array}$ & $\begin{array}{l}\text { Sample } \\
\text { frames }\end{array}$ & PSU & Strata & $\begin{array}{l}\text { Adult } \\
\text { response } \\
\text { rate }\end{array}$ & Weights & $\begin{array}{l}\text { Sample } \\
\text { size }^{1}\end{array}$ \\
\hline $2002 / 03$ & No & $\begin{array}{l}\text { Area-based } \\
\text { frame }\end{array}$ & $\begin{array}{l}2001 \text { Census } \\
\text { meshblocks } \\
(n=1178)\end{array}$ & $\begin{array}{l}\text { Ethnicity- } \\
\text { based } \\
\text { PSU } \\
\text { groupings } \\
(\mathrm{N}=7)\end{array}$ & $72 \%$ & $\begin{array}{l}\text { Calibrated } \\
\text { selection weights } \\
\& \text { delete-a-group } \\
\text { jackknife weights }\end{array}$ & $\mathrm{n}=12,177$ \\
\hline $2006 / 07$ & No & $\begin{array}{l}\text { Area-based } \\
\text { frame }\end{array}$ & $\begin{array}{l}2001 \text { Census } \\
\text { Meshblocks } \\
(n=1378)^{2}\end{array}$ & $\begin{array}{l}\text { DHBs } \\
(\mathrm{N}=21)\end{array}$ & $68 \%$ & $\begin{array}{l}\text { Calibrated } \\
\text { selection weights } \\
\& \text { delete-a-group } \\
\text { jackknife weights }\end{array}$ & $\mathrm{n}=11,924$ \\
\hline $2011 / 12$ & Yes & Dual-frame $e^{3}$ & $\begin{array}{l}2006 \text { Census } \\
\text { meshblocks } \\
(n=1209)\end{array}$ & $\begin{array}{l}\text { DHBs } \\
(\mathrm{N}=21)\end{array}$ & $79 \%$ & $\begin{array}{l}\text { Calibrated } \\
\text { selection weights }\end{array}$ & $\mathrm{n}=12,213$ \\
\hline $2012 / 13$ & Yes & Dual-frame $^{3}$ & $\begin{array}{l}2006 \text { Census } \\
\text { meshblocks } \\
(\mathrm{n}=1220)\end{array}$ & $\begin{array}{l}\text { DHBs } \\
(\mathrm{N}=21)\end{array}$ & $80 \%$ & $\begin{array}{l}\text { Calibrated } \\
\text { selection weights }\end{array}$ & $\mathrm{n}=12,611$ \\
\hline $2013 / 14$ & Yes & Dual-frame ${ }^{3}$ & $\begin{array}{l}2006 \text { Census } \\
\text { meshblocks } \\
(n=1240)\end{array}$ & $\begin{array}{l}\text { DHBs } \\
(\mathrm{N}=21)\end{array}$ & $80 \%$ & $\begin{array}{l}\text { Calibrated } \\
\text { selection weights }\end{array}$ & $\mathrm{n}=12,899$ \\
\hline $2014 / 15$ & Yes & Dual-frame ${ }^{3}$ & $\begin{array}{l}2013 \text { Census } \\
\text { meshblocks } \\
(\mathrm{n}=1250)\end{array}$ & $\begin{array}{l}\text { DHBs } \\
(\mathrm{N}=21)\end{array}$ & $79 \%$ & $\begin{array}{l}\text { Calibrated } \\
\text { selection weights } \\
\text { \& delete-a-group } \\
\text { jackknife weights }\end{array}$ & $\mathrm{n}=13,025$ \\
\hline $2015 / 16$ & Yes & Dual-frame ${ }^{3}$ & $\begin{array}{l}\text { Household } \\
\text { surveys frame } \\
\text { PSU } \\
(n=1707)\end{array}$ & $\begin{array}{l}\text { DHBs } \\
(\mathrm{N}=20)^{4}\end{array}$ & $80 \%$ & $\begin{array}{l}\text { Calibrated } \\
\text { selection weights } \\
\text { \& delete-a-group } \\
\text { jackknife weights }\end{array}$ & $\mathrm{n}=13,309$ \\
\hline
\end{tabular}

${ }^{2} \mathrm{n}=1378$ in data received from Statistics New Zealand differs from $\mathrm{n}=1385$ listed in Ministry of Health (2008).

${ }^{3}$ Area-based \& list-based electoral roll sample.

${ }^{4}$ Otago and Southland DHBs merged into Southern DHB. 
of self-reported fees, these were compared to Ministry of Health data collating the schedule of fees by age-group reported by general practices. I find similar magnitudes and distributions of self-reported and scheduled fees, suggesting the distributions identified in this analysis are plausible (see Appendix B).

Utilisation was measured through two questions: i) "In the past 12 months, have you seen a GP, or been visited by a GP, about your own health? By health, I mean your mental and emotional health as well as your physical health", and ii) "How many times did you see a GP in the past 12 months?". Again, there are minor wording differences before and after the 2011/12 survey, but there is no reason to expect results to be invalidated. The former question is a binary yes/no variable, while the latter is a continuous variable top-coded at 55 visits to reduce skew from outlying observations.

Unmet need due to cost was measured by the yes/no question "In the past 12 months, was there a time when you had a medical problem but did not visit a GP because of cost?". While there was a question exploring reasons for having unmet GP need prior to 2011/12, no question explicitly targeted cost barriers, meaning the questions are not directly comparable. Hence, the unmet need models only include data from 2011/12 to 2015/16.

\subsubsection{Independent variables}

These dependent variables are regressed on a vector of demographic and socioeconomic characteristics, indicators of substitute service use, health behaviours, and health status variables. Sociodemographic variables included sex, age group, prioritised ethnicity, highest level of education, household income, number of hours worked per week, having been born outside New Zealand, and having a 'usual practice' to attend when sick.

Age groups correspond to those used in capitation funding formulae and general practice scheduled fees; that is, 18-24, 25-44, 45-65, and with the 65+ category decomposed into 65-79 and 80+ as per Cumming et al. [27]. This is a preferable alternative to a linear or quadratic treatment of age due to the non-linear step-change in fees as individuals move between age-dependent fee categories. The decomposition of the 65+ category into 65-79 and $80+$ is intended to capture marked growth in health need associated with advanced age [158, 159], and is made possible by the study's large sample size. This study excludes NZHS participants aged 15-17 as general practices charge these individuals a substantially lower rate than 18-24 year olds, thereby compromising the validity of the statistical grouping. 
In line with the standard approach used by Statistics New Zealand, where multiple ethnicities were recorded, individuals were assigned a single value according to the following priority order: Māori, Pacific Peoples, Asian, NZ European/Other [151]. It is preferable to combine residual ethnicities with the NZ European category rather than treat them distinctly due to low subsample sizes.

The education variable consists of indicators for secondary qualifications, vocational qualifications, undergraduate qualifications, and postgraduate qualifications, as well as a baseline category for individuals who did not report any qualifications. The vocational qualification category includes diplomas, teaching and nursing certificates, trade or technical certificates. Where a data wave included an "Other" category, this was combined with the vocational qualification category due to low sample sizes and inconsistent data availability. The vocational category was the most intuitive match, produced the most similar bivariate relationships with the dependent variables, and did not change the interpretation of the final model coefficients.

Household income was preferred over personal income in acknowledgement of updates to the Grossman model demonstrating that members of a family unit act strategically in producing health for themselves and each other $[160,161]$. The inclusion of a variable measuring hours regularly worked per week ensures the effect of time spent in labour market activity is separated from higher income. Household income was transformed from a categorical to continuous variable in the same manner as practice fees to allow for adjustment for inflation. The final variable was retransformed into categorical bands matching those used in the 2015/16 NZHS. The deprivation level of the respondent's community is measured by NZDep quintiles. NZDep measures the relative deprivation of meshblock neighbourhood units across New Zealand and stratifies them into five equal quintiles.

The models indicate whether the respondent has utilised public hospitals, private hospitals, and specialist services in the past 12 months, respectively. All three variables were binary. Three health behaviour binary variables were included as controls. The first indicated hazardous consumption of alcohol, as defined by an Alcohol Use Disorders Identification Test (AUDIT) score of greater than or equal to 8 as recommended by the World Health Organisation [162]. The second indicated that the respondent was a current smoker. From 2006/07 onwards, current smokers were defined as have smoked more than 100 cigarettes in their lifetime, and currently smoking at least once a month. However, current smoking in 
2002/03 was defined as smoking a cigarette daily. As a result, smokers comprise a larger proportion of sample totals in this wave than in later waves. The third indicated whether the respondent is covered by any health or medical insurance and is a binary variable.

I follow the approach taken in previous New Zealand household survey studies [26, $163,27]$ by proxying poor latent health with a variable indicating "fair" or "poor" self-rated global health and an index of co-morbidity incorporating information on diabetes, heart problems (angina, heart failure, and heart attacks), arthritis, strokes, high blood pressure, and high blood cholesterol. I add an indicator of whether the patient reported feeling "down-anddepressed" all or most of the time in the past four weeks. Data on whether the respondent reports having been formally diagnosed with depression is not available in the first wave of study, and the implications of using the less precise measure are explored in Appendix C. Briefly, the "down-and-depressed" variable has larger standard errors, has a weaker association with utilisation, and partials out less of the 'depression' effect from chronic illness than the "diagnosed-depression" variable does.

Finally, the analyses make use of the anthropometric measurement of body mass index (BMI) via height and weight measurements to instrument for self-reported health status. The BMI variable was categorised into the World Health Organisation's categories I, II, and III of obesity, with a base category capturing all non-obese participants. This transformation allows a clear theoretical expectation that higher values should monotonically correlate with poorer levels of latent health.

\subsection{Missing data}

Missing data present a threat to the validity of observational research. The presence and severity of resulting bias depends on why data are thought to be missing. In this section, I discuss the expected nature and extent of missing data bias using the seminal framework of Rubin [164] and subsequent scholarship with colleagues [165-168]. Briefly, this framework classifies data as (1) missing completely at random (MCAR) if there is no systematic relationship between data missingness and the expected values of the variable or its covariates, (2) missing at random (MAR) if there is a relationship between the missingness of the data and an observed covariate/s, but not with the value of the missing data itself, or (3) missing not at random (MNAR) if there are systematic differences in the likelihood of missingness based on the value of the latent missing variable itself. Deleting MCAR observations introduces no bias and is hence ignorable. MAR observations introduce no bias 
conditional on correct handling of the known relationship between the missing data and the correlated covariate/s. MNAR observations are the most problematic and will introduce bias if deleted.

Table 4.2 displays data missing in this study as a proportion of total respondents. Variables missing less than 5 percent of observations whose missingness does not depend self-evidently on any particular mechanism are considered ignorable, given that they are unlikely to change the interpretation of findings [169]. These missing datapoints are deleted list-wise from the final analyses. There are non-ignorable proportions of missing data for the variables measuring the fee paid for GP services, household income, and obesity. The treatment of missing fees data was elaborated in Section 4.1.2, and is not reiterated here.

Missing household income data is likely to be produced through (1) lower propensity to report extremely high or low income values $[170,171]$ (MNAR) and (2) methodological issues, which are likely due to fairly high variability between waves (likely MCAR). The NZHS 2015/16 Methodology Document notes improvements made to the way in which questions on income are delivered to reduce item non-response, including developing a picture show-card to help respondents estimate their annual personal income by displaying the weekly and fortnightly equivalent of each annual income band [157]. This may explain the moderate reduction in participants reporting they did not know their household income between 2014/15 and 2015/16. Data collection was administered by different actors across waves, which may influence the success of eliciting personal financial information.

I conservatively treat missing household income values as MNAR by constructing a "Don't know/refused" category in the regression modelling. This is advantageous because it allows direct observation of how missingness relates to the dependent variables and avoids list-wise deletion which would bias the coefficients for other covariates and levels of household income through selection effects. 
Table 4.2: Proportion of data missing for analytic model variables, by wave

\begin{tabular}{|c|c|c|c|c|c|c|c|}
\hline & $2002 / 03$ & $2006 / 07$ & 2011/12 & $2012 / 13$ & $2013 / 14$ & $2014 / 15$ & $2015 / 16$ \\
\hline Consultation fees & $22.5 \%$ & $20.8 \%$ & $25.5 \%$ & $23.8 \%$ & $24.9 \%$ & $23.0 \%$ & $24.0 \%$ \\
\hline Visited a GP & $0.1 \%$ & $0.2 \%$ & $0.2 \%$ & $0.1 \%$ & $0.2 \%$ & $0.1 \%$ & $0.2 \%$ \\
\hline Unmet need due to cost & - & - & $0.1 \%$ & $0.1 \%$ & $0.2 \%$ & $0.1 \%$ & $0.1 \%$ \\
\hline Gender & $0.0 \%$ & $0.2 \%$ & $0.0 \%$ & $0.0 \%$ & $0.0 \%$ & $0.0 \%$ & $0.0 \%$ \\
\hline Age & $0.0 \%$ & $0.2 \%$ & $0.0 \%$ & $0.0 \%$ & $0.0 \%$ & $0.0 \%$ & $0.0 \%$ \\
\hline Ethnicity & $0.0 \%$ & $0.2 \%$ & $0.0 \%$ & $0.0 \%$ & $0.0 \%$ & $0.0 \%$ & $0.0 \%$ \\
\hline Education & $0.1 \%$ & $0.3 \%$ & $1.0 \%$ & $1.2 \%$ & $1.4 \%$ & $1.0 \%$ & $1.3 \%$ \\
\hline Household income & $24.2 \%$ & $13.3 \%$ & $33.7 \%$ & $30.5 \%$ & $29.8 \%$ & $18.3 \%$ & $15.1 \%$ \\
\hline Hours worked & $0.0 \%$ & $1.0 \%$ & $2.2 \%$ & $2.1 \%$ & $2.2 \%$ & $1.3 \%$ & $1.7 \%$ \\
\hline NZDep level & $0.2 \%$ & $0.2 \%$ & $0.1 \%$ & $0.2 \%$ & $0.2 \%$ & $0.4 \%$ & $0.4 \%$ \\
\hline Born overseas & $0.0 \%$ & $0.2 \%$ & $0.0 \%$ & $0.1 \%$ & $0.1 \%$ & $0.0 \%$ & $0.1 \%$ \\
\hline Has usual practice & $0.1 \%$ & $0.2 \%$ & $0.1 \%$ & $0.0 \%$ & $0.1 \%$ & $0.1 \%$ & $0.1 \%$ \\
\hline Public hospital & $0.1 \%$ & $0.2 \%$ & $0.1 \%$ & $0.2 \%$ & $0.2 \%$ & $0.1 \%$ & $0.2 \%$ \\
\hline Private hospital & $0.0 \%$ & $0.2 \%$ & $0.1 \%$ & $0.1 \%$ & $0.1 \%$ & $0.1 \%$ & $0.1 \%$ \\
\hline Specialist & $0.1 \%$ & $0.3 \%$ & $0.0 \%$ & $0.7 \%$ & $0.6 \%$ & $0.8 \%$ & $0.7 \%$ \\
\hline Smoker & $0.0 \%$ & $0.2 \%$ & $0.3 \%$ & $0.4 \%$ & $0.2 \%$ & $0.3 \%$ & $0.3 \%$ \\
\hline Drinker & $0.0 \%$ & $0.4 \%$ & $1.6 \%$ & $1.3 \%$ & $1.2 \%$ & $0.7 \%$ & $1.1 \%$ \\
\hline Has insurance & $1.1 \%$ & $0.6 \%$ & $1.4 \%$ & $1.3 \%$ & $1.2 \%$ & $1.3 \%$ & $1.4 \%$ \\
\hline Self-rated health & $0.0 \%$ & $0.2 \%$ & $0.2 \%$ & $0.3 \%$ & $0.2 \%$ & $0.1 \%$ & $0.2 \%$ \\
\hline Chronic conditions & $1.8 \%$ & $0.4 \%$ & $1.6 \%$ & $1.9 \%$ & $2.3 \%$ & $2.6 \%$ & $2.4 \%$ \\
\hline Depressed & $0.0 \%$ & $0.0 \%$ & $0.2 \%$ & $0.2 \%$ & $0.3 \%$ & $0.2 \%$ & $0.2 \%$ \\
\hline Obesity & $9.6 \%$ & $6.6 \%$ & $15.1 \%$ & $8.2 \%$ & $5.4 \%$ & $5.4 \%$ & $6.2 \%$ \\
\hline
\end{tabular}


I construct obesity classes from NZHS BMI data, which is in turn derived from anthropometric measurements for height and weight. Missing obesity data is likely to occur through three channels: (1) ineligibility to participate in anthropometric measurement (MAR), (2) refusal to have particularly extreme measurements taken (MNAR), and (3) methodological issues (likely MCAR).

Table 4.5 displays the reasons obesity data were missing in each wave. Pregnant respondents were ineligible to have anthropometric measurements taken, as were those who were in pain or wheelchair-bound [154]. Note that the coding system for missing data differs across time - for example, in 2006/07 pregnancy is incorporated into the 'unable' classification, whereas from the following wave it is recorded separately. While specific weights controlling for participation in the measurement section are included from 2011/12 survey onwards, these are not available for all waves and hence deleting missing observations will not take into account the differential probability of selection.

Missingness varies substantially across years, suggesting much of the missingness is due to methodology rather than changes in the population. Participants who refused height and weight measurements, ranging from $2.0 \%$ to $7.5 \%$ of respondents, raise more serious questions about whether the data are MNAR, as they may be more likely to refuse measurement if they have extreme values.

Treatment of this missing data was handled with respect to two critical concerns. First, the approach needs to account for the lowered probability of participants having anthropometric measurements taken, compared to participating in the core survey. Second, the approach needs to reflect the role of obesity classes in this study as exogenous instruments. This means the approach should eliminate to the greatest extent possible any correlation between the instruments and the error term.

Table 4.5: Reasons for missingness of obesity data

\begin{tabular}{lccccccc}
\hline & $\mathbf{2 0 0 2 / 0 3}$ & $\mathbf{2 0 0 6 / 0 7}$ & $\mathbf{2 0 1 1 / 1 2}$ & $\mathbf{2 0 1 2 / 1 3}$ & $\mathbf{2 0 1 3 / 1 4}$ & $\mathbf{2 0 1 4 / 1 5}$ & $\mathbf{2 0 1 5 / 1 6}$ \\
\hline Pregnant & - & - & $2.40 \%$ & $1.65 \%$ & $1.46 \%$ & $1.49 \%$ & $1.44 \%$ \\
Refused & - & $3.21 \%$ & $7.47 \%$ & $3.28 \%$ & $1.96 \%$ & $3.90 \%$ & $4.79 \%$ \\
Unable & - & $3.25 \%$ & $5.06 \%$ & $3.25 \%$ & $1.95 \%$ & $0 \%$ & $0 \%$ \\
Other & $9.63 \%$ & $0.17 \%$ & $0.16 \%$ & $0.03 \%$ & - & - & - \\
Total & $9.6 \%$ & $6.6 \%$ & $15.1 \%$ & $8.2 \%$ & $5.4 \%$ & $5.4 \%$ & $6.2 \%$ \\
\hline
\end{tabular}

Percent of total observations 
I employ a common solution to instrument missingness by incorporating missing values into the base group ("not obese") and creating dummy variables for each type of missingness to soak up the 'missingness' effects. I also interact these with survey wave dummies to allow for heterogeneous coding methods. These coefficients are omitted from all results tables for space. The results are robust to alternative strategies, such as singly or multiply imputing missing obesity values using both the interacted missing variable dummies and information about respondent age, ethnicity, gender, household income, deprivation level, physical functioning, and morbidity of chronic conditions, with adjustment for year of study to control for secular changes over time. Imputed estimates are virtually unchanged in magnitude or significance.

Both the dummy and imputation approaches imperfectly account for the MNAR refusals to participate [172]. Any remaining failure of my instrumentation strategy to take into account extreme values of BMI should logically downwardly bias the relationship between obesity and self-rated health by omitting those whose health is expected to be worst. Regardless, I find a strong relationship between obesity and self-rated health (see Tables 5.2 $\& 5.3$ ), meaning that any potential bias is insufficient to mask this relationship, and that the instruments are, if anything, even stronger than my associative results demonstrate.

\subsection{Analysis}

All analyses were conducted in StataSE 14.2. Linear models were estimated using the regress, ivregress, and heckman commands. The models requiring incorporation of both Heckman selection procedures and instrumental variables were estimated using the usergenerated program cmp [173]. Binary-outcome models were run using probit transformations with commands probit and ivprobit. All models were estimated using the Limited Information Maximum Likelihood (LIML) estimator where applicable. Monte Carlo evidence suggests LIML estimators perform at least as well as its alternatives in a wide variety of applications, and commonly demonstrate less bias and smaller confidence intervals [174176]. In practice, results were robust to specification of alternative estimators. All estimates account for survey design strata, clusters, and probability weights using Stata's svy suite. 


\section{Chapter 5: Results}

This chapter reports the results of the empirical investigation. First, proxies of access are explored through descriptive statistics. Next, these variables are modelled through regression analysis. Finally, I examine how robust the results are to alternative methodological specifications.

\subsection{Descriptive statistics}

Table 5.1 displays the outcome variable descriptive means and sample sizes for respondents to the 2002/03, 2006/07 and pooled 2011/12-2015/16 NZHS by selected demographic, socioeconomic and health variables. The periods respectively represent a baseline before widespread roll-out of First-Contact subsidies, near-complete roll-out of First-Contact subsidies, and a period characterised by price differentiation between VLCA and non-VLCA practices. I also observe the proportion of participants reporting poor or fair health. While comparisons between groups are not likely to be accurate due to self-reporting bias, changes within each group over time provides useful insight which can later be compared to the regression models.

The results show that aside from people aged 65+ (who became eligible for Interim subsidies in July 2004) those age 45-64 (who received Interim subsidies in July 2006), and people earning $\$ 30,000-\$ 100,000$, most groups reported paying more in $2006 / 07$ than in 2002/03. The fees for 18-24 year olds were notably higher despite having been eligible for new subsidies since July 2005, although the smaller proportion reporting poor health and fewer visits per year suggests this may have been driven by fewer 18-24 year olds being sufficiently ill to receive high-use discounts. The observed fees rose particularly sharply for 18-44 year olds, Asians, and people with little to no earnings.

The proportion of males, non-NZ Europeans, and people on middle incomes visiting a doctor rose. For Pacific Peoples and the group earning $\$ 30,001-50,000$, this may be driven by a substantially rising proportion of people reporting poor health. The increased prevalence of poor self-reported health might reflect genuine population health changes, but it is possible that visiting a doctor made these groups more conscious of their poor health. Looking at the sample sizes by income groups, another explanation might be that real wage rises altered the health composition of groups. Fewer people with poor health reported visiting a doctor in 2006/07, while more people in good and excellent health reported visiting a doctor. In tandem 
with the generally lowered number of visits made per year across most groups, this suggests that new utilisers in 2006/07 were people with good or better health who may not have visited otherwise. That the observed fees are generally higher for these groups appears consistent with the hypothesis that people with low reservation prices (whether through good health or insufficient means) are not observed and subsequently downwardly bias the observed average price for a given population characteristic.

Trends in the more recent survey waves were characterised by the VLCA system, and by a completed roll-out of Interim subsidies to all other age-groups. Unfortunately, NZHS data does not distinguish between VLCA and non-VLCA patients, and it is likely that the average fees hide important distinctions between these groups. Respondents reported lower fees than in 2006/07, were less likely to visit doctors, and visited fewer times on average. As expected, after the completed roll-out of Interim subsidies, there was less variation in copayments between age-groups. However, the proportion of 18-24 year olds visiting a doctor dropped substantially. Asians and high-income earners reported paying substantially lower fees than in $2006 / 07$, but this appears to be at least partially explainable by the selection effect from lowered utilisation, while the lower fees for the lowest-earning group are not accompanied by any noticeable change in utilisation. Compared to 2006/07, the proportion of people reporting good health who visited a doctor declined substantially, and this is reflected in a lower observed fee.

Taken together, it appears that most groups visited doctors more frequently by 2006/07 (particularly Māori, middle-income earners, and people with "good” or better health) but these gains were not preserved in recent years. However, these descriptive analyses do not control for interrelationships between variables, such as age and ethnicity. Furthermore, they do not address endogenous self-reporting errors in health or missing data problems such as self-selection into reporting fees. Without accounting for the latter in particular, the descriptive results seem to counterintuitively suggest that higher fees are related to better access. Finally, the analyses cannot comment on simultaneous relationships and changes in group membership - for example, the decline in utilisation by people with poor health and rise in utilisation by people with good health in 2006/07 may reflect that people who were treated reported better health. These issues are explored further in the multivariable analytic models. 
Table 5.1: Average past-year fees and service use for respondents to the New Zealand Health Survey waves 2002/03 - 2015/16, by selected demographic, socioeconomic and health variables. Sample sizes in parentheses.

\begin{tabular}{|c|c|c|c|c|c|c|c|c|c|c|c|c|}
\hline & \multicolumn{3}{|c|}{$\begin{array}{c}\text { Average fee paid, \$NZD } \\
2015(N)\end{array}$} & \multicolumn{3}{|c|}{$\begin{array}{c}\text { \% visiting a doctor in past } \\
12 \text { months }(N)\end{array}$} & \multicolumn{3}{|c|}{$\begin{array}{c}\text { Average number of visits in } \\
\text { past } 12 \text { months }(N)\end{array}$} & \multicolumn{3}{|c|}{$\%$ reporting poor or fair health $(N)$} \\
\hline & $2002 / 03$ & $2006 / 07$ & $2011-16$ & $2002 / 03$ & $2006 / 07$ & $2011-16$ & $2002 / 03$ & $2006 / 07$ & $2011-16$ & $2002 / 03$ & $2006 / 07$ & $2011-16$ \\
\hline \multicolumn{13}{|l|}{ Gender } \\
\hline \multirow[t]{2}{*}{ Male } & $\$ 38.04$ & $\$ 40.98$ & $\$ 34.61$ & $76.7 \%$ & $78.6 \%$ & $75.2 \%$ & 2.8 & 2.6 & 2.6 & $11.0 \%$ & $10.8 \%$ & $10.9 \%$ \\
\hline & $(3458)$ & $(3823)$ & $(19621)$ & $(4710)$ & $(5001)$ & (27139) & $(4710)$ & $(4766)$ & $(27070)$ & $(4712)$ & $(5002)$ & $(27125)$ \\
\hline \multirow[t]{2}{*}{ Female } & $\$ 37.06$ & $\$ 38.09$ & $\$ 33.74$ & $85.3 \%$ & $85.2 \%$ & $84.0 \%$ & 3.7 & 3.4 & 3.4 & $10.3 \%$ & $10.4 \%$ & $11.1 \%$ \\
\hline & $(6047)$ & $(5743)$ & $(29469)$ & $(7456)$ & $(6922)$ & $(36823)$ & $(7452)$ & $(6660)$ & $(36644)$ & $(7463)$ & $(6921)$ & $(36814)$ \\
\hline \multicolumn{13}{|l|}{ Age } \\
\hline \multirow[t]{2}{*}{$18-24$} & $\$ 30.53$ & $\$ 35.27$ & $\$ 29.43$ & $76.8 \%$ & $77.1 \%$ & $69.7 \%$ & 3.0 & 2.6 & 2.5 & $10.3 \%$ & $8.7 \%$ & $9.2 \%$ \\
\hline & $(807)$ & $(809)$ & $(3703)$ & (1212) & (1099) & (5899) & (1212) & (989) & $(5885)$ & (1214) & (1099) & (5895) \\
\hline \multirow[t]{2}{*}{$25-44$} & $\$ 38.50$ & $\$ 45.95$ & $\$ 35.53$ & $76.3 \%$ & $77.0 \%$ & $73.4 \%$ & 2.6 & 2.4 & 2.5 & $8.4 \%$ & $8.8 \%$ & $9.7 \%$ \\
\hline & $(3663)$ & (3505) & (15358) & $(5033)$ & (4657) & (21822) & (5032) & (4417) & $(21780)$ & (5038) & (4657) & (21829) \\
\hline \multirow[t]{2}{*}{$45-64$} & $\$ 41.02$ & $\$ 38.50$ & $\$ 35.16$ & $83.0 \%$ & $83.4 \%$ & $82.4 \%$ & 3.2 & 3.0 & 3.0 & $10.2 \%$ & $10.3 \%$ & $11.7 \%$ \\
\hline & $(3015)$ & (3066) & (16645) & (3715) & (3807) & $(21231)$ & (3713) & $(3697)$ & (21159) & (3717) & (3808) & (21225) \\
\hline \multirow[t]{2}{*}{$65-79$} & $\$ 34.63$ & $\$ 31.14$ & $\$ 32.90$ & $93.8 \%$ & $94.3 \%$ & $92.5 \%$ & 4.9 & 4.4 & 4.1 & $16.6 \%$ & $15.3 \%$ & $12.4 \%$ \\
\hline & (1559) & (1658) & (9814) & (1711) & (1793) & (11020) & (1711) & (1765) & (10959) & (1711) & (1793) & (11004) \\
\hline \multirow[t]{2}{*}{$80+$} & $\$ 32.69$ & $\$ 31.04$ & $\$ 32.69$ & $96.2 \%$ & $96.6 \%$ & $96.6 \%$ & 5.9 & 5.8 & 5.0 & $20.5 \%$ & $21.8 \%$ & $17.3 \%$ \\
\hline & $(461)$ & $(528)$ & (3570) & (495) & $(567)$ & (3990) & (494) & (558) & (3931) & (495) & $(566)$ & (3986) \\
\hline \multicolumn{13}{|l|}{ Ethnicity } \\
\hline \multirow{4}{*}{$\begin{array}{r}\text { NZ European/ } \\
\text { Other } \\
\text { Māori }\end{array}$} & $\$ 39.25$ & $\$ 40.84$ & $\$ 36.48$ & $83.4 \%$ & $83.6 \%$ & $82.3 \%$ & 3.3 & 3.0 & 3.0 & $10.3 \%$ & $9.8 \%$ & $10.0 \%$ \\
\hline & $(5176)$ & (5577) & (33341) & (6213) & (6759) & (42187) & $(6211)$ & (6534) & (42018) & (6218) & (6759) & (42185) \\
\hline & $\$ 28.74$ & $\$ 30.37$ & $\$ 25.99$ & $74.3 \%$ & $79.9 \%$ & $74.9 \%$ & 3.5 & 3.3 & 3.4 & $14.1 \%$ & $14.1 \%$ & $16.9 \%$ \\
\hline & (2914) & $(2321)$ & (9664) & (3949) & (2926) & (13236) & (3947) & (2791) & (13187) & (3952) & (2926) & (13226) \\
\hline Pacific & $\$ 24.02$ & $\$ 26.24$ & $\$ 21.61$ & $77.1 \%$ & $80.7 \%$ & $77.3 \%$ & 3.3 & 3.3 & 3.3 & $9.0 \%$ & $14.4 \%$ & $15.0 \%$ \\
\hline & (689) & (661) & $(2651)$ & $(875)$ & $(836)$ & $(3517)$ & (875) & (794) & $(3502)$ & (874) & $(836)$ & $(3510)$ \\
\hline Asian & $\$ 36.88$ & $\$ 45.41$ & $\$ 32.16$ & $66.5 \%$ & $71.9 \%$ & $69.8 \%$ & 2.1 & 2.3 & 2.1 & $10.6 \%$ & $10.7 \%$ & $9.1 \%$ \\
\hline & (726) & (1007) & $(3434)$ & (1129) & (1402) & $(5022)$ & (1129) & (1307) & $(5007)$ & $(1131)$ & (1402) & $(5018)$ \\
\hline Household & & & & & & & & & & & & \\
\hline income & & & & & & & & & & & & \\
\hline Loss or up to & $\$ 27.59$ & $\$ 33.85$ & $\$ 28.49$ & $84.6 \%$ & $83.3 \%$ & $83.7 \%$ & 4.6 & 4.4 & 4.4 & $21.1 \%$ & $21.4 \%$ & $21.5 \%$ \\
\hline$\$ 20,000$ & (1395) & (839) & (5299) & (1737) & (1025) & (6483) & (1737) & (977) & (6445) & (1737) & (1025) & $(6473)$ \\
\hline$\$ 20,001$ to & $\$ 30.10$ & $\$ 32.36$ & $\$ 31.14$ & $86.5 \%$ & $88.1 \%$ & $86.1 \%$ & 4.2 & 4.4 & 4.2 & $16.6 \%$ & $17.8 \%$ & $17.2 \%$ \\
\hline$\$ 30,000$ & $(1414)$ & $(1436)$ & $(5168)$ & (1694) & $(1665)$ & $(6161)$ & (1694) & $(1616)$ & $(6142)$ & (1694) & $(1665)$ & (6157) \\
\hline$\$ 30,001$ to & $\$ 35.52$ & $\$ 32.83$ & $\$ 32.34$ & $81.6 \%$ & $83.1 \%$ & $82.5 \%$ & 3.4 & 3.4 & 3.4 & $9.5 \%$ & $14.8 \%$ & $12.5 \%$ \\
\hline$\$ 50,000$ & $(1470)$ & $(1454)$ & $(7163)$ & $(1885)$ & (1798) & (8978) & $(1885)$ & (1737) & (8962) & (1889) & (1798) & (8982) \\
\hline$\$ 50,001$ to & $\$ 37.32$ & $\$ 37.08$ & $\$ 34.44$ & $80.5 \%$ & $80.2 \%$ & $79.2 \%$ & 3.1 & 2.7 & 2.7 & $10.8 \%$ & $9.6 \%$ & $9.0 \%$ \\
\hline$\$ 70,000$ & (726) & (1509) & (6139) & (911) & (1903) & $(8073)$ & (911) & (1829) & $(8065)$ & (910) & (1903) & $(8079)$ \\
\hline$\$ 70,001$ to & $\$ 44.15$ & $\$ 40.64$ & $\$ 36.14$ & $80.1 \%$ & $80.8 \%$ & $79.2 \%$ & 2.6 & 2.5 & 2.6 & $7.9 \%$ & $8.0 \%$ & $7.9 \%$ \\
\hline$\$ 100,000$ & $(1016)$ & (1157) & $(6120)$ & (1267) & $(1472)$ & $(8010)$ & (1267) & (1408) & $(8005)$ & (1268) & (1472) & $(8007)$ \\
\hline$\$ 100,001$ and & $\$ 45.12$ & $\$ 47.75$ & $\$ 39.61$ & $81.2 \%$ & $81.9 \%$ & $79.8 \%$ & 2.5 & 2.5 & 2.4 & $4.6 \%$ & $5.9 \%$ & $6.3 \%$ \\
\hline above & $(1472)$ & $(2100)$ & $(8213)$ & $(1864)$ & (2644) & (10818) & (1863) & $(2530)$ & (10812) & (1867) & (2644) & (10834) \\
\hline Don't know/ & $\$ 34.48$ & $\$ 35.61$ & $\$ 30.51$ & $77.7 \%$ & $80.1 \%$ & $76.2 \%$ & 3.4 & 3.3 & 3.1 & $12.5 \%$ & $11.7 \%$ & $13.5 \%$ \\
\hline refused & (2012) & $(1071)$ & (10988) & $(2808)$ & $(1416)$ & (15439) & $(2805)$ & (1329) & (15283) & $(2810)$ & $(1416)$ & (15407) \\
\hline Self-rated & & & & & & & & & & & & \\
\hline health & & & & & & & & & & & & \\
\hline Poor/fair & $\$ 33.68$ & $\$ 34.48$ & $\$ 30.87$ & $94.0 \%$ & $91.6 \%$ & $89.2 \%$ & 7.1 & 6.2 & 5.7 & - & - & - \\
\hline & $(1321)$ & (1288) & (7057) & (1484) & $(1440)$ & (8289) & (1483) & (1394) & $(8213)$ & - & - & - \\
\hline Good & $\$ 37.49$ & $\$ 38.09$ & $\$ 32.95$ & $85.1 \%$ & $87.2 \%$ & $82.9 \%$ & 3.6 & 3.4 & 3.4 & - & - & - \\
\hline & $(3256)$ & (3118) & (16621) & (3965) & (3719) & (20841) & (3964) & (3549) & (20744) & - & - & - \\
\hline Very good & $\$ 38.00$ & $\$ 40.28$ & $\$ 35.13$ & $80.4 \%$ & $80.5 \%$ & $79.1 \%$ & 2.6 & 2.4 & 2.5 & - & - & - \\
\hline & (3539) & $(3701)$ & (18773) & $(4624)$ & $(4706)$ & (24827) & (4623) & $(4524)$ & (24775) & - & - & - \\
\hline Excellent & $\$ 39.33$ & $\$ 43.23$ & $\$ 36.82$ & $68.7 \%$ & $72.2 \%$ & $69.5 \%$ & 1.9 & 1.8 & 1.8 & - & - & - \\
\hline & (1388) & (1459) & (6554) & (2091) & (2057) & (9891) & (2090) & (1958) & (9872) & - & - & - \\
\hline Total & $\$ 37.50$ & $\$ 39.41$ & $\$ 34.13$ & $81.2 \%$ & $82.1 \%$ & $79.8 \%$ & 3.2 & 3.0 & 3.0 & $10.6 \%$ & $10.6 \%$ & $11.0 \%$ \\
\hline & (9505) & (9566) & (49089) & (12166) & (11923) & (63961) & (12162) & (11426) & (63713) & (12175) & (11923) & (63938) \\
\hline
\end{tabular}




\subsection{Regression analysis}

\subsubsection{Choice of estimator}

Before reporting the main results, I first observe the effects of modelling the dependent variables with different estimators, using all waves of data for simplicity of reporting.

Table 5.2 columns 1-4 present coefficients for fees models estimated by OLS regression, IV regression, and their Heckman-adjusted analogues. Looking across model specifications, Heckman selection modelling raised $\mathrm{N}$ from approximately $76 \%$ to $96 \%$ of the eligible sample. In the instrumented models, the first-stage obesity coefficients were strongly and monotonically related to self-rated health as hypothesised, and the Kleibergern-Paap Ftest of their joint significance significantly rejects the null hypothesis of their irrelevance. The F-statistic in each case is well above the rule-of-thumb of 10 denoting a strong instrument [177] and is sufficient to limit weak-instrument bias to less than 5 percent of the endogeneity bias [178]. Instrumentation in model 2 substantially transformed the non-significant relationship between fees and having poor health in the OLS model into a highly significant negative relationship, presumably through HUHC and CarePlus discounting. However, this model may inaccurately estimate the differences between people with good and poor health by excluding people who do not go to the doctor - for example, if the price is particularly high in a given area or if their income is low. Similarly, the Heckman model mistakenly suggests people with poor health pay more for visits by failing to account for the fact that healthier people self-evaluate against different personal and social benchmarks.

Compared to the instrumented model, the Heckman-adjusted instrumented model identifies a further $\$ 0.80$ gap between those rating their health poor/fair and others. It also moderates the lower price paid by participants aged $80+$ compared to $25-44$ year olds, as well as between those without and with a usual practice. Both variables were strongly and positively significant in the first-stage selection equations, meaning the resulting difference in price estimates between models are likely to reflect endogenous selection effects. Other coefficients were generally of a similar magnitude, meaning the selection function does not appear to be endogenous to the level of fees paid in these instances. Overall, the models suggest estimates can be improved by accounting for both self-reporting style and selfselection, and hence the Heckman IV model is preferred. 
Table 5.2: Choice of estimators using pooled data, 2002/03-2015/16

\begin{tabular}{|c|c|c|c|c|c|c|c|c|c|c|c|c|c|c|c|c|}
\hline \multirow[b]{3}{*}{ Female } & \multicolumn{8}{|c|}{ Average fee paid, \$NZD 2015} & \multicolumn{4}{|c|}{ Likelihood of visiting a doctor in past 12 months } & \multicolumn{4}{|c|}{ Number of visits in the past 12 months } \\
\hline & \multicolumn{2}{|c|}{ OLS } & \multicolumn{2}{|c|}{ IV } & \multicolumn{2}{|c|}{ Heckman } & \multicolumn{2}{|c|}{ Heck-IV } & & & & & & & & \\
\hline & 0.43 & {$[0.26]$} & 0.12 & {$[0.28]$} & $2.72^{* * * *}$ & {$[0.29]$} & 0.24 & {$[0.27]$} & $0.23^{* n+4}$ & {$[0.02]$} & $0.24^{* * * *}$ & {$[0.02]$} & $0.43^{* * *}$ & {$[0.03]$} & $0.53^{* * *}$ & {$[0.04]$} \\
\hline Age (base: 25-44) & & & & & & & & & & & & & & & & \\
\hline $18-24$ & $-4.21^{* * *}$ & [0.60] & $-4.83^{* * *}$ & {$[0.61]$} & $-4.89^{* * *}$ & {$[0.62]$} & $-4.87^{* * * *}$ & {$[0.61]$} & $0.06^{*}$ & {$[0.03]$} & $0.09^{*+* *}$ & {$[0.03]$} & 0.07 & {$[0.06]$} & $0.19^{* *}$ & {$[0.07]$} \\
\hline $45-64$ & $-1.41^{* * *}$ & [0.31] & $-1.67^{* * *}$ & {$[0.32]$} & 0.25 & [0.34] & $-1.60^{* * * *}$ & {$[0.32]$} & $0.15^{* * * *}$ & {$[0.02]$} & $0.14^{* * * *}$ & {$[0.02]$} & $0.18^{* * *}$ & {$[0.04]$} & $0.18^{* * *}$ & [0.04] \\
\hline $65-79$ & $-1.59^{* * *}$ & {$[0.38]$} & $-2.99^{* * * *}$ & {$[0.44]$} & $2.94^{* * *}$ & {$[0.42]$} & $-2.66^{* * *}$ & {$[0.42]$} & $0.58^{* * *}$ & {$[0.03]$} & $0.60^{* * * *}$ & {$[0.03]$} & $0.53^{* * *}$ & {$[0.06]$} & $0.75^{* * *}$ & {$[0.07]$} \\
\hline $80+$ & -0.88 & [0.55] & $-2.07^{* * * *}$ & [0.59] & $3.34^{* * *}$ & [0.59] & $-1.68^{* *}$ & {$[0.58]$} & $0.92^{* * * *}$ & {$[0.05]$} & $0.89^{*+* *}$ & {$[0.05]$} & $1.03^{* * *}$ & {$[0.10]$} & $1.18^{* * * *}$ & {$[0.10]$} \\
\hline Ethnicity (base: NZ & & & & & & & & & & & & & & & & \\
\hline European/ Other) & & & & & & & & & & & & & & & & \\
\hline Māori & $-6.79^{* * *}$ & [0.33] & $-6.15^{* * * *}$ & {$[0.35]$} & $-7.97^{* * *}$ & {$[0.36]$} & $-6.20^{* * * *}$ & {$[0.35]$} & $-0.16^{* * *}$ & {$[0.02]$} & $-0.19^{* * * *}$ & {$[0.02]$} & $0.19^{* * *}$ & {$[0.06]$} & 0.04 & {$[0.07]$} \\
\hline Pacific & - & [0.54] & - & {$[0.57]$} & - & {$[0.60]$} & - & {$[0.56]$} & -0.04 & {$[0.04]$} & $-0.07^{*}$ & {$[0.03]$} & $0.22^{* *}$ & {$[0.08]$} & 0.11 & {$[0.09]$} \\
\hline & $10.99^{* * *}$ & & $10.68^{* * * *}$ & & $10.58^{* * * *}$ & & $10.49^{* * * *}$ & & & & & & & & & \\
\hline Asian & $-4.47^{* * *}$ & [0.65] & $-4.29^{* * * *}$ & {$[0.65]$} & $-5.44^{* * *}$ & {$[0.67]$} & $-4.45^{* * * *}$ & {$[0.65]$} & $-0.10^{* * * *}$ & {$[0.03]$} & $-0.10^{* * * *}$ & {$[0.03]$} & $-0.21^{* * *}$ & {$[0.06]$} & $-0.24^{* * * *}$ & {$[0.06]$} \\
\hline $\begin{array}{l}\text { Qualifications (base: } \\
\text { none) }\end{array}$ & & & & & & & & & & & & & & & & \\
\hline Secondary & 0.63 & [0.35] & 0.42 & {$[0.37]$} & $1.28^{* *}$ & {$[0.40]$} & 0.53 & {$[0.36]$} & 0.04 & {$[0.02]$} & $0.04^{*}$ & {$[0.02]$} & -0.06 & {$[0.05]$} & -0.04 & {$[0.06]$} \\
\hline Vocational & $1.47^{* * *}$ & [0.28] & $1.11^{* * *}$ & {$[0.30]$} & $1.96^{* * * *}$ & {$[0.32]$} & $1.20^{* * * *}$ & {$[0.29]$} & $0.05^{*}$ & {$[0.02]$} & $0.06^{* * * *}$ & {$[0.02]$} & $-0.09^{*}$ & [0.04] & -0.01 & {$[0.05]$} \\
\hline Undergraduate & $3.33^{* * *}$ & [0.50] & $2.97^{* * *}$ & {$[0.50]$} & $4.14^{* * *}$ & {$[0.53]$} & $3.04^{* * * *}$ & {$[0.50]$} & $0.10^{* * * *}$ & {$[0.03]$} & $0.12^{* * * *}$ & {$[0.02]$} & -0.08 & [0.05] & 0.01 & {$[0.06]$} \\
\hline Postgraduate & $2.48^{* * *}$ & [0.54] & $2.22^{* * *}$ & [0.55] & $3.32^{* * * *}$ & [0.59] & $2.22^{* * * *}$ & {$[0.55]$} & $0.08^{*}$ & {$[0.03]$} & $0.10^{* * *}$ & {$[0.03]$} & $-0.14^{*}$ & {$[0.06]$} & -0.07 & {$[0.06]$} \\
\hline Household income & & & & & & & & & & & & & & & & \\
\hline (base: loss or up to & & & & & & & & & & & & & & & & \\
\hline$\$ 20,000)$ & & & & & & & & & & & & & & & & \\
\hline$\$ 20,001$ to $\$ 30,000$ & 0.64 & {$[0.47]$} & 0.26 & {$[0.50]$} & $1.42^{* *}$ & {$[0.53]$} & 0.21 & {$[0.49]$} & 0.07 & {$[0.04]$} & $0.10^{* * *}$ & {$[0.04]$} & -0.04 & {$[0.09]$} & 0.07 & {$[0.10]$} \\
\hline$\$ 30,001$ to $\$ 50,000$ & $1.18^{*}$ & {$[0.46]$} & 0.33 & {$[0.50]$} & $2.30^{* * * *}$ & {$[0.52]$} & 0.28 & {$[0.50]$} & $0.09^{* * *}$ & {$[0.04]$} & $0.15^{* * *}$ & {$[0.03]$} & $-0.21^{*}$ & {$[0.08]$} & 0.01 & {$[0.09]$} \\
\hline$\$ 50,001$ to $\$ 70,000$ & $1.89^{* * *}$ & {$[0.51]$} & 0.74 & {$[0.56]$} & $2.62^{* * * *}$ & {$[0.57]$} & 0.71 & {$[0.56]$} & $0.08^{*}$ & {$[0.04]$} & $0.17^{* * * *}$ & {$[0.04]$} & $-0.41^{* * *}$ & {$[0.08]$} & -0.12 & {$[0.10]$} \\
\hline$\$ 70,001$ to $\$ 100,000$ & $2.99^{* * *}$ & {$[0.52]$} & $1.84^{* * *}$ & {$[0.58]$} & $4.27^{* * * *}$ & {$[0.57]$} & $1.84^{* *}$ & {$[0.58]$} & $0.12^{* * *}$ & {$[0.04]$} & $0.21^{* * *}$ & {$[0.04]$} & $-0.37^{* * *}$ & {$[0.08]$} & -0.07 & {$[0.10]$} \\
\hline$\$ 100,001$ and above & $4.51^{* * *}$ & {$[0.55]$} & $3.24^{* * *}$ & {$[0.60]$} & $5.76^{* * * *}$ & {$[0.60]$} & $3.26^{* * * *}$ & {$[0.60]$} & $0.15^{* * * *}$ & {$[0.04]$} & $0.25^{* * * *}$ & {$[0.04]$} & $-0.36^{* * *}$ & {$[0.08]$} & -0.04 & {$[0.10]$} \\
\hline Don't know/refused & $0.92^{*}$ & {$[0.46]$} & 0.31 & {$[0.50]$} & 0.33 & {$[0.52]$} & 0.21 & {$[0.49]$} & 0.03 & {$[0.03]$} & $0.08^{* *}$ & {$[0.03]$} & $-0.24^{* *}$ & {$[0.08]$} & -0.08 & {$[0.09]$} \\
\hline Hours worked & $0.07^{* * *}$ & {$[0.01]$} & $0.05^{* * *}$ & {$[0.01]$} & $0.06^{* * * *}$ & {$[0.01]$} & $0.05^{* * *}$ & {$[0.01]$} & -0.000 & {$[0.000]$} & $0.001^{*}$ & {$[0.000]$} & $-0.01^{* * *}$ & [0.001] & $-0.005^{* * *}$ & {$[0.001]$} \\
\hline Born overseas & $1.33^{* * *}$ & {$[0.36]$} & $1.25^{* * *}$ & {$[0.37]$} & $1.18^{* * *}$ & {$[0.40]$} & $1.24^{* * * *}$ & {$[0.37]$} & 0.004 & {$[0.02]$} & 0.01 & {$[0.02]$} & 0.005 & {$[0.04]$} & 0.02 & {$[0.04]$} \\
\hline Has usual practice & - & {$[1.60]$} & - & [1.61] & $7.84^{* * * *}$ & {$[1.56]$} & - & {$[1.60]$} & $1.21^{* * *}$ & {$[0.03]$} & $1.07^{* * * *}$ & {$[0.04]$} & $1.50^{* * *}$ & {$[0.05]$} & $1.44^{* * *}$ & {$[0.06]$} \\
\hline & $11.78^{* * *}$ & & $11.74^{* * * *}$ & & & & $11.11^{* * * *}$ & & & & & & & & & \\
\hline NZDep Quintile & & & & & & & & & & & & & & & & \\
\hline (base: NZDep 1) & & & & & & & & & & & & & & & & \\
\hline NZDep 2 & $-1.74^{* * * *}$ & {$[0.51]$} & $-1.39^{* * *}$ & {$[0.52]$} & $-1.63^{* *}$ & {$[0.55]$} & $-1.41^{* *}$ & {$[0.51]$} & $0.05^{*}$ & {$[0.03]$} & 0.03 & {$[0.03]$} & $0.13^{*}$ & {$[0.05]$} & 0.05 & {$[0.05]$} \\
\hline NZDep 3 & $-3.84^{* * *}$ & [0.47] & $-3.35^{* * *}$ & {$[0.49]$} & $-3.84^{* * *}$ & {$[0.51]$} & $-3.33^{* * * *}$ & {$[0.48]$} & 0.01 & {$[0.03]$} & -0.03 & {$[0.03]$} & $0.12^{*}$ & {$[0.05]$} & 0.003 & {$[0.05]$} \\
\hline NZDep 4 & $-5.87^{* * * *}$ & {$[0.49]$} & $-5.18^{* * * *}$ & {$[0.50]$} & $-5.58^{* * * *}$ & {$[0.52]$} & $-5.15^{* * * *}$ & {$[0.50]$} & $0.06^{*}$ & {$[0.03]$} & 0.003 & {$[0.03]$} & $0.26^{* * *}$ & {$[0.05]$} & 0.10 & {$[0.06]$} \\
\hline $\begin{array}{r}\text { NZDep } 5 \text { (most } \\
\text { deprived) }\end{array}$ & $-9.39^{* * * *}$ & [0.52] & $-8.53^{* * *}$ & {$[0.54]$} & $-8.79^{* * *}$ & {$[0.55]$} & $-8.51^{* * * *}$ & {$[0.54]$} & $0.08^{* *}$ & {$[0.03]$} & 0.004 & {$[0.03]$} & $0.45^{* * *}$ & {$[0.06]$} & $0.26^{* * *}$ & {$[0.07]$} \\
\hline Public hospital & $-2.37^{* * *}$ & [0.24] & $-0.74^{*}$ & {$[0.36]$} & $1.52^{2 * * *}$ & {$[0.28]$} & -0.59 & {$[0.36]$} & $0.38^{* * * *}$ & [0.02] & $0.25^{* * * *}$ & {$[0.03]$} & $1.33^{* * *}$ & {$[0.05]$} & $1.05^{* * *}$ & {$[0.06]$} \\
\hline Private hospital & 0.72 & {$[0.39]$} & $0.95^{*}$ & {$[0.41]$} & $4.17^{n * * *}$ & {$[0.44]$} & $1.06^{* *}$ & {$[0.41]$} & $0.30^{* * * *}$ & {$[0.05]$} & $0.29^{* * *}$ & {$[0.04]$} & $0.62^{* * *}$ & {$[0.09]$} & $0.69^{* *+* t}$ & {$[0.10]$} \\
\hline Specialist & - & - & - & - & - & - & - & - & $0.55^{*+* *}$ & {$[0.02]$} & $0.41^{* * * * *}$ & {$[0.03]$} & $1.35^{* * *}$ & {$[0.05]$} & $1.09^{* * * *}$ & {$[0.06]$} \\
\hline Current smoker & -0.31 & {$[0.31]$} & -0.23 & {$[0.31]$} & 0.18 & {$[0.33]$} & -0.22 & {$[0.31]$} & 0.04 & {$[0.02]$} & 0.03 & {$[0.02]$} & $0.09^{*}$ & {$[0.04]$} & 0.07 & {$[0.04]$} \\
\hline Heavy drinker & 0.06 & [0.33] & 0.13 & {$[0.34]$} & 0.14 & {$[0.38]$} & 0.16 & {$[0.34]$} & 0.005 & {$[0.02]$} & -0.003 & {$[0.02]$} & -0.004 & {$[0.04]$} & -0.03 & {$[0.04]$} \\
\hline Has insurance & 0.43 & {$[0.27]$} & 0.38 & {$[0.28]$} & $0.68^{*}$ & {$[0.30]$} & 0.43 & {$[0.28]$} & $0.04^{*}$ & {$[0.02]$} & $0.03^{*}$ & {$[0.02]$} & -0.01 & {$[0.03]$} & -0.001 & {$[0.04]$} \\
\hline Poor self-rated & -0.13 & {$[0.32]$} & - & {$[2.78]$} & $2.04^{* * * x}$ & {$[0.37]$} & - & [2.94] & $0.31^{* * * *}$ & {$[0.03]$} & $1.73^{* * * *}$ & {$[0.17]$} & $2.13^{* * *}$ & {$[0.08]$} & $6.49^{* * *}$ & {$[0.59]$} \\
\hline health & & & $18.15^{* * *}$ & & & & $18.95^{* * * *}$ & & & & & & & & & \\
\hline Chronic conditions & & & & & & & & & & & & & & & & \\
\hline (base: no conditions) & & & & & & & & & & & & & & & & \\
\hline 1 condition & -0.12 & [0.27] & $0.60^{*}$ & {$[0.30]$} & $1.54^{* * * *}$ & [0.31] & $0.58^{*}$ & {$[0.29]$} & $0.19^{* * * *}$ & {$[0.02]$} & $0.13^{* * *}$ & {$[0.02]$} & $0.44^{* * *}$ & [0.04] & $0.29^{* * * *}$ & {$[0.05]$} \\
\hline$\geq 2$ conditions & $-1.13^{* * *}$ & {$[0.31]$} & 0.55 & {$[0.42]$} & 0.56 & {$[0.36]$} & 0.53 & {$[0.42]$} & $0.22^{* * * *}$ & {$[0.02]$} & $0.08^{* * *}$ & {$[0.03]$} & $0.81^{* * *}$ & {$[0.05]$} & $0.45^{* * * *}$ & {$[0.07]$} \\
\hline Depressed & 0.53 & {$[0.68]$} & $5.50^{* * *}$ & {$[1.08]$} & $1.97^{* *}$ & {$[0.75]$} & $5.66^{n+* *}$ & {$[1.08]$} & $0.22^{* * * *}$ & {$[0.05]$} & -0.12 & {$[0.08]$} & $1.51^{* * *}$ & {$[0.18]$} & 0.34 & {$[0.25]$} \\
\hline Year (base: 2002/03) & & & & & & & & & & & & & & & & \\
\hline $2006 / 07$ & $1.26^{*}$ & [0.54] & $1.37^{*}$ & {$[0.57]$} & 0.85 & {$[0.58]$} & $1.46^{*}$ & {$[0.57]$} & 0.01 & {$[0.03]$} & -0.01 & {$[0.03]$} & $-0.25^{* * *}$ & {$[0.07]$} & $-0.29^{* * * *}$ & {$[0.07]$} \\
\hline $2011 / 12$ & $-3.26^{* * *}$ & [0.52] & $-3.47^{* * * *}$ & {$[0.55]$} & $-4.89^{* * *}$ & {$[0.58]$} & $-3.44^{* * * *}$ & {$[0.54]$} & $-0.10^{* * *}$ & {$[0.03]$} & $-0.09^{* *}$ & {$[0.03]$} & $-0.34^{* * *}$ & {$[0.07]$} & $-0.36^{* * *}$ & {$[0.07]$} \\
\hline $2012 / 13$ & $-3.91^{* * *}$ & [0.49] & $-4.37^{* * *}$ & {$[0.52]$} & $-5.25^{* * *}$ & {$[0.54]$} & $-4.18^{* * * *}$ & {$[0.52]$} & $-0.10^{* * *}$ & {$[0.03]$} & $-0.08^{* *}$ & {$[0.03]$} & $-0.26^{* * *}$ & {$[0.07]$} & $-0.23^{* *}$ & {$[0.07]$} \\
\hline $2013 / 14$ & $-3.25^{* * *}$ & [0.49] & $-4.14^{* * * *}$ & {$[0.52]$} & $-4.99^{* * *}$ & {$[0.54]$} & $-4.02^{* * * *}$ & {$[0.51]$} & $-0.12^{* * * *}$ & {$[0.03]$} & $-0.07^{*}$ & {$[0.03]$} & $-0.35^{* * *}$ & {$[0.06]$} & $-0.23^{* * *}$ & {$[0.07]$} \\
\hline $2014 / 15$ & $-2.97^{* * * *}$ & {$[0.50]$} & $-3.18^{* * * *}$ & {$[0.53]$} & $-4.32^{* * * *}$ & {$[0.54]$} & $-3.14^{* * * *}$ & {$[0.52]$} & $-0.08^{* * *}$ & {$[0.03]$} & $-0.08^{* *}$ & {$[0.03]$} & $-0.31^{* * *}$ & {$[0.07]$} & $-0.32^{* * * *}$ & {$[0.07]$} \\
\hline $2015 / 16$ & $-2.41^{* * * *}$ & {$[0.48]$} & $-2.37^{* * * *}$ & {$[0.50]$} & $-4.41^{* * * *}$ & {$[0.54]$} & $-2.32^{* * * *}$ & {$[0.50]$} & $-0.14^{* * * *}$ & {$[0.03]$} & $-0.14^{* * * *}$ & {$[0.03]$} & $-0.52^{* * *}$ & {$[0.07]$} & $-0.55^{* * * *}$ & {$[0.07]$} \\
\hline Obesity $^{1}$ & & & & & & & & & & & & & & & & \\
\hline Class I & - & & $0.03 * * * *$ & {$[0.001]$} & - & & $0.03 * * *$ & {$[0.00]$} & - & & $0.03 * * *$ & {$[0.00]$} & - & & $0.03 * * *$ & {$[0.00]$} \\
\hline Class II & - & & $0.08 * * * *$ & {$[0.01]$} & - & & $0.08 * * *$ & {$[0.01]$} & - & & $0.08 * * *$ & {$[0.01]$} & - & & $0.08 * * *$ & {$[0.01]$} \\
\hline Class III & - & & $0.16 * * *$ & {$[0.01]$} & - & & $0.15^{* * *}$ & {$[0.01]$} & - & & $0.15^{* * * *}$ & {$[0.01]$} & - & & $0.15 * * *$ & {$[0.01]$} \\
\hline Kleibergen-Paap F & & & $\mathrm{F}(3,902$ & $=138.07$ & & & $F(3,902$ & $=140.3 *$ & & & $\mathrm{~F}(3,9021$ & $=135.82 *$ & & & $F(3,9020)$ & $=137.34 * *$ \\
\hline & & & 2) & $* * *$ & & & 2) & $* *$ & & & ) & $* *$ & & & & * \\
\hline $\bar{N}$ & 63898 & & 63898 & & 82114 & & 82431 & & 82023 & & 82023 & & 81351 & & 81351 & \\
\hline
\end{tabular}

' First-stage coefficients 
Columns 5-8 present non-instrumented and instrumented models of the probability of a past-year GP visit and the number of visits. The instrumented models find a substantially stronger relationship between poor health and both the probability and number of past-year GP visits, at the expense of other health variable coefficients. Instrumentation also reveals a much less socioeconomically equitable pattern of service use than naïve regression would suggest. Those with higher income levels become much more likely to have accessed doctors in the past 12 months, but without the high number of uses that would suggest poor health. For variables associated with good health such as high income, instrumentation reveals a much less equitable pattern of service use than naïve regression would suggest (evidenced by wider gaps in the probability of visits, but fewer visits made overall). The inverse is true of variables indicative of poor health, such as Māori ethnicity and high deprivation. The results suggest it is important to instrument differences in self-reporting style to control for endogenous effects on simultaneously determined coefficients.

\subsubsection{Main results}

Having identified how the results are affected by the choice of estimators, I now turn to the substantive results. Table 5.3 compares the distribution of co-payments and proxies of access across population groups at different time points. The fees models were estimated using Heckman-adjusted IV methods, the utilisation models were estimated using IV regression, and unmet need was estimated using probit regression. The Kleibergen-Paap F tests are again strongly significant in all analyses. The F statistic is weaker in the unpooled waves and does not exceed the greater-than-10 rule-of-thumb in 2002/03. Nevertheless, the effect of obesity remains strongly and monotonically related to self-rated health in all analyses.

Women visited doctors more than men in all years, but the differential declined in $2006 / 07$ before increasing again in recent years. The descriptive results suggest this has largely been driven by increased utilisation among men, with women still more likely than men to report unmet need due to cost in recent years. Age-based differences in fees were greatly curtailed by 2011/12-2015/16 excluding a $\$ 3.75$ lower fee for 18-24 year olds compared to the base group, and 25-44 year olds became much less likely to use services than older age-groups. The lower-cost access for Māori and Pacific Peoples was maintained across all three periods, but Asians paid substantially less in recent years than in 2006/07, despite having generally good health. It is interesting to note through comparisons to the descriptive 
means that the differences in fees between Māori and Pacific Peoples compared to the base group have been moderated through selection modelling and controlling for covariates. While the subsidies rolled out by 2006/07 eased disparities of utilisation for Māori, these gains have been lost in recent years, and Māori remain more likely to report cost barriers to access. Fees and utilisation have remained relatively static across qualification types, with the only major changes being between those with no qualifications and those with secondary or vocational qualifications.

The wide stratification of fees by income level in 2002/03 reflects the exclusive targeting of subsidies by income level in the pre-PHCS system. By 2006/07, the highest and lowest income groups paid fees that were similar to one another, and this was only partially reversed in later years. High-income groups remained more likely to visit a doctor over all periods, but the gap between richest and poorest was somewhat ameliorated by 2006/07. Fees were monotonically stratified by the level of neighbourhood deprivation across all periods in similar measure, and while deprivation was not associated with different odds of past-year GP visits, more deprived groups made a higher number of visits per year and were more likely to report unmet need, suggesting the results are driven by higher health need.

The PHCS made access to new subsidies contingent on enrolment with a GP, and this is reflected in substantial differences between those who do and do not report having a usual practice, both in terms of fees paid (\$13-14 less for those with a usual practice) and utilisation coefficients (much higher for those with a usual practice) from 2006/07 onward. The margin of error is high because most patients had a usual practice. Use of secondary and tertiary services was more closely linked to GP service use from 2006/07 onwards, although it is difficult to disentangle why different services were used together from these results. However, the fact that public hospitals and not other services were significantly associated with unmet need for GPs may suggest that those with poor access to PHC substituted with the fully publicly-funded secondary system. Interestingly, having medical insurance became temporarily relevant to the price and use of GP services in 2006/07. People with insurance may be willing to pay more, or alternatively GPs may have charged patients with insurance more..

In 2002/03, by far the strongest factor associated with reporting a low-cost consultation was poor health status, as intended by the targeted subsidy regime. This substantial price differential had largely disappeared by $2006 / 07$. While poor health remained 
strongly associated with service use in later years, the size of the relationship was moderated. People with multiple chronic conditions made much more use of GP services following the introduction of new capitation payments and CarePlus in the 2006/07 data, but in recent years the relationship vanished. People who reported feeling depressed for most or all of the past four weeks reported substantially higher fees for service in 2002/03 for unclear reasons. . All three health variables were strongly predictive of cost barriers to access in 2011/12-2015/16.

In summary, the results show that between 2002/03 and 2006/07 the difference in utilisation between Māori and NZ Europeans/Others disappeared, and high-income earners paid lower fees similar to those paid by low-and-middle income earners. While poor health was still associated with paying lower fees and making more visits, the associations were of a lesser degree than in 2002/03. These trends have mostly held steady through the more recent VLCA era, but the increased Māori utilisation rates have not been sustained, while fees for typically-healthy Asians have fallen substantially, which is a foreseeable but not explicitly intended result of universalising subsidy access under the PHCS. Unmet need due to cost remains more common among women, 25-44 year olds, Māori, low-income earners, people in more deprived areas, and people with poor health, chronic conditions, and depressive feelings. 
Table 5.3: Determinants of fees for and access to GP service

\begin{tabular}{|c|c|c|c|c|c|c|c|c|c|c|}
\hline & \multicolumn{3}{|c|}{ Average fee paid, \$NZD 2015} & \multicolumn{3}{|c|}{ Probability of making a past-year GP visit } & \multicolumn{3}{|c|}{ Number of past-year GP visits } & \multirow{2}{*}{$\begin{array}{c}\text { Unmet need } \\
\text { due to cost } \\
2011 / 12- \\
2015 / 16\end{array}$} \\
\hline & $2002 / 03$ & 2006/07 & $\begin{array}{l}2011 / 12- \\
2015 / 16 \\
\end{array}$ & $2002 / 03$ & 2006/07 & 2011/12-2015/16 & $2002 / 03$ & 2006/07 & 2011/12-2015/16 & \\
\hline Female & $\begin{array}{c}0.70 \\
{[0.63]}\end{array}$ & $\begin{array}{l}-1.09 \\
{[0.92]}\end{array}$ & $\begin{array}{c}0.69^{*} \\
{[0.29]}\end{array}$ & $\begin{array}{l}0.25^{* * *} \\
{[0.04]}\end{array}$ & $\begin{array}{l}0.18^{* * *} \\
{[0.04]}\end{array}$ & $\begin{array}{l}0.25^{* * *} \\
{[0.02]}\end{array}$ & $\begin{array}{l}0.62^{* * *} \\
{[0.16]}\end{array}$ & $\begin{array}{l}0.46^{* * *} \\
{[0.09]}\end{array}$ & $\begin{array}{l}0.52^{* * *} \\
{[0.04]}\end{array}$ & $\begin{array}{l}0.27^{* * * *} \\
{[0.02]}\end{array}$ \\
\hline Age (base: $25-44$ ) & & & & & & & & & & \\
\hline $18-24$ & $\begin{array}{l}-4.71^{* * * *} \\
-11221\end{array}$ & $\begin{array}{l}-8.11^{* * * *} \\
-2341\end{array}$ & $\begin{array}{l}-3.75^{* * *} \\
{[0.66]}\end{array}$ & $0.16^{*}$ & $0.14^{*}$ & $0.07^{*}$ & 0.40 & $\begin{array}{l}0.27 \\
0.271\end{array}$ & $0.15^{*}$ & $-0.16^{* * * *}$ \\
\hline $45-64$ & $2.66^{* * *}$ & $\begin{array}{l}-8.38^{* * * * *} \\
{[1.08]}\end{array}$ & $\begin{array}{l}-1.13^{* *} \\
{[0.35]}\end{array}$ & $\begin{array}{c}0.08 \\
{[0.05}\end{array}$ & $\begin{array}{c}0.04 \\
{[0.04]}\end{array}$ & $0.15^{* * *}$ & $\begin{array}{c}0.23 \\
{[0.12]}\end{array}$ & $\begin{array}{c}0.16 \\
{[0.10]}\end{array}$ & $0.15^{* * * *}$ & $-0.41^{* * * *}$ \\
\hline $65-79$ & $2.07^{*}$ & $-10.64^{* * *}$ & $-1.32^{* *}$ & $0.49^{* * * *}$ & $0.42^{* * *}$ & $0.62^{2 * * *}$ & $0.71^{* * *}$ & 0.24 & $0.78^{* * * *}$ & $\begin{array}{l}-1.03^{* * * *} \\
-1.0\end{array}$ \\
\hline & [1.01] & {$[1.29]$} & {$[0.44]$} & {$[0.11]$} & {$[0.08]$} & {$[0.03]$} & {$[0.25]$} & {$[0.17]$} & {$[0.08]$} & {$[0.04]$} \\
\hline $80+$ & $\begin{array}{c}1.65 \\
{[1.35]}\end{array}$ & $\begin{array}{l}-8.73^{* * * *} \\
{[1.46]}\end{array}$ & $\begin{array}{c}-0.52 \\
{[0.65]}\end{array}$ & $\begin{array}{l}0.62^{* * *} \\
{[0.19]}\end{array}$ & $\begin{array}{l}0.61^{* * * *} \\
{[0.14]}\end{array}$ & $\begin{array}{l}0.94^{* * *} \\
{[0.06]}\end{array}$ & $\begin{array}{l}1.41^{*+* n *} \\
{[0.38]}\end{array}$ & $\begin{array}{l}0.98^{* *} \\
{[0.34]}\end{array}$ & $\begin{array}{l}1.16^{* * * * *} \\
{[0.11]}\end{array}$ & $\begin{array}{l}-1.52^{* * * *} \\
{[0.06]}\end{array}$ \\
\hline Ethnicity (base: NZ & & & & & & & & & & \\
\hline Māori & $\begin{array}{l}-5.37^{* * *} \\
{[1.07]}\end{array}$ & $\begin{array}{l}-7.26^{* * *} \\
{[0.89]}\end{array}$ & $\begin{array}{l}-6.64^{* * *} \\
{[0.37]}\end{array}$ & $\begin{array}{l}-0.21^{* * * *} \\
{[0.06]}\end{array}$ & $\begin{array}{l}-0.07 \\
{[0.05]}\end{array}$ & $\begin{array}{l}-0.19^{* * * *} \\
{[0.021}\end{array}$ & $\begin{array}{l}0.05 \\
{[0.20]}\end{array}$ & $\begin{array}{c}0.18 \\
{[0.12\rceil}\end{array}$ & $\begin{array}{c}0.03 \\
{[0.08]}\end{array}$ & $\begin{array}{l}0.13^{3 * * *} \\
{[0.021}\end{array}$ \\
\hline Pacific & $\begin{array}{l}-10.77^{* * *} \\
{[1.51]}\end{array}$ & $\begin{array}{l}-12.10^{* * * *} \\
{[1.53]}\end{array}$ & $\begin{array}{l}-10.57^{* * * *} \\
{[0.62]}\end{array}$ & $\begin{array}{c}0.02 \\
{[0.08]}\end{array}$ & $\begin{array}{l}-0.03 \\
{[0.07]}\end{array}$ & $\begin{array}{l}-0.08 \\
{[0.04]}\end{array}$ & $\begin{array}{c}0.43 \\
{[0.26]}\end{array}$ & $\begin{array}{c}0.34 \\
{[0.19]}\end{array}$ & $\begin{array}{c}0.05 \\
{[0.11]}\end{array}$ & $\begin{array}{l}0.09^{*} \\
{[0.04]}\end{array}$ \\
\hline Asian & -1.01 & 1.43 & $-5.51^{* * * *}$ & $-0.17^{*}$ & $-0.17^{*}$ & $-0.09^{* *}$ & -0.34 & -0.14 & $-0.26^{* * *}$ & $-0.24^{* * *}$ \\
\hline & [1.59] & [2.40] & {$[0.69]$} & {$[0.08]$} & {$[0.07]$} & {$[0.03]$} & {$[0.22]$} & [0.16] & {$[0.07]$} & {$[0.04]$} \\
\hline $\begin{array}{l}\text { Qualifications (base: } \\
\text { none) }\end{array}$ & & & & & & & & & & \\
\hline Secondary & $\begin{array}{l}2.11^{* * *} \\
{[0.79]}\end{array}$ & $\begin{array}{c}-0.98 \\
{[0.97]}\end{array}$ & $\begin{array}{c}0.55 \\
{[0.44]}\end{array}$ & $\begin{array}{l}0.14^{* *} \\
{[0.05]}\end{array}$ & $\begin{array}{c}0.09 \\
{[0.06]}\end{array}$ & $\begin{array}{c}0.01 \\
{[0.03]}\end{array}$ & $\begin{array}{l}-0.06 \\
{[0.21]}\end{array}$ & $\begin{array}{c}-0.25 \\
{[0.16]}\end{array}$ & $\begin{array}{l}-0.04 \\
{[0.07]}\end{array}$ & $\begin{array}{c}0.04 \\
{[0.03]}\end{array}$ \\
\hline Vocational & 1.48 & $1.87^{*}$ & $1.22^{* * * *}$ & $0.20^{* * * * *}$ & 0.003 & $0.06^{*}$ & 0.02 & $-0.32^{*}$ & 0.03 & 0.01 \\
\hline & {$[0.78]$} & {$[0.93]$} & {$[0.32]$} & {$[0.05]$} & {$[0.05]$} & {$[0.02]$} & [0.19] & {$[0.14]$} & {$[0.05]$} & {$[0.02]$} \\
\hline Undergraduate & $3.39^{* * *}$ & 2.86 & $3.55^{* * * *}$ & 0.09 & 0.08 & $0.12^{* * * *}$ & -0.25 & -0.35 & 0.06 & -0.03 \\
\hline & {$[1.26]$} & [1.93] & {$[0.52]$} & {$[0.07]$} & {$[0.07]$} & {$[0.03]$} & {$[0.21]$} & {$[0.18]$} & {$[0.06]$} & {$[0.03]$} \\
\hline Postgraduate & 1.64 & 2.00 & $2.72^{2 * * * x}$ & $0.24^{*}$ & $0.18^{*}$ & 0.06 & 0.19 & -0.19 & -0.09 & -0.03 \\
\hline & [1.91] & {$[1.83]$} & {$[0.57]$} & {$[0.11]$} & {$[0.09]$} & {$[0.04]$} & {$[0.30]$} & {$[0.19]$} & {$[0.07]$} & {$[0.04]$} \\
\hline $\begin{array}{l}\text { Household income } \\
\text { (base: loss or up to } \\
\$ 20,000 \text { ) }\end{array}$ & & & & & & & & & & \\
\hline$\$ 20,001$ to $\$ 30,000$ & $\begin{array}{c}0.60 \\
{[1.23]}\end{array}$ & $\begin{array}{l}-1.78 \\
{[1.80]}\end{array}$ & $\begin{array}{l}1.03^{*} \\
{[0.48]}\end{array}$ & $\begin{array}{c}0.12 \\
{[0.09]}\end{array}$ & $\begin{array}{c}0.14 \\
{[0.09]}\end{array}$ & $\begin{array}{c}0.09^{*} \\
{[0.04]}\end{array}$ & $\begin{array}{c}-0.04 \\
{[0.27]}\end{array}$ & $\begin{array}{c}0.05 \\
{[0.23]}\end{array}$ & $\begin{array}{c}0.08 \\
{[0.12]}\end{array}$ & $\begin{array}{l}-0.04 \\
{[0.04]}\end{array}$ \\
\hline$\$ 30,001$ to $\$ 50,000$ & $3.17^{* * 4}$ & $-4.18^{*}$ & $1.10^{*}$ & $0.27^{* * *}$ & $\begin{array}{c}0.09 \\
0.09\end{array}$ & $0.16^{* * * *}$ & 0.23 & $-0.45^{*}$ & $\begin{array}{l}0.05] \\
0.05\end{array}$ & $-0.22^{* * * *}$ \\
\hline & {$[1.20]$} & {$[1.84]$} & {$[0.50]$} & {$[0.09]$} & {$[0.09]$} & {$[0.04]$} & {$[0.35]$} & {$[0.22]$} & {$[0.11]$} & {$[0.04]$} \\
\hline$\$ 50,001$ to $\$ 70,000$ & $4.53^{* * 4}$ & $-4.25^{*}$ & $1.77^{* * *}$ & 0.17 & 0.15 & $0.17^{* * * *}$ & 0.08 & -0.42 & -0.10 & $-0.34^{* * *}$ \\
\hline & {$[1.50]$} & {$[2.03]$} & {$[0.54]$} & {$[0.10]$} & {$[0.09]$} & {$[0.04]$} & {$[0.34]$} & {$[0.22]$} & {$[0.11]$} & {$[0.04]$} \\
\hline$\$ 70,001$ to $\$ 100,000$ & $8.84^{* * * *}$ & -2.94 & $2.22^{2 * * *}$ & $0.23^{*}$ & $0.25^{* *}$ & $0.21^{* * * *}$ & -0.20 & -0.26 & -0.04 & $-0.50^{* * * *}$ \\
\hline & {$[1.32]$} & {$[2.23]$} & {$[0.56]$} & {$[0.09]$} & {$[0.09]$} & {$[0.04]$} & {$[0.34]$} & {$[0.24]$} & {$[0.11]$} & {$[0.04]$} \\
\hline$\$ 100,001$ and above & $7.72^{* * * *}$ & 1.84 & $3.20^{* * * * *}$ & $0.35^{* * * *}$ & $0.24^{* *}$ & $0.23^{* * * *}$ & 0.20 & -0.20 & -0.06 & $-0.74^{* * * *}$ \\
\hline & {$[1.35]$} & {$[2.38]$} & {$[0.58]$} & {$[0.09]$} & {$[0.10]$} & {$[0.04]$} & {$[0.39]$} & {$[0.25]$} & {$[0.11]$} & {$[0.04]$} \\
\hline Don't know/refused & $3.68^{* * *}$ & -3.15 & 0.37 & 0.09 & 0.11 & $0.09^{*}$ & 0.07 & -0.23 & -0.09 & $-0.31^{* * * *}$ \\
\hline & {$[1.18]$} & {$[2.30]$} & {$[0.48]$} & {$[0.08]$} & {$[0.10]$} & {$[0.04]$} & {$[0.27]$} & {$[0.24]$} & {$[0.10]$} & {$[0.03]$} \\
\hline Hours worked & $0.07^{* * * *}$ & $0.07^{*}$ & $0.06^{* * * *}$ & 0.002 & -0.001 & $0.001^{*}$ & -0.01 & $-0.01^{* * * *}$ & $-0.004^{* * *}$ & $-0.003^{* * * *}$ \\
\hline & {$[0.02]$} & {$[0.03]$} & {$[0.01]$} & {$[0.001]$} & {$[0.001]$} & {$[0.001]$} & {$[0.004]$} & {$[0.003]$} & {$[0.001]$} & {$[0.001]$} \\
\hline Born overseas & 1.27 & $3.50^{1 * *}$ & $0.84^{*}$ & -0.02 & 0.02 & 0.01 & -0.19 & -0.13 & 0.07 & -0.002 \\
\hline & {$[0.80]$} & {$[1.30]$} & {$[0.40]$} & {$[0.05]$} & {$[0.05]$} & {$[0.02]$} & {$[0.13]$} & {$[0.12]$} & {$[0.05]$} & {$[0.03]$} \\
\hline Has usual practice & 0.79 & $-14.19^{* *}$ & $-13.33^{* * *}$ & $0.66^{6 * * x}$ & $1.10^{* * m+x}$ & $1.12^{* * * *}$ & $1.36^{6 * m}$ & $1.82^{2 * * *+}$ & $1.40^{* * * * *}$ & 0.03 \\
\hline & {$[2.43]$} & {$[4.50]$} & {$[2.02]$} & {$[0.18]$} & {$[0.12]$} & {$[0.05]$} & {$[0.16]$} & {$[0.09]$} & {$[0.06]$} & {$[0.04]$} \\
\hline $\begin{array}{l}\text { NZDep Quintile } \\
\text { (base: NZDep 1) }\end{array}$ & & & & & & & & & & \\
\hline NZDep 2 & -1.32 & -0.43 & $-1.78^{* *}$ & 0.10 & -0.001 & 0.02 & $0.36^{*}$ & $0.34^{* *}$ & -0.04 & 0.07 \\
\hline & {$[1.04]$} & {$[1.43]$} & {$[0.60]$} & {$[0.07]$} & {$[0.07]$} & {$[0.03]$} & {$[0.14]$} & {$[0.13]$} & {$[0.06]$} & {$[0.04]$} \\
\hline NZDep 3 & $-3.04^{* *}$ & $-4.50^{* * * *}$ & $-3.55^{* * * *}$ & 0.12 & -0.01 & -0.05 & $0.42^{* *}$ & $0.25^{*}$ & -0.10 & $0.11^{* *}$ \\
\hline & {$[1.09]$} & {$[1.26]$} & {$[0.56]$} & {$[0.06]$} & {$[0.07]$} & {$[0.03]$} & {$[0.15]$} & {$[0.11]$} & {$[0.06]$} & {$[0.04]$} \\
\hline NZDep 4 & $-3.89^{* * *}$ & $-4.24^{* *}$ & $-6.00^{* * *}$ & 0.03 & 0.02 & -0.002 & 0.22 & $0.38^{* *}$ & 0.04 & $0.14^{4 * * * x}$ \\
\hline & {$[1.09]$} & {$[1.35]$} & {$[0.58]$} & {$[0.07]$} & {$[0.07]$} & {$[0.03]$} & {$[0.19]$} & {$[0.14]$} & {$[0.07]$} & {$[0.04]$} \\
\hline NZDep 5 (most & $-8.37^{* * * *}$ & $-8.12^{* * *}$ & $-9.19^{* * * * *}$ & 0.12 & 0.05 & -0.02 & $0.52^{*}$ & $0.32^{*}$ & $0.21^{* *}$ & $0.14^{2+* * *}$ \\
\hline deprived) & {$[1.17]$} & {$[1.67]$} & {$[0.60]$} & {$[0.08]$} & {$[0.08]$} & {$[0.03]$} & {$[0.21]$} & {$[0.14]$} & {$[0.08]$} & {$[0.04]$} \\
\hline Public hospital & -0.51 & $-3.60^{* * * *}$ & $-1.32^{* * *}$ & 0.14 & $0.27^{* * *}$ & $0.26^{* * *}$ & $1.29^{* * m *}$ & $1.03^{* * * *}$ & $1.03^{* * * *}$ & $0.23^{* * *}$ \\
\hline & {$[0.78]$} & {$[0.77]$} & {$[0.28]$} & {$[0.12]$} & {$[0.09]$} & {$[0.03]$} & {$[0.26]$} & {$[0.19]$} & {$[0.07]$} & {$[0.02]$} \\
\hline Private hospital & 1.60 & -0.45 & $0.99^{*}$ & $0.33^{* *}$ & $0.36^{* *}$ & $0.27^{* * *}$ & $0.70^{* *}$ & $0.59^{*}$ & $0.71^{* * * *}$ & -0.05 \\
\hline & {$[1.22]$} & {$[1.27]$} & {$[0.44]$} & {$[0.12]$} & {$[0.12]$} & {$[0.05]$} & {$[0.26]$} & {$[0.24]$} & {$[0.12]$} & {$[0.04]$} \\
\hline Specialist & - & - & - & 0.25 & $0.49^{* * * *}$ & $0.40^{* * * *}$ & $1.35^{*+m}$ & $1.26^{* * * *}$ & $1.01^{* * * * *}$ & 0.04 \\
\hline & - & - & - & {$[0.13]$} & {$[0.10]$} & {$[0.04]$} & {$[0.24]$} & {$[0.14]$} & {$[0.07]$} & {$[0.02]$} \\
\hline Current smoker & 0.16 & -1.39 & -0.30 & 0.04 & $-0.10^{*}$ & 0.03 & 0.09 & -0.14 & $0.10^{*}$ & $0.05^{*}$ \\
\hline & {$[0.67]$} & {$[1.03]$} & {$[0.36]$} & {$[0.04]$} & {$[0.05]$} & {$[0.02]$} & {$[0.11]$} & {$[0.13]$} & {$[0.05]$} & {$[0.02]$} \\
\hline Heavy drinker & 1.29 & 0.13 & -0.22 & -0.03 & 0.02 & -0.01 & 0.14 & -0.05 & -0.05 & -0.03 \\
\hline & {$[0.82]$} & {$[1.35]$} & {$[0.36]$} & {$[0.05]$} & {$[0.06]$} & {$[0.02]$} & {$[0.17]$} & {$[0.11]$} & {$[0.05]$} & {$[0.03]$} \\
\hline Has insurance & -0.61 & $3.81^{* *}$ & -0.15 & 0.03 & $0.17^{* * * *}$ & 0.02 & 0.01 & 0.12 & -0.04 & 0.005 \\
\hline & {$[0.64]$} & {$[1.18]$} & {$[0.29]$} & {$[0.04]$} & {$[0.04]$} & {$[0.02]$} & {$[0.12]$} & {$[0.09]$} & {$[0.04]$} & {$[0.02]$} \\
\hline Poor/fair health & $-26.44^{* * *}$ & -3.86 & $-5.23^{* * *}$ & $2.88^{* * * * *}$ & $1.50^{*}$ & $1.65^{* * *}$ & $7.01^{*}$ & $4.14^{* * *}$ & $6.70^{* * * *}$ & $0.42^{* * * *}$ \\
\hline & {$[1.78]$} & {$[2.28]$} & {$[0.69]$} & {$[0.47]$} & {$[0.60]$} & {$[0.19]$} & {$[2.92]$} & {$[1.58]$} & {$[0.66]$} & {$[0.03]$} \\
\hline $\begin{array}{l}\text { Chronic conditions } \\
\text { (base: no conditions) }\end{array}$ & & & & & & & & & & \\
\hline 1 condition & $1.84^{* * *}$ & $-2.03^{*}$ & 0.21 & -0.001 & $0.16^{* *}$ & $0.13^{* * *}$ & 0.33 & $0.34^{* *}$ & $0.28^{* * *}$ & $0.06^{* *}$ \\
\hline & {$[0.69]$} & {$[0.87]$} & {$[0.30]$} & {$[0.06]$} & {$[0.06]$} & {$[0.02]$} & {$[0.17]$} & {$[0.10]$} & {$[0.05]$} & {$[0.02]$} \\
\hline$\geq 2$ conditions & $3.23^{* * * *}$ & -1.67 & -0.52 & -0.16 & $0.62^{* * *}$ & $0.06^{*}$ & 0.60 & $1.50^{* * * * *}$ & $0.32^{* * *}$ & $0.10^{\text {wime }}$ \\
\hline & {$[0.97]$} & {$[0.96]$} & {$[0.36]$} & {$[0.13]$} & {$[0.18]$} & {$[0.03]$} & {$[0.43]$} & {$[0.27]$} & {$[0.08]$} & {$[0.03]$} \\
\hline Depressed & $12.67^{* * * *}$ & 0.52 & $1.57^{*}$ & $-0.82^{* * *}$ & 0.09 & -0.07 & 0.84 & 1.36 & 0.18 & $0.41^{\text {wate }}$ \\
\hline & {$[2.46]$} & {$[2.17]$} & {$[0.80]$} & {$[0.22]$} & {$[0.24]$} & {$[0.08]$} & {$[1.39]$} & {$[0.73]$} & {$[0.08]$} & {$[0.04]$} \\
\hline Obesity $^{1}$ & & & & & & & & & & \\
\hline Class I & $0.03 * *$ & $0.02 *$ & $0.03 * * *$ & $0.03 * *$ & 0.02 & $0.03 * * *$ & $0.03 * *$ & 0.02 & $0.03^{* * *}$ & - \\
\hline & {$[0.01]$} & {$[0.01]$} & {$[0.01]$} & {$[0.01]$} & {$[0.01]$} & {$[0.01]$} & {$[0.01]$} & {$[0.01]$} & {$[0.001]$} & - \\
\hline Class II & $0.04 *$ & $0.07 * * *$ & $0.08 * * *$ & $0.04 *$ & $0.07 * * *$ & $0.08 * * *$ & $0.05^{*}$ & $0.07 * * *$ & 0.08 & - \\
\hline & {$[0.02]$} & {$[0.02]$} & {$[0.01]$} & {$[0.02]$} & {$[0.02]$} & {$[0.01]$} & {$[0.02]$} & {$[0.02]$} & {$[0.01]$} & - \\
\hline Class III & $0.09 * * *$ & $0.14 * * *$ & $0.16^{* * * *}$ & $0.09 * * *$ & $0.13^{* * * *}$ & $0.16^{* * * *}$ & $0.09 * *$ & $0.13^{* * * *}$ & $0.16^{* * * *}$ & - \\
\hline & {$[0.03]$} & {$[0.02]$} & {$[0.01]$} & [0.02] & {$[0.02]$} & {$[0.01]$} & {$[0.03]$} & {$[0.02]$} & {$[0.01]$} & - \\
\hline Kleibergen-Paap F & $\mathrm{F}(3,1167)$ & $\mathrm{F}(3,1353)$ & $\mathrm{F}(3,6498)$ & $F(3,1167)$ & $\mathrm{F}(3,1353)$ & $\mathrm{F}(3,6497)$ & $\mathrm{F}(3,1167)$ & $\mathrm{F}(3,1353)$ & $\mathrm{F}(3,6496)$ & - \\
\hline & $=5.9^{* * *}$ & $=16.0^{* * * *}$ & $=118.7 * * *$ & $=5.8^{* * *}$ & $=15.1 * * *$ & $=115.1 * * *$ & $=5.7 * * *$ & $=15.1 * * *$ & $=117.3^{* * * *}$ & \\
\hline $\mathrm{N}$ & 11963 & 12041 & 59927 & 11730 & 11705 & 58588 & 11727 & 11706 & 58404 & 60756 \\
\hline
\end{tabular}

Standard errors in brackets

Unreported controls: Year dummies (2012/13-2015/16), indicators of instrument missingness interacted with year dummies.

First-stage coefficients 


\subsection{Robustness tests}

I conduct further tests to explore the possibility that results are driven by methodological considerations rather than true variation in the target population. In particular, I examine (1) simultaneity and self-reporting error associated with health variables in general and chronic illness in particular, (2) whether the decrease in GP utilisation for certain groups is explainable by concurrent changes in the mix of service delivery, and (3) whether results are sensitive to alternative instrumentation strategies.

\subsubsection{Chronic conditions, simultaneity, and error-in-variables bias}

Theory and previous empirical studies suggest there is a simultaneous relationship between health and service use [31, 36, 32]. This simultaneous relationship occurs partly through inverse causality, but may also arise due to dependence on similar demographic and socioeconomic predictors. To assess the extent to which health variables share variance with other covariates, the single-stage models are compared with and without health variables pooling all data waves (see Appendix D, Table D.1).

The results demonstrate that including health variables generally reduces the coefficients on the population characteristics that we would expect to be associated with health need. For example, women paid \$2.62 more than men without accounting for health variables, while including them removed significance. The number of visits associated with older age-groups declined after adding health variables, while the significantly higher price paid also disappeared or reversed in sign. Health variables also seem to drive a good deal of the visit numbers for Māori in particular. The large price differential paid by higher income groups was lessened after accounting for their good health compared to those eligible for high-use health discounts. Most notably, the coefficient relating having a usual practice to fees switches from $\$ 8.05$ to $-\$ 11.54$ demonstrating a strong correlation between health status and selection into having a usual practice. Results for unmet need are the most robust to controls for health status, given that some degree of health control is already built into the survey question. These results help to explain the unique portion of variance being captured by health variables.

Relatedly, while my instrumentation strategy controls for endogenous measurement error associated with self-reporting health, there is reason to believe that self-reported morbidities are affected by the same biases. For example, Sutton et al. [31] found evidence of error-in-variables and simultaneity biases in self-reported morbidities. This may particularly 
be an issue if the endogeneity of chronic conditions influences other variables through associations between reporting characteristics and, say, sociodemographic characteristics like education [32]. Due to a lack of further valid instruments, it is not possible to correct for endogeneity in both variables simultaneously with the available data. To assess whether this constituted a problem for my results, I re-estimated the models without chronic conditions (see Appendix D, Table D.2). Removing chronic conditions produced virtually no change in the magnitude of coefficients. The magnitude of bias may be relatively small in the present case because interviewers in the NZHS ask the respondent whether the condition has been diagnosed by a doctor or whether they currently take medication for the condition, which therefore removes some degree of ambiguity.

Collectively, the results suggest there is potential for a notable degree of simultaneity between health and other characteristics, but also demonstrates that after instrumenting for objective health status, the results appear to be much more stable to alternative specifications. Nevertheless, the cross-sectional data and broad number of parameters of interest in this study necessitate associative rather than causal inference.

\subsubsection{The rise of multidisciplinary teams}

The PHCS intended population-based funding to incentivise the use of multidisciplinary teams, which would enable professionals to efficiently allocate their time to areas of comparative advantage in addressing the drivers of population health need $[1,63]$. Secular changes in the proportion of PHC delivered by nurses and allied health professionals as opposed to GPs might explain the decline in GP utilisation for particular groups in later years of study. The NZHS includes a consistently worded question from 2011/12 onward asking whether the respondent visited a nurse without seeing a doctor in the past 12 months. Controlling for this variable is expected to weaken the coefficients on the year of study if it confounds secular changes in GP use.

To test these hypotheses, I re-estimated models using data from 2011/12 onward with and without the variable indicating having seen a nurse without a doctor (see Appendix D, Table D.3A). The coefficients for year of study are not qualitatively affected by inclusion of the nursing variable, meaning it does not appear that a secular change in demand met by nursing is able to account for the decline in GP utilisation. This variable was independently associated with paying \$1.08 less, higher odds of visiting a GP, a greater number of visits per year, and slightly greater odds of unmet need. The latter three relationships are presumably 
driven by simultaneous relationships with poorer latent health. While the coefficients on most variables remained unchanged, some were significantly weakened. For example, the significant difference in fees between people aged 65-79 and 25-44 narrowed by 23\%, and the coefficients relating the number of past-year GP visits to female gender, age-groups, and Asian ethnicity were weakened by an average of $26 \%$. This suggests some degree of differences in service use for these groups is explained by their health need being met by nurses rather than doctors, and hence the main results may slightly overestimate the associations with these variables. This interpretation was unaltered when the models were respecified with an interaction between nurse visits and year.

To further explore the extent to which nurses are substituting doctors, I compared the models using GP utilisation and unmet need as the outcome variables with a new model using the variable for nursing visits as an outcome variable. Data again come from survey waves $2011 / 12$ to $2015 / 16$. The results show that income stratification of utilisation is much weaker for nurse visits than GP visits. Compared to the significant negative coefficient on Māori GP utilisation, nurse utilisation was more ambivalent, suggesting Māori may consult with nurses rather than doctors when they can access services. Pacific Peoples and Asians were much less likely than NZ Europeans/Others to see nurses, and these coefficients were larger than the equivalent model for GP visits. Other coefficients were of a roughly similar size and sign across models (see Appendix D, Table D.3B). Taken together with the previous test, the results imply that to the limited extent that nurses are displacing doctors, they have done so for low-income groups and some ethnicities, rather than across the board. Such patients often have health profiles which are appropriately handled by nurses, such as respiratory illness, diabetes, and infectious diseases [179]. Alternatively, practices with lower-income enrolees may contain price increases by reducing the cost of their labour inputs. The health implications of substituting nurses for doctors has been scoped in prior work, with a number of studies reviewed by the Ministry of Health [180] finding equivalent health outcomes for patients and greater interpersonal skills, although the effect is likely to depend on the match between the health professional's expertise and the patient's conditions.

\subsubsection{Alternative instrumentation strategies}

To maintain internal validity, results should not differ using different specifications of the instrument. While I construct classes of obesity as instruments of objective health status to allow very clear theoretical predictions of how the instruments should relate to latent 
health status, Sutton et al. [31] instead uses normalised BMI and its squared term to capture linear and non-linear effects. Applying this specification does not change the interpretation of the weak-instrument test, and moderately changes the size (heath coefficients are larger) but not sign of the interpretation of results, including for health and the potentially simultaneous income variables (see Appendix D, Tables D.4A and D4.B).

Another theoretically relevant specification of BMI is the absolute distance between observed BMI and the midpoint of the World Health Organisation's [145] 'healthy' BMI range (18.5-24.9). Higher values of this specification not only account for obesity, but also for the harmful health effects of very low BMI values. Under this specification, both the diagnostic and final results are again unchanged in interpretation. This specification produces coefficients of a closer magnitude to the obesity instrument than the Sutton specification, perhaps because both instruments clearly relate higher values to a lower expected selfreported value of health status. Overall, the results show that the instrument appears to be robust to alternative specifications, even those which include participants with extremely low BMI values in addition to high values.

An important check of an instrument's external validity is whether similar results are produced by other valid instruments using the same causal channel but affecting different subpopulations [181]. The instrumentation strategy makes an assumption that (1) decreases in objective health will decrease self-rated health for any given individual; and (2) the way in which obesity affects self-rated health for the subset of obese respondents will be similar to the way in which other objective health conditions affect self-reported health for other subpopulations. The claim to external validity can be strengthened by demonstrating that other health conditions affecting different subpopulations through the same assumed causal mechanism yield similar results.

In 2012/13, the NZHS introduced additional anthropometric measurements for diastolic blood pressure, systolic blood pressure, and heartrate. These are expected to affect self-rated health through the same causal channel as anthropometric BMI measurements, but do so through distinct (but partially overlapping) subpopulations. That is, they are expected to causally affect latent health through the channel of objective health while excluding the person-specific reporting characteristics that confound the self-reported health measure. Pairwise correlations between obesity and the three alternative instruments show there is a weak overlap in subpopulations conceptualised as having poor health under each instrument, 
with coefficients of $0.235,0.104$, and 0.126 for diastolic blood pressure, systolic blood pressure, and heartrate respectively.

To test whether different instruments produced consistent results, I compared estimates produced by the original instrument to those produced with diastolic blood pressure, systolic blood pressure and heartrate instruments sequentially using data from 2012/13 onward (see Appendix D, Table D.5A and Table D.5B). As with BMI, missing data for ineligible participants were imputed to maintain the appropriateness of the probability weights. All instruments rejected the weak-instruments hypothesis under a Kleibergen-Paap F-test, and the F values were sufficient to both satisfy Staiger and Stock's [177] greater-than10 rule-of-thumb and limit weak-instrument bias to less than 5 percent of the endogeneity bias [178]. No alternative instruments demonstrated a stronger F statistic than obesity.

Diastolic blood pressure performs strongly on the Kleibergen-Paap weak-instrument test and produces reduces very similar results to instrumenting with obesity. Diastolic blood pressure shared the most similarities with obesity in the pair-wise correlations, indicating they share a greater proportion of participants than the other instruments. Systolic blood pressure demonstrated much less relevance as an instrument and produces non-significant relationships between health variables and access proxies, in contrast to other instruments. Finally, heartrate was the strongest of the three alternative instruments, and finds stronger relationships between health variables and access proxies than obesity or diastolic blood pressure. It is notable that the significance of the relationship varies with the strength of the instrument, and not noticeably with the instrument's degree of overlap with obesity. This suggests that the instrumentation strategy does not depend on the specific subpopulation identified by the instrument, and therefore has a strengthened claim to external validity. 


\section{Chapter 6: Discussion and conclusions}

This chapter serves to draw together the evidence presented within and beyond this study. After identifying the key trends and distributional shifts in co-payments and utilisation since the PHCS was adopted, it identifies the key implications for policy-making ahead of the government's health system review. To guide the discussion, I return to the study's research questions. That is, I first discuss trends in the aggregate levels of co-payments and access, and then observe how the distribution of these variables changes over time.

\subsection{How have fees for and access to GPs changed since the PHCS was adopted?}

The co-payments reported in 2006/07 were not substantially lower than 2002/03 despite the roll-out of new capitation funding. The results are more pessimistic than previous results using administrative records from a sample of 99 GPs, which found evidence of lowered consultation fees between 2001-2005 particularly in Access practices, but not at the rates the government hoped for in Interim practices [12]. In spite of this, utilisation rates are higher in 2006/07 than in 2002/03.

These results may suggest the Heckman modelling strategy was not able to fully account for the self-selection of patients with high reservation prices. Nevertheless, there are at least three policy factors that may contribute to imperfect translation between the new subsidisation scheme and lowered co-payments. Firstly, subsidies may not yet have been visible in self-reported data because at the time of data collection for 2006/07, new subsidies had not reached 25-44-year olds in Interim practices and had been introduced to 45-64 year olds less than 12 months ago. Secondly, prior to the government's more stringent agreements with PHOs on the translation of new funds into co-payment reductions, some portion of additional Interim funding intended for co-payment reductions is thought to have merely replaced pre-existing discounts provided by practices prior to the PHCS [28]. Relatedly, the subsidy payments may have simply been pocketed as income without affecting over-thecounter fees for patients, such as they could within the bounds of the government's fee review mechanisms. By contrast, the average price may have dropped in later years because the VLCA funding stream established in 2006 made additional funding conditional on unambiguous caps on co-payments, although this does not affect patients outside of VLCA practices. Thirdly, First-Contact payments increase the financial risk borne by GPs because funding is allocated based on expected rather than actual consultations, and therefore GPs whose populations make more visits than anticipated pass their shortfall on to patients [182]. 
Outside of policy considerations, it is possible that the global recession beginning 2009 led GPs to reduce their fees or temper price increases to stay competitive.

Utilisation rates improved in $2006 / 07$ but subsequently returned to rates similar to those in 2002/03. I draw on supporting evidence to explore candidate explanations for why utilisation has declined in recent years.

First, the PHCS may not have been able to sustain expanded access if critics are correct in asserting that the previous government chronically underfunded the sector $[29,71$ $73,183,184]$. As discussed earlier, Crown expenditure on healthcare as a proportion of GDP has been in decline since 2008 [71]. In the same period, fees have grown faster than inflation for non-VLCA practices [29]. Critics in clinical practice have argued insufficient funding pressured GPs outside the VLCA funding stream to raise prices, with particularly worrisome consequences for low-income earners without access to VLCA-funded practices [183, 184]. Unfortunately, the NZHS does not distinguish between VLCA and non-VLCA patients, and so no comparisons between their behaviour can be made. Another way in which underfunding might lead to reduced utilisation is through constraining the ability of services to expand to meet demand. This may explain the increasing tendency for patients to report inability to make an appointment within 24 hours [29].

Second, subsidies will have suboptimal effects on utilisation if they are poorly targeted. A discussion document prepared by Sapere Research Group on behalf of GPNZ demonstrates that $44 \%$ of the 'high-needs' population defined by present funding formulae (approximately 563,000 people) were enrolled in a non-VLCA practice, while $44 \%$ of the approximately 1.277 million patients enrolled in VLCA practices did not fit the definition of the funding policy's "high needs" population. [185]. Many practices have sizeable proportions of low-needs enrolees, particularly those that joined the VLCA scheme before it was restricted to practices with majority high-needs populations [186]. Access is unlikely to be contingent on low-cost consultation fees for patients who already have good health and are able to afford healthcare without public assistance. Therefore, if the goal of VLCA is to provide targeted low-cost access to groups whose access is contingent on heavily-subsidised access, it is currently inefficiently targeted. This argument is consistent with those advanced in a report to the Minister for Health developed by the Primary Care Working Group [186], which proposed changes in funding allocation to better fit patient need. Their recommendations to the Minister include reinstating CSC as a capitation funding variable, 
using a combination of CSC and deprivation to determine patient eligibility for low-cost payment wherever they are enrolled, and allowing all practices (including VLCA practices) to charge non-high-needs patients a fee commensurate with service.

Third, macroeconomic and policy conditions may have reduced service demand. Given the breadth of this claim, I focus here on the Global Financial Crisis (GFC) as a highprofile example. International research suggests that the global recession beginning in 2009 depressed demand for treatment of lesser-intensity health issues such as those addressed at PHC settings than more serious conditions [35]. The descriptive data trends between survey waves 2006/07 and 2011/12 are consistent with this interpretation, with decreased proportions of the population making one or two doctor's visits per year, an increased proportion making either no visits or more than three visits, and a reduced proportion of the total population visiting GPs overall despite substantially reduced fees. Conceptually, the GFC could affect utilisation through two routes: reducing resources available to access services and altering the preferences of consumers for consultation on low-intensity health conditions.

Comparing unmet need due to cost before and after the GFC's onset would help to separate changes in access from changes in health status, since this measure controls for selfassessed health need. Unfortunately, questions on unmet need in the NZHS are inconsistent prior to 2011/12. However, by comparing a near-identical question in the 2004/05 Survey of Family, Income and Employment (SOFIE) Health survey with the 2011/12 NZHS, there does not appear to be evidence of increased unmet need for doctors, with $15.5 \%$ of a nationallyrepresentative sample of respondents reporting unmet need due to cost in the SOFIE survey [26] compared to $14.2 \%$ reported in the $2011 / 12$ NZHS. This comparison is limited by differences in the representativeness of the SOFIE-Health's sample and insufficient reported information to evaluate whether these estimates are within a margin of error of one another. Nevertheless, the available information appears to suggest unmet need affects a qualitatively similar proportion of the population before and after the GFC.

One final complication in the GFC narrative is that utilisation of services has not fully recovered with the economy in the later survey waves. While the descriptive statistics show a modest recovery in 2014/15 and 2015/16, the regression models suggest that later years continue to be associated with lower utilisation than the base year after controlling for covariates. This might suggest that the GFC has had lasting effects on consumer preferences 
rather than merely constraining resources available for demanded care or might suggest that other external factors are important. The global financial crisis is certainly not the only confounding historical factor - others include major policy initiatives to improve population health such as targeted policy around rheumatic fever and insulation and the introduction of Working-For-Families tax credits, as well as substantial increases in housing costs which may constrain resources available for healthcare [187, 188].

Fourth, secular improvements in health engendered by the PHCS or other factors may have reduced service need. The PHCS may have contributed to reduced health need through incentivising PHOs to tackle the drivers of poor health via population-based funding as intended [1], or through early intervention enabled by lower fees. Alternatively, health need may have been tracking downward irrespective of changes associated with the PHCS. This explanation is less appealing due to the limited timeframe in which population health hypothetically improved, and health data in the NZHS and supporting literature do not strongly support this hypothesis. On the one hand, the population does appear to be becoming healthier in the long-run. Age-standardised health loss has been trending downward since at least 1990 according to evidence from the New Zealand Burden of Diseases, Injuries and Risk Factors Study [189]. On the other hand, there is little sign of significant recent reductions in causes of mortality amenable to early intervention such as influenza, pneumonia and ischaemic heart disease [190], with the exception of rheumatic fever following concerted policy attention in recent years [191]. According to national hospital events data, the agestandardised public hospital discharge rate for 2014/15 was 13\% higher than 2005/06 [192]. A greater proportion of participants report chronic conditions in later waves of the NZHS, and the mean self-reported health status in the NZHS declined modestly across the study period, although as demonstrated by the instrumentation strategy (see pp. 33-34), this variable may not relate directly to poorer objective health outcomes [32]. On balance, there is insufficient evidence to support the claim that the reduction in utilisation reflects secular reductions in health need.

Finally, as explored in Section 5.3.2, there is some indication that nurses are substituting doctors for low-income earners and Māori, therefore contributing to a reduced net utilisation rate. However, the role of nurses should logically have expanded from 2001 onward with the PHCS, yet utilisation rates for GPs improved in 2006/07. It is therefore unlikely that nurse substitution has been a major driver of aggregate change. 
Overall, the data show that the lowered co-payments by 2011/12-2015/16 were accompanied by a decline, rather than increase, in utilisation over the long-run. Supporting evidence suggests that improvements in access may have been restrained by (1) sectoral underfunding, which may have constrained the ability of non-VLCA practices to maintain low fees; (2) inefficient allocation of funding via VLCA and capitation payments, which mismatches low-cost access and patient need; and (3) external macroeconomic and policy conditions including the GFC, which depresses low-intensity health demand through resource constraint and shifts in consumer preference. The next section disaggregates the inference into access by population groups, enabling a clearer contextualised picture to emerge.

\subsection{How has the distribution of co-payments and access changed over time?}

The key findings on the distribution of access and fees are summarised in Table 6.1. The distributional changes are then discussed sequentially for the period prior to the roll-out of First-Contact subsidies, following roll-out, and following the establishment of the VLCA system.

\subsubsection{Distribution prior to roll-out of First-Contact subsidies}

My results for 2002/03 can be compared to prior analyses using the same data [23, 27]. Looking first at the distribution of co-payments, a study using 1996/97 and 2002/03 NZHS data found similar relationships between reported fees and most population characteristics to my study [27]. However, my analysis finds a much more pronounced differential between ethnicities. I argue this is partially because the earlier study includes 1996/97 data, which has a flatter ethnic distribution of co-payments, and partially because my results account for the omission of people with low reservation prices, which would otherwise make ethnic groups appear to report similar fees. I also find that co-payments are strongly related to health status, at odds with the earlier study. I argue this is because my research design has been able to remove self-reporting biases from health status, which leads healthier and less healthy people to report their health in a similar fashion. My results are a closer intuitive fit, given that people with high health need were the exclusive beneficiaries of health subsidies in the pre-PHCS health system, alongside low-income earners.

A study assessing the distribution of utilisation in 1996/97 and 2002/03 found similar results to this study in terms of higher utilisation by women and older age-groups compared to men and 25-44 year olds, lower utilisation by Māori and Asians compared to NZ Europeans, and no differences across community deprivation levels [23]. However, my study 
Table 6.1: Summary of key findings

Gender:

Age:

Ethnicity:

Education:

Born overseas:

Has usual

practice:

Household

income \&

NZDep:

Secondary and

tertiary service

use:

Health

behaviours:

Insurance:

Health:
Access is poorer for women due to higher health needs than men, and the narrowing of this gap in

2006/07 was driven by greater male utilisation. Women still report more unmet need

Older age-groups make the most use of GP services and are least likely to report unmet need 25-44 year olds are most likely to report having unmet need due to cost.

Māori utilisation was not substantially different to NZ Europeans/Others in 2006/07, but were significantly less likely to visit than NZ Europeans/Others by 2011/12-2015/16, incommensurate with their greater health need. Asians paid substantially less than Pakeha/Others in 2011/12-2015/16 and were even less likely than in previous periods (relative to NZ Europeans/Others) to visit despite already having good health.

New capitation funding evened out some of differences in utilisation between people with differing levels of education, but people with tertiary degrees were still more likely to utilise doctors in recent years.

no accompanying behavioural change.

As expected with shift to capitation funding for enrolled populations, having a regular practice became much more important following the PHCS, particularly for the fees paid.

The wide stratification of co-payments by household income largely disappeared with the expansion of universal subsidies, with increased utilisation for lower-income earners and relatively little change for higher-earning groups, consistent with the NZHS' strategic goals. In recent years, higher income earners are more likely to pay higher fees again, likely due to being outside of VLCA scheme, but the income distribution of utilisation has changed little. Patterns across community deprivation level have not substantially changed across the study period.

The association between public hospital and GP service use strengthened following expanded subsidies, which provides weak evidence of substitution between these services. Private hospital and specialist use did not exhibit the same associations.

Not related to access.

Only briefly related to access in 2006/07.

While poor health status was the closest correlate with low fees in the pre-PHCS targeted subsidy system, the co-payments reported for people with better health were substantially lower from 2006/07 onward. New utilisation has tended to come from people in 'good' or better health, while people in poorer health have made fewer annual visits since 2006/07, suggesting they may have difficulties making appointments. 
finds the highest income group to have a significantly higher utilisation rate than those with no income or loss, while the earlier study accounts for this with an employment status variable. The earlier study also found a significant relationship with insurance, which appears to be particular to the $1996 / 97$ data.

\subsubsection{Distribution following First-Contact subsidy expansion}

The distributional changes between 2002/03 and 2006/07 lend insight into the performance of the universal capitation subsidies. Universal subsidies appear to have benefitted both intended groups (Māori and low-income earners) and less explicitly intended groups (high-income earners, Asians, people in good health). Most new utilisation appears to come from groups who have not traditionally been targeted by subsidisation, such as men and those who report being in good health, while service use by people in the poorest health has declined in both absolute and relative terms.

These effects are broadly consistent with what is known about universal subsidisation, namely that it increases both appropriate and inappropriate service use [18-20]. The expanded subsidisation affects both demand decisions through reducing the financial penalty of inappropriate service use, and supply decisions by practices about whom to prioritise for consultations. Because GPs in New Zealand continue to rely on co-payments for a substantial portion of their income, they have an incentive to prioritise patients who can afford to pay.

While it might seem inefficient to subsidise high-income earners whose utilisation behaviour is not substantially changed by lower-cost access, there are a number of reasons why it might be defensible. First, universal access to subsidies prevents the hardest-to-reach vulnerable populations from 'slipping through the cracks', such as the approximately $21 \%$ of people eligible for the CSC who fail to uptake their eligibility [12]. Secondly, encouraging healthier people to seek preventive care is an intentional and desirable component of a strong PHC system, and is justified by reduced counterfactual acute-care costs. Thirdly, public support for welfare systems is stronger when the non-poor also receive benefit [193].

Nevertheless, the results provide grounds to worry that the increased service demand has pushed some with poor health out of the system due to increased difficulty making an appointment. Approximately $18 \%$ of the analytic sample reported being unable to access a GP in the past 12 months in both 2006/07 and 2015/16, with a lowered proportion in the interim years. It is worth interpreting the cross-sectional results here with caution. If the PHCS has succeeded in improving health outcomes, then the people who are most amenable 
to taking up new treatment in the 'poor/fair' health categories may subsequently report their health as 'good' in 2006/07, making it appear as though those remaining in the 'poor/fair' category are worse off.

\subsubsection{Distribution following the establishment of VLCA}

Between 2006/07 and 2011/12-2015/16, age-based co-payment discrepancies closed but 25-44 year olds remained less likely to visit a doctor, Māori were once again less likely to visit doctors, Asians began to pay substantially less than NZ Europeans/Others, and the gap between the number of visits made by people with poor/fair and good or better health halved, while most other changes observed between 2002/03 and 2006/07 were preserved.

While the age results are best explained by the finished roll-out of Interim subsidies, the remaining results are logically consistent with the features of the VLCA system, which distributes low-cost access according to practice-level rather than individual-level characteristics. As discussed earlier, there are sizeable proportions of high-needs patients enrolled in non-VLCA practices and low-needs patients enrolled in VLCA practices [185]. It is therefore unsurprising that some typically healthier groups, such as high-income earners and Asians, with access to VLCA practices no longer pay as much as they would have, while access for low-income earners enrolled in non-VLCA practices remains dependent on the CSC. The modelling showing a declining number of visits made by those with poor health prompts concern that increased service demand from healthier groups has adversely affected high-needs patients' ability to make a timely appointment. Between 1999 and 2012, the number of full-time equivalent GPs per 100,000 New Zealanders declined from 84 to 72 [194], suggesting the government could have invested more in the workforce pipeline to mitigate this issue.

Given the associative nature of inference in this study, the conclusions able to be drawn do not extend to comparisons with the counterfactual non-adoption of the PHCS, which might have seen even less equitable developments occurring in the same macroeconomic and policy climate. However, associative evidence is perfectly capable of identifying that present policy settings have not been able to produce and maintain equitable access by socioeconomic status. Moreover, the observed trends are logically consistent with system design flaws identified in broader stakeholder criticisms of VLCA and the present capitation funding formulae $[185,186,195]$. The substantive implications are that present funding arrangements are inefficiently targeted, which unjustly benefits high-income earners 
financially and fails to address residual access issues for low-income earners in non-VLCA areas and those with poor health.

\subsection{Strengths and limitations}

This study makes a number of valuable contributions to the existing literature. Firstly, it provides inference into the intrinsically valued access through comparison of four dependent variables, therefore avoiding the pitfalls associated with observation of utilisation alone. Secondly, it summarises trends over the entire post-PHCS period, enabling the analysis to look past transient early effects and observe the long-term success of the strategy. Thirdly, it explores multiple sources of endogeneity, some of which the literature has previously not observed. These include error-in-variables bias, simultaneity bias, selection bias, and endogenously missing data.

There are, however, limitations which must be taken into account when interpreting the findings. Firstly, the study is not able to formally comment on the drivers of changes in access at the aggregate level due to the necessitated use of proxies. There is better ability to interpret how the results reflect access for specific population groups than the population as a whole due to the benefits of greater context and more precise theoretical expectations.

Secondly, despite controls for some sources of endogeneity, the data are crosssectional and the number of parameters of interest are sufficiently large that relationships must be treated as associative. This means there remain questions about the extent to which the parameters of interest are influenced by ongoing simultaneity bias and confounding historical events such as macroeconomic conditions and external policy settings. This also creates difficulty in quantifying the change in strength of associations across time. Such critiques are common to all associational studies, and indeed this study successfully examines relationships between a large array of variables and sets the scene for more specific empirical questions.

Thirdly, the missing time points between 2002/03 and 2006/07, and again between the latter and 2011/12 prevent firm conclusions on the timing of particular causes and effects. Observation of more time points may have allowed better inference into the relationship between the roll-out of Interim subsidies, reductions in co-payments, and changes in utilisation behaviour. It also would allow better inference into the early effects of establishing the VLCA system. 
Finally, coefficients could be better controlled against omitted variables bias if consistent data were available across all waves for household size, urban/rural status, spatial characteristics, unmet need due to cost, and enrolment with a VLCA practice. Household size is likely to be an important control for the effect of household income, while omission of urban/rural status may influence coefficients on demographic variables through a range of unique access characteristics associated with rural populations in particular, including greater distance to services, less availability of public transport, and greater likelihood of living close to lower cost practices $[23,196,197]$. Relatedly, a range of spatial variables (such as the density of general practitioners, distance between the patient and their practice, and the availability of public transport) were unavailable in this study's confidentialised public data. This could have biased associations between the area-based NZDep measure and access if there were, for example, fewer doctors and transport options in more deprived areas.

Observing unmet need due to cost over all years would allow greater insight into the potential influence of the GFC over utilisation behaviour. Finally, observing VLCA status directly would allow separate calculation of access proxies for VLCA and non-VLCA enrolees, acknowledging that trends across these groups are likely to follow different trajectories.

\subsection{Implications for policy and future study}

The results in this study have demonstrated that universal subsidisation can be a powerful driver of service demand among both high-needs and low-needs groups. New utilisation by people in good health should be expected if there is to be a transition to a preventive healthcare model. Whether this equates to better outcomes depends on how prepared GP services are to cope with increased service demand and how they respond to the financial incentives within the funding system. Similarly, while this study is unable to formally comment on the drivers of distributional change, the results are consistent with the VLCA system's logical strengths and weaknesses. On the one hand, the observed reduction in average fees is consistent with VLCA's price-capping for some patients. However, it distributes low-cost access inefficiently, through blunt application at the practice-level rather than individual-level. If VLCA's objective is to provide targeted low-cost access to the population it defines as "high-needs", it does so inefficiently by including many who do not meet these criteria and excluding many who do, on the basis of the practice they are enrolled in. While further investigation is needed to make causal claims, my results warrant concern that the scheme may not be providing equal access for patients with equal need as the PHCS intended [1]. 
The results are relevant to the Government's planned health system review and particularly for its review of PHC funding. First and foremost, the results justify revision of current PHC settings due to evidence of ongoing inequities in health care access. They demonstrate that price remains a barrier for the population groups mentioned above, and it is therefore defensible to target further interventions toward these groups. They also suggest that area-based funding schemes like VLCA warrant further investigation to determine the extent to which stakeholder criticisms hold up to empirical scrutiny. Patients with poor health continue to face barriers to access despite the intent of HUHC and CarePlus arrangements, lending support to calls for reform made by the Primary Care Working Group [186]. While the present study did not formally investigate non-cost reasons for unmet need, the results suggest increased service demand may have contributed to inability to get an appointment. Other sources demonstrate the need to consider barriers such as transport, time restrictions, and inadequate cultural sensitivity $[29,38,110]$.

Methodologically, this study highlights the utility of both instrumenting for selfreporting errors and correcting for selection probability in healthcare utilisation studies. Among the benefits of instrumenting were an expanded gap between men and women's utilisation patterns, suggesting previous studies have underestimated gender differences. Selection modelling tended to broaden the differences between groups, because unadjusted models only compare market takers in each group without accounting for the probability of accepting the market price. My novel instrument can improve estimates of fees distributions wherever they are cross-sectional, including self-reported and administrative data.

Having identified ongoing inequities of utilisation, and specifically price barriers to access, future research can help to address ongoing evidence gaps in formulating a policy response. In particular, the health system review would benefit from investigation into (1) the return on PHC subsidies in terms of unmet need; (2) population characteristics associated with reporting different kinds of financial and non-financial unmet need, with emphasis on identifying latent classes of individuals with particular types of unmet need; and (3) estimation of the specific reduction in fees needed to induce needed health-seeking behaviour for specific population groups.

The government's review of PHC funding in the health system review will be usefully informed by estimation of the value of each additional dollar spent in terms of reducing barriers to access, both for the "average" person and for people with high and low risk of 
deferring doctor's visits. Causal inference is possible using longitudinal SOFIE data by exploiting the fact that between 2004-07, subsidies were successively rolled out across Interim-funded primary care providers via a known treatment assignment mechanism (agegroups). This creates a natural experiment that allows causal interpretation of the expected change in likelihood and frequency of deferred visits due to cost when patients receive access to expanded subsidisation, after adjusting estimates to account for age-based eligibility and other covariates like period-specific health status.

Investigation into heterogeneity of unmet need could proceed through latent class analysis of different kinds of unmet need, or through qualitative methods. This work can help to unravel any contradictory causal mechanisms hiding behind the 'average'. For example, we might find that transport issues are common for middle-aged rural Pakeha women, but also for Māori urban-dwelling young adults. This allows identification of better-tailored policy solutions.

Further research could use a willingness-to-pay survey to estimate the level of fees reductions needed to induce service utilisation among groups found in this study to have cost barriers. Willingness-to-pay surveys are a cost-effective method of estimating consumer reservation price for those whose data is not observed in market data [198]. The government may find it cost-effective to identify the level of fees reductions needed to produce a targeted reduction in unmet need before reviewing its funding levels.

\subsection{Conclusions}

This study has examined how the distribution of GP co-payments and utilisation of services have changed in the years following the adoption of the PHCS to date. I find evidence of improved utilisation rates following the roll-out of new universal subsidies, particularly for Māori, men, and those with 'good' or better health. While these patterns suggest the subsidy expansions were able to achieve their policy goals of improving access for Māori and encouraging healthier people to seek preventive care, service demand may have increased faster than capacity given the rapidly declining number of annual visits reported by those with the greatest health need. After gaining access to subsidisation, high income earners paid low fees similar to lower income earners but did not visit doctors more often. This financial transfer to high-income earners is often seen as the cost of ensuring the hardest-to-reach population segments do not slip through the cracks of a targeted system by failing to take up subsidies they are eligible for. 
The heightened utilisation for both the whole population and for Māori have not survived into the VLCA era, and instead low-cost access has been inefficiently meted out to patients with varying levels of service need. While this study cannot formally explain the drivers of these changes, they are logically consistent with the poor allocative efficiency of the VLCA system, which fails to assign low-cost access to large proportions of high needs patients who live outside of the most deprived areas while simultaneously subsidising many who do not meet its "high-needs" criteria. The problems of these patients may be compounded by sectoral underfunding, which critics claim has inhibited the ability of nonVLCA practices to maintain low fees $[183,184]$. Service demand is also likely to have been lowered by concurrent macroeconomic and policy developments such as the global recession. Cost barriers to access continue to be inequitably distributed to the detriment of women, 2544 year olds, Māori, low-income earners, people in more deprived areas, and people with poor health, chronic conditions, and depressive feelings. The results are robust to a range of methodological checks.

The health system review presents a timely opportunity to amend the shortcomings in present institutional healthcare arrangements, and to redress the inequities faced by groups with little means or high health need. The VLCA system of distributing low-cost access should be a first candidate for reform. Funding should follow individuals rather than area units to allow high-needs patients to receive access wherever they are enrolled. Provisions for patients with complex health needs also need reviewing, given that these patients continue to report cost barriers to access. Policy reform offers a chance to affirm and strengthen the PHCS's Alma-Ata inspired vision of a primary care system accessible for all, at cost the community can afford. 


\section{Appendices}

\section{Appendix A: Instrumental variables}

\section{Endogeneity tests}

I estimate Hausman statistics comparing coefficients for self-rated health in singleequation and instrumental variables models. IV models are less efficient than OLS but are consistent. Hence, if there is no bias in the candidate endogenous regressor, the coefficients estimated across models should not be significantly different [199]. Table A.1 demonstrates that the null hypothesis of exogeneity is rejected in all models, but the endogeneity is much weaker in the analysis of unmet need. I argue this is consistent with the theoretical understanding that the majority of bias is due to person-specific reporting characteristics, and that the UNMET model already accounts for this by including these characteristics on both sides of the equation. The remaining bias is due to simultaneity between present health status and past-year utilisation behaviour and necessitates associative rather than causal inferences. The UNMET results give an indication of the level of endogeneity expected for other dependent variables after purging self-reporting bias.

Table A.1: Hausman tests for exogeneity of self-rated health

\begin{tabular}{ll}
\hline FEES: & $\mathrm{F}(1,9020)=87.60$ Prob $>\mathrm{F}=0.0000$ \\
VISPROB: & $\mathrm{F}(1,9023)=68.69 \quad$ Prob $>\mathrm{F}=0.0000$ \\
VISNUM: & $\mathrm{F}(1,9023)=149.56$ Prob $>\mathrm{F}=0.0000$ \\
UNMET: & $\mathrm{F}(1,6499)=6.47$ Prob $>\mathrm{F}=0.0110$ \\
\hline
\end{tabular}

\section{Overidentification tests}

Overidentification tests of validity are inappropriate because it is clearly not feasible to hypothesise that my instrumentation strategy has identified a causal effect of present health status on past-year utilisation. As with all instrumentation strategies, the robustness of the strategy appeals primarily to theoretical reasoning. I argue that my instrumentation strategy has usefully purged the health status estimates of self-reporting biases, but that the estimates remain associative due to the simultaneity of my cross-sectional variables. 


\section{Appendix B: Validity of self-reported fees}

Table B.1 compares scheduled fees reported by practices to the Ministry of Health against the average fees self-reported in the NZHS by age and year, for the years 2011-2015. Fees are unadjusted for inflation, and the age-groups 65-79 and 80+ are collapsed in the NZHS data to allow direct comparability. On observation, the fees self-reported in the NZHS appear to closely match the fees scheduled by practices, both in absolute terms and in the structure of fees across age-groups. This lends confidence to the validity of statistical findings using this measure.

There are differences between the two datasets, with fees self-reported in the NZHS tending to be higher than those in scheduled fees for those aged 25 and over. Differences might reflect measurement error associated with recalling fees paid up to 12 months ago or confusion about the question. Another explanation might be that because fees are only observed in the NZHS when individuals access GP services, there may be self-selection, especially if utilisation is related to variables associated with low socioeconomic status as this study has shown. For example, if people living in areas with low-cost VLCA are less likely to visit a doctor due to real or perceived cost, transport, or cultural barriers, then the estimated average fees in this dataset will be higher than the schedule fee average. A third reason the datasets may differ is if there are differences between the charges GPs advertise and their de facto price. Relatedly, schedule fees represent the fees offered before discounting or other adjustments to cost. Given that the observed data are higher than the schedule fees, this suggests any discounting is at the very least not prominent enough to counteract sources of upward bias, such as self-selection or measurement error. 
Table B.1: Comparison of scheduled fees with self-reported fees, 2011-2015

\begin{tabular}{llllllllll}
\hline & \multicolumn{3}{c}{ MOH scheduled fees data } & \multicolumn{3}{c}{ NZHS self-reported fees data } \\
& $18-24$ & $25-44$ & $45-64$ & $65+$ & $18-24$ & $25-44$ & $45-64$ & $65+$ \\
\hline 2011 & $\$ 29.07$ & $\$ 30.41$ & $\$ 30.43$ & $\$ 29.17$ & $\$ 29.55$ & $\$ 33.74$ & $\$ 33.68$ & $\$ 30.87$ \\
& & & & & {$[ \pm 2.66]$} & {$[ \pm 1.40]$} & {$[ \pm 1.19]$} & {$[ \pm 0.99]$} \\
2012 & $\$ 29.64$ & $\$ 31.01$ & $\$ 31.04$ & $\$ 29.68$ & $\$ 28.55$ & $\$ 34.30$ & $\$ 33.38$ & $\$ 31.26$ \\
& & & & & {$[ \pm 2.86]$} & {$[ \pm 1.26]$} & {$[ \pm 1.00]$} & {$[ \pm 0.97]$} \\
2013 & $\$ 29.92$ & $\$ 31.41$ & $\$ 31.50$ & $\$ 30.04$ & $\$ 27.46$ & $\$ 34.84$ & $\$ 35.40$ & $\$ 32.79$ \\
& & & & & {$[ \pm 2.44]$} & {$[ \pm 1.12]$} & {$[ \pm 1.18]$} & {$[ \pm 1.04]$} \\
2014 & $\$ 30.73$ & $\$ 32.46$ & $\$ 32.45$ & $\$ 30.87$ & $\$ 29.32$ & $\$ 35.39$ & 35.34 & $\$ 33.21$ \\
& & & & & {$[ \pm 2.26]$} & {$[ \pm 1.24]$} & {$[ \pm 1.20]$} & {$[ \pm 0.99]$} \\
$\mathbf{2 0 1 5}$ & $\$ 31.22$ & $\$ 32.88$ & $\$ 32.91$ & $\$ 31.39$ & $\$ 30.36$ & $\$ 37.01$ & $\$ 35.67$ & $\$ 33.77$ \\
& & & & & {$[ \pm 2.27]$} & {$[ \pm 1.39]$} & {$[ \pm 1.01]$} & {$[ \pm 1.21]$} \\
\hline
\end{tabular}

Confidence intervals in brackets.

NZHS data come from waves 2011/12-2015/16 


\section{Appendix C: Specifying depression}

To understand the impact of using the "down-and-depressed" measure of depression rather than a diagnosis of depression, I compared results estimated with either the selfreported or diagnosed depression for waves 2-7. The standard errors for diagnosed depression are roughly a third of the size of self-reported depressive feelings in the models for fees, visit probability, and visit numbers, which has a sizeable effect on the magnitude (but not the sign) of results (see Table C.1). While the effect is not large, after specifying with a more accurate depression diagnosis, the difference between women and men in number of GP visits decreased, the coefficients on chronic conditions were weakened due to 'cannibalisation' from the more accurate depression diagnosis, suggesting the effect can be attributed to more accurate representation of the latent concept of mental health. Hence, the coefficient for depression should be treated with caution, and instead be seen as an improvement in the precision of other estimates compared to the counterfactual exclusion of any variable measuring depression (results of full regression tables omitted for space; available on request).

Table C.1: Comparison between specifying depression through the "down-and-depressed" survey question versus a self-reported doctor's diagnosis

\begin{tabular}{|c|c|c|c|c|}
\hline & FEES & VISPROB & VISNUM & UNMET \\
\hline \multirow[t]{2}{*}{ Down \& depressed } & $3.46^{* * * *}$ & 0.12 & $0.79^{* * *}$ & $0.38^{* * * *}$ \\
\hline & {$[0.90]$} & {$[0.07]$} & {$[0.20]$} & {$[0.05]$} \\
\hline Diagnosed with & $2.01^{* * *}$ & $0.31^{* * * *}$ & $0.96^{* * *}$ & $0.35^{* * * *}$ \\
\hline depression & {$[0.40]$} & {$[0.04]$} & {$[0.08]$} & {$[0.02]$} \\
\hline
\end{tabular}

Standard errors in brackets

${ }^{*} p<0.05,{ }^{* *} p<0.01,{ }^{* * *} p<0.001$

Models include all final-model covariates. Data come from waves 2006/07-2015/16. 
Appendix D: Robustness Checks, Tables

Table D.1: Single-stage models excluding and including health variables, NZHS waves 2002/03-2015/16

\begin{tabular}{|c|c|c|c|c|c|c|c|c|}
\hline & \multicolumn{2}{|c|}{ FEES } & \multicolumn{2}{|c|}{ VISPROB } & \multicolumn{2}{|c|}{ VISNUM } & \multicolumn{2}{|c|}{ UNMET } \\
\hline & (1) & (2) & (3) & (4) & (5) & (6) & (7) & (8) \\
\hline \multirow[t]{2}{*}{ Female } & $2.62^{* * *}$ & 0.43 & $0.22^{* * *}$ & $0.25^{* * *}$ & $0.36^{* * *}$ & $0.47^{* * *}$ & $0.25^{* * *}$ & $0.28^{* * * *}$ \\
\hline & {$[0.28]$} & {$[0.26]$} & {$[0.02]$} & {$[0.02]$} & {$[0.03]$} & {$[0.03]$} & {$[0.02]$} & {$[0.02]$} \\
\hline \multicolumn{9}{|l|}{ Age (base: 25-44) } \\
\hline \multirow[t]{2}{*}{$18-24$} & $-5.14^{* * *}$ & $-4.20^{* * *}$ & 0.04 & $0.07^{7^{*}}$ & -0.04 & 0.09 & $-0.18^{* * *}$ & $-0.15^{* * * *}$ \\
\hline & {$[0.61]$} & {$[0.60]$} & {$[0.03]$} & {$[0.03]$} & {$[0.06]$} & {$[0.06]$} & {$[0.03]$} & {$[0.03]$} \\
\hline \multirow[t]{2}{*}{$45-64$} & 0.50 & $-1.38^{* * *}$ & $0.18^{* * *}$ & $0.15^{* * * *}$ & $0.31^{* * * *}$ & $0.18^{* * *}$ & $-0.38^{* * *}$ & $-0.42^{* * *}$ \\
\hline & {$[0.33]$} & {$[0.31]$} & {$[0.02]$} & {$[0.02]$} & {$[0.04]$} & {$[0.04]$} & {$[0.02]$} & {$[0.02]$} \\
\hline \multirow[t]{2}{*}{$65-79$} & $3.18^{* * *}$ & $-1.56^{* * *}$ & $0.62^{* * *}$ & $0.60^{* * *}$ & $0.64^{* * *}$ & $0.53^{* * *}$ & $-1.02^{* * *}$ & $-1.03^{* * * *}$ \\
\hline & {$[0.40]$} & {$[0.39]$} & {$[0.03]$} & {$[0.03]$} & {$[0.06]$} & {$[0.06]$} & {$[0.03]$} & {$[0.04]$} \\
\hline \multirow[t]{2}{*}{$80+$} & $3.51^{* * *}$ & -0.89 & $0.98^{* * *}$ & $0.93^{* * *}$ & $1.28^{* * *}$ & $1.01^{* * *}$ & $-1.49^{* * * *}$ & $-1.53^{* * * *}$ \\
\hline & {$[0.57]$} & {$[0.55]$} & {$[0.05]$} & {$[0.05]$} & {$[0.10]$} & {$[0.09]$} & {$[0.06]$} & {$[0.06]$} \\
\hline Ethnicity (base: NZ Europear & & & & & & & & \\
\hline Māori & $-7.84^{* * *}$ & $-6.79^{* * *}$ & $-0.14^{* * *}$ & $-0.18^{* * *}$ & $0.30^{* * *}$ & $0.13^{*}$ & $0.15^{* * *}$ & $0.12^{* * *}$ \\
\hline & {$[0.36]$} & {$[0.33]$} & {$[0.02]$} & {$[0.02]$} & {$[0.06]$} & {$[0.06]$} & {$[0.02]$} & {$[0.02]$} \\
\hline Pacific & $-10.45^{* * *}$ & $-10.99^{* * * *}$ & -0.02 & -0.05 & $0.32^{* * *}$ & $0.20^{*}$ & $0.10^{*}$ & $0.08^{*}$ \\
\hline & {$[0.59]$} & {$[0.55]$} & {$[0.03]$} & [0.04] & {$[0.08]$} & {$[0.08]$} & {$[0.04]$} & {$[0.04]$} \\
\hline Asian & $-5.33^{* * *}$ & $-4.40^{* * *}$ & $-0.10^{* * *}$ & $-0.12^{* * * *}$ & $-0.19^{* * *}$ & $-0.28^{* * *}$ & $-0.24^{* * *}$ & $-0.26^{* * *}$ \\
\hline & {$[0.66]$} & {$[0.65]$} & {$[0.03]$} & {$[0.03]$} & {$[0.06]$} & {$[0.06]$} & {$[0.04]$} & {$[0.04]$} \\
\hline Qualifications (base: none) & & & & & & & & \\
\hline Secondary & $1.27^{7^{*}}$ & 0.64 & 0.03 & 0.03 & -0.09 & -0.08 & 0.05 & 0.04 \\
\hline & {$[0.39]$} & {$[0.35]$} & {$[0.02]$} & {$[0.02]$} & {$[0.05]$} & {$[0.05]$} & {$[0.03]$} & {$[0.03]$} \\
\hline Vocational & $1.88^{* * *}$ & $1.47^{* * *}$ & 0.03 & $0.05^{*}$ & $-0.14^{* *}$ & -0.07 & -0.01 & 0.01 \\
\hline & {$[0.32]$} & {$[0.28]$} & {$[0.02]$} & {$[0.02]$} & {$[0.04]$} & {$[0.04]$} & {$[0.02]$} & [0.02] \\
\hline Undergraduate & $4.08^{* * *}$ & $3.33^{* * *}$ & $0.08^{* *}$ & $0.11^{* * *}$ & $-0.16^{* *}$ & -0.04 & -0.05 & -0.01 \\
\hline & {$[0.52]$} & {$[0.50]$} & {$[0.03]$} & {$[0.03]$} & {$[0.05]$} & {$[0.05]$} & {$[0.03]$} & {$[0.03]$} \\
\hline Postgraduate & $3.17^{* * *}$ & $2.46^{* * *}$ & $0.07^{*}$ & $0.10^{* *}$ & $-0.22^{* * *}$ & -0.07 & -0.05 & -0.01 \\
\hline & [0.59] & [0.54] & {$[0.03]$} & {$[0.03]$} & {$[0.06]$} & {$[0.06]$} & {$[0.04]$} & {$[0.04]$} \\
\hline Household income (base: los & & & & & & & & \\
\hline$\$ 20,000)$ & & & & & & & & \\
\hline$\$ 20,001$ to $\$ 30,000$ & $1.34^{*}$ & 0.63 & 0.05 & $0.08^{*}$ & -0.14 & -0.02 & -0.06 & -0.03 \\
\hline & {$[0.53]$} & {$[0.47]$} & {$[0.04]$} & {$[0.04]$} & {$[0.10]$} & {$[0.09]$} & {$[0.04]$} & {$[0.04]$} \\
\hline$\$ 30,001$ to $\$ 50,000$ & $2.02^{* * * *}$ & $1.19^{* *}$ & 0.06 & $0.11^{* *}$ & $-0.41^{* * *}$ & $-0.19^{*}$ & $-0.26^{* * *}$ & $-0.21^{* * *}$ \\
\hline & [0.51] & {$[0.46]$} & {$[0.03]$} & {$[0.03]$} & {$[0.08]$} & {$[0.08]$} & {$[0.04]$} & {$[0.04]$} \\
\hline$\$ 50,001$ to $\$ 70,000$ & $2.37^{* * *}$ & $1.88^{* * *}$ & 0.05 & $0.10^{* *}$ & $-0.66^{* * *}$ & $-0.38^{* * *}$ & $-0.39^{* * *}$ & $-0.33^{* * *}$ \\
\hline & {$[0.55]$} & {$[0.51]$} & {$[0.03]$} & {$[0.04]$} & {$[0.08]$} & {$[0.08]$} & {$[0.04]$} & {$[0.04]$} \\
\hline$\$ 70,001$ to $\$ 100,000$ & $3.93^{* * *}$ & $2.98^{* * *}$ & $0.09^{*}$ & $0.15^{* * * *}$ & $-0.64^{* * * *}$ & $-0.33^{* * *}$ & $-0.55^{* * *}$ & $-0.48^{* * *}$ \\
\hline & {$[0.57]$} & {$[0.52]$} & {$[0.04]$} & {$[0.04]$} & {$[0.08]$} & {$[0.08]$} & {$[0.04]$} & {$[0.04]$} \\
\hline$\$ 100,001$ and above & $5.48^{* * *}$ & $4.50^{* * *}$ & $0.12^{* * *}$ & $0.18^{* * *}$ & $-0.63^{* * *}$ & $-0.30^{* * *}$ & $-0.78^{* * * *}$ & $-0.72^{* * * *}$ \\
\hline & [0.59] & [0.55] & {$[0.04]$} & [0.04] & {$[0.08]$} & {$[0.08]$} & {$[0.04]$} & {$[0.04]$} \\
\hline Don't know/refused & 0.08 & 0.90 & 0.00 & 0.04 & $-0.39^{* * *}$ & $-0.24^{* *}$ & $-0.33^{* * *}$ & $-0.31^{* * *}$ \\
\hline & [0.51] & {$[0.47]$} & {$[0.03]$} & {$[0.03]$} & {$[0.08]$} & {$[0.08]$} & {$[0.03]$} & {$[0.03]$} \\
\hline Has usual practice & $8.05^{* * *}$ & $-11.54^{* * *}$ & $1.21^{* * *}$ & $1.20^{* * *}$ & $1.56^{* * *}$ & $1.44^{* * *}$ & 0.05 & 0.02 \\
\hline & [1.57] & {$[1.60]$} & {$[0.03]$} & {$[0.03]$} & {$[0.05]$} & {$[0.05]$} & {$[0.04]$} & {$[0.04]$} \\
\hline NZDep Quintile (base: NZDe & & & & & & & & \\
\hline NZDep 2 & $-1.64^{* * *}$ & $-1.73^{* * *}$ & $0.06^{*}$ & 0.05 & $0.19^{* * *}$ & $0.12^{*}$ & $0.08^{*}$ & 0.07 \\
\hline & [0.55] & {$[0.51]$} & {$[0.03]$} & [0.03] & {$[0.05]$} & {$[0.05]$} & {$[0.04]$} & {$[0.04]$} \\
\hline NZDep 3 & $-3.88^{* * *}$ & $-3.83^{* * *}$ & 0.01 & -0.00 & $0.19^{* * *}$ & 0.09 & $0.12^{* *}$ & $0.10^{* *}$ \\
\hline & {$[0.52]$} & {$[0.47]$} & {$[0.03]$} & {$[0.03]$} & {$[0.05]$} & {$[0.05]$} & {$[0.04]$} & [0.04] \\
\hline NZDep 4 & $-5.56^{* * *}$ & $-5.85^{* * *}$ & $0.08^{* *}$ & 0.05 & $0.39^{* * *}$ & $0.23^{* * *}$ & $0.17^{* * *}$ & $0.13^{* * *}$ \\
\hline & {$[0.52]$} & {$[0.49]$} & {$[0.03]$} & {$[0.03]$} & {$[0.05]$} & {$[0.05]$} & {$[0.04]$} & {$[0.04]$} \\
\hline NZDep 5 & $-8.74^{* * *}$ & $-9.36^{* * *}$ & $0.09^{* * *}$ & $0.06^{*}$ & $0.61^{* * *}$ & $0.41^{* * *}$ & $0.18^{* * *}$ & $0.13^{* *}$ \\
\hline (most deprived) & {$[0.55]$} & {$[0.52]$} & {$[0.03]$} & {$[0.03]$} & {$[0.06]$} & {$[0.06]$} & {$[0.04]$} & [0.04] \\
\hline Public hospital & $1.90^{* * *}$ & $-2.27^{* * *}$ & $0.40^{* * *}$ & $0.36^{* * *}$ & $1.54^{* * *}$ & $1.28^{* * *}$ & $0.27^{* * *}$ & $0.21^{* * *}$ \\
\hline & {$[0.27]$} & {$[0.24]$} & {$[0.02]$} & {$[0.02]$} & {$[0.05]$} & {$[0.05]$} & {$[0.02]$} & {$[0.02]$} \\
\hline Private hospital & $4.35^{* * *}$ & $0.78^{*}$ & $0.29^{* * *}$ & $0.30^{* * * *}$ & $0.57^{* * *}$ & $0.61^{* * *}$ & -0.05 & -0.04 \\
\hline & [0.44] & {$[0.39]$} & {$[0.05]$} & [0.05] & {$[0.09]$} & [0.09] & [0.04] & {$[0.04]$} \\
\hline Specialist & - & - & $0.58^{* * *}$ & $0.53^{* * *}$ & $1.55^{* * *}$ & $1.30^{* * *}$ & $0.08^{* * *}$ & 0.01 \\
\hline & - & - & {$[0.02]$} & {$[0.02]$} & {$[0.05]$} & {$[0.04]$} & {$[0.02]$} & {$[0.02]$} \\
\hline Self-rated health & - & 0.18 & - & $-0.19^{* * * *}$ & - & $-0.80^{* * *}$ & - & $-0.21^{* * *}$ \\
\hline & - & {$[0.13]$} & - & [0.01] & - & {$[0.02]$} & - & {$[0.01]$} \\
\hline Chronic conditions (base: no & & & & & & & & \\
\hline 1 condition & - & -0.07 & - & $0.18^{* * *}$ & - & $0.39^{* * *}$ & - & $0.05^{*}$ \\
\hline & - & {$[0.27]$} & - & {$[0.02]$} & - & {$[0.04]$} & - & {$[0.02]$} \\
\hline$\geq 2$ conditions & - & $-1.07^{* * *}$ & - & $0.20^{* * *}$ & - & $0.75^{* * *}$ & - & $0.08^{* * *}$ \\
\hline & - & {$[0.31]$} & - & {$[0.02]$} & - & {$[0.05]$} & - & {$[0.03]$} \\
\hline Depressed & - & 0.68 & - & $0.24^{* * *}$ & - & $1.49^{* * *}$ & - & $0.38^{* * *}$ \\
\hline & - & {$[0.68]$} & - & {$[0.05]$} & - & {$[0.18]$} & - & {$[0.04]$} \\
\hline $\bar{N}$ & 86829 & 85163 & 86735 & 85072 & 86042 & 84400 & 62154 & 60756 \\
\hline
\end{tabular}

${ }^{*} p<0.05,{ }^{* *} p<0.01,{ }^{* * *} p<0.001$

Models (1) (3) (5) and (7) are estimated excluding health variables, while the remainder include health variables. All models are conducted using their single-stage forms (ie, without instrumentation). FEES has been corrected for selection bias.

Other controls omitted for space: Hours worked, Born overseas, Smoker, Drinker, Has insurance, Year. 
Table D.2: Removing chronic conditions, NZHS waves 2002/03-2015/16

\begin{tabular}{|c|c|c|c|c|c|c|}
\hline \multirow[b]{3}{*}{ Includes chronic illness } & \multicolumn{2}{|c|}{ FEES } & \multicolumn{2}{|c|}{ VISPROB } & \multicolumn{2}{|c|}{ VISNUM } \\
\hline & (1) & (2) & (3) & (4) & (5) & (6) \\
\hline & No & Yes & No & Yes & No & Yes \\
\hline \multirow[t]{2}{*}{ Female } & 0.05 & 0.02 & $0.27^{* * *}$ & $0.27^{* * *}$ & $0.57^{* * *}$ & $0.56^{* * * *}$ \\
\hline & {$[0.27]$} & {$[0.27]$} & {$[0.02]$} & {$[0.02]$} & {$[0.04]$} & {$[0.04]$} \\
\hline \multicolumn{7}{|l|}{ Age (base: $25-44$ ) } \\
\hline \multirow[t]{2}{*}{$18-24$} & $-4.66^{* * * *}$ & $-4.60^{* * * *}$ & $0.08^{* *}$ & $0.09^{* * *}$ & $0.13^{*}$ & $0.16^{*}$ \\
\hline & {$[0.60]$} & {$[0.61]$} & {$[0.03]$} & {$[0.03]$} & {$[0.06]$} & {$[0.06]$} \\
\hline \multirow[t]{2}{*}{$45-64$} & $-1.21^{* * *}$ & $-1.28^{* * *}$ & $0.16^{* * *}$ & $0.15^{* * *}$ & $0.24^{* * *}$ & $0.18^{* * *}$ \\
\hline & {$[0.31]$} & {$[0.31]$} & {$[0.02]$} & {$[0.02]$} & {$[0.04]$} & {$[0.04]$} \\
\hline \multirow[t]{2}{*}{$65-79$} & $-1.86^{* * *}$ & $-1.93^{* * *}$ & $0.65^{* * *}$ & $0.62^{* * *}$ & $0.77^{* * *}$ & $0.65^{* * *}$ \\
\hline & {$[0.37]$} & {$[0.40]$} & {$[0.03]$} & {$[0.03]$} & {$[0.06]$} & {$[0.06]$} \\
\hline \multirow[t]{2}{*}{$80+$} & -0.98 & -0.98 & $0.96^{* * *}$ & $0.92^{* * *}$ & $1.25^{* * *}$ & $1.07^{* * *}$ \\
\hline & {$[0.54]$} & {$[0.55]$} & {$[0.05]$} & {$[0.05]$} & {$[0.10]$} & {$[0.10]$} \\
\hline \multicolumn{7}{|c|}{ Ethnicity (base: NZ European/ Other) } \\
\hline Māori & $-6.26^{* * * *}$ & $-6.22^{* * *}$ & $-0.21^{* * *}$ & $-0.21^{* * *}$ & 0.02 & 0.01 \\
\hline & {$[0.34]$} & {$[0.35]$} & {$[0.02]$} & {$[0.02]$} & {$[0.06]$} & {$[0.06]$} \\
\hline Pacific & $-10.67^{* * *}$ & $-10.66^{* * *}$ & -0.06 & -0.06 & 0.15 & 0.13 \\
\hline & {$[0.54]$} & {$[0.55]$} & {$[0.04]$} & {$[0.04]$} & {$[0.09]$} & {$[0.09]$} \\
\hline Asian & $-4.09^{* * *}$ & $-4.17^{* * *}$ & $-0.14^{* * *}$ & $-0.14^{* * *}$ & $-0.36^{* * *}$ & $-0.35^{* * *}$ \\
\hline & {$[0.65]$} & {$[0.65]$} & {$[0.03]$} & {$[0.03]$} & {$[0.06]$} & {$[0.06]$} \\
\hline Qualifications (base: none) & & & & & & \\
\hline Secondary & $0.69^{*}$ & 0.62 & 0.03 & 0.03 & -0.07 & -0.06 \\
\hline & [0.35] & {$[0.35]$} & {$[0.02]$} & {$[0.02]$} & {$[0.05]$} & {$[0.05]$} \\
\hline Vocational & $1.26^{* * *}$ & $1.26^{* * *}$ & $0.06^{* *}$ & $0.06^{* *}$ & -0.03 & -0.02 \\
\hline & {$[0.28]$} & {$[0.29]$} & {$[0.02]$} & {$[0.02]$} & {$[0.04]$} & {$[0.04]$} \\
\hline Undergraduate & $3.03^{* * *}$ & $2.95^{* * *}$ & $0.13^{* * *}$ & $0.14^{* * *}$ & 0.05 & 0.05 \\
\hline & {$[0.49]$} & {$[0.50]$} & {$[0.03]$} & {$[0.03]$} & {$[0.05]$} & {$[0.05]$} \\
\hline Postgraduate & $2.04^{* * *}$ & $2.04^{* * *}$ & $0.11^{* * *}$ & $0.12^{* * *}$ & 0.02 & 0.03 \\
\hline & {$[0.54]$} & {$[0.54]$} & {$[0.03]$} & {$[0.03]$} & {$[0.06]$} & {$[0.06]$} \\
\hline Household income (base: loss or & & & & & & \\
\hline$\$ 20,001$ to $\$ 30,000$ & 0.34 & 0.30 & $0.09^{*}$ & $0.10^{* * *}$ & 0.06 & 0.07 \\
\hline & {$[0.47]$} & {$[0.48]$} & {$[0.04]$} & {$[0.04]$} & {$[0.10]$} & {$[0.10]$} \\
\hline$\$ 30,001$ to $\$ 50,000$ & 0.52 & 0.56 & $0.13^{* * *}$ & $0.14^{* * *}$ & -0.07 & -0.06 \\
\hline & {$[0.48]$} & {$[0.48]$} & {$[0.03]$} & {$[0.04]$} & {$[0.09]$} & {$[0.09]$} \\
\hline$\$ 50,001$ to $\$ 70,000$ & 1.03 & 1.03 & $0.14^{* * *}$ & $0.14^{* * *}$ & $-0.22^{*}$ & $-0.20^{*}$ \\
\hline & {$[0.53]$} & {$[0.55]$} & {$[0.04]$} & {$[0.04]$} & {$[0.09]$} & {$[0.09]$} \\
\hline$\$ 70,001$ to $\$ 100,000$ & $2.02^{* * *}$ & $2.09^{* * *}$ & $0.19^{* * *}$ & $0.19^{* * *}$ & -0.15 & -0.14 \\
\hline & {$[0.56]$} & {$[0.57]$} & {$[0.04]$} & {$[0.04]$} & {$[0.09]$} & {$[0.09]$} \\
\hline$\$ 100,001$ and above & $3.40^{* * *}$ & $3.44^{* * *}$ & $0.24^{* * *}$ & $0.24^{* * *}$ & -0.07 & -0.07 \\
\hline & {$[0.58]$} & [0.59] & {$[0.04]$} & {$[0.04]$} & [0.09] & [0.09] \\
\hline Don't know/ refused & 0.49 & 0.53 & 0.05 & 0.05 & $-0.17^{*}$ & -0.15 \\
\hline & {$[0.47]$} & {$[0.47]$} & {$[0.03]$} & {$[0.03]$} & {$[0.08]$} & {$[0.08]$} \\
\hline Has usual practice & $-11.09^{* * * *}$ & $-10.96^{* * *}$ & $1.16^{* * *}$ & $1.16^{* * *}$ & $1.35^{* * *}$ & $1.35^{* * *}$ \\
\hline & {$[1.63]$} & {$[1.60]$} & {$[0.03]$} & {$[0.03]$} & {$[0.05]$} & {$[0.05]$} \\
\hline NZDep Quintile (base: NZDep & & & & & & \\
\hline NZDep 2 & $-1.55^{* *}$ & $-1.53^{* *}$ & 0.04 & 0.04 & 0.07 & 0.06 \\
\hline & {$[0.51]$} & {$[0.51]$} & {$[0.03]$} & {$[0.03]$} & {$[0.05]$} & {$[0.05]$} \\
\hline NZDep 3 & $-3.53^{* * *}$ & $-3.45^{* * *}$ & -0.03 & -0.02 & -0.01 & 0.01 \\
\hline & {$[0.48]$} & {$[0.48]$} & {$[0.03]$} & {$[0.03]$} & {$[0.05]$} & {$[0.05]$} \\
\hline NZDep 4 & $-5.37^{* * * *}$ & $-5.29^{* * *}$ & 0.01 & 0.02 & $0.11^{*}$ & 0.11 \\
\hline & {$[0.50]$} & {$[0.50]$} & {$[0.03]$} & {$[0.03]$} & {$[0.06]$} & {$[0.06]$} \\
\hline NZDep 5 (most deprived) & $-8.77^{* * *}$ & $-8.71^{* * *}$ & 0.01 & 0.02 & $0.27^{* * *}$ & $0.26^{* * *}$ \\
\hline & {$[0.54]$} & {$[0.54]$} & {$[0.03]$} & {$[0.03]$} & {$[0.06]$} & {$[0.06]$} \\
\hline Public hospital & $-1.08^{* *}$ & $-1.05^{* *}$ & $0.31^{* * *}$ & $0.31^{* * *}$ & $1.11^{* * *}$ & $1.10^{* * *}$ \\
\hline & [0.34] & {$[0.35]$} & {$[0.02]$} & {$[0.02]$} & {$[0.05]$} & {$[0.05]$} \\
\hline Private hospital & $1.12^{* *}$ & $1.08^{* *}$ & $0.30^{* * *}$ & $0.31^{* * *}$ & $0.63^{* * *}$ & $0.64^{* * *}$ \\
\hline & [0.39] & {$[0.40]$} & {$[0.05]$} & {$[0.05]$} & {$[0.09]$} & {$[0.09]$} \\
\hline Specialist & - & - & $0.48^{* * *}$ & $0.47^{* * *}$ & $1.14^{* * * *}$ & $1.12^{* * *}$ \\
\hline & - & - & {$[0.03]$} & {$[0.03]$} & {$[0.05]$} & {$[0.05]$} \\
\hline Self-rated health & $3.51^{* * *}$ & $3.90^{* * *}$ & $-0.41^{* * *}$ & $-0.39^{* * *}$ & $-1.67^{* * *}$ & $-1.55^{* * *}$ \\
\hline & {$[0.67]$} & {$[0.80]$} & {$[0.04]$} & {$[0.04]$} & {$[0.10]$} & {$[0.11]$} \\
\hline Chronic conditions (base: no cor & & & & & & \\
\hline 1 condition & - & 0.53 & - & $0.14^{* * *}$ & - & $0.28^{* * *}$ \\
\hline & - & {$[0.30]$} & - & {$[0.02]$} & - & {$[0.04]$} \\
\hline$\geq 2$ conditions & - & 0.09 & - & $0.14^{* * *}$ & - & $0.53^{* * *}$ \\
\hline & - & {$[0.40]$} & - & {$[0.03]$} & - & {$[0.06]$} \\
\hline Depressed & - & $3.46^{* * *}$ & - & 0.08 & - & $0.95^{* * *}$ \\
\hline & - & {$[0.91]$} & - & {$[0.06]$} & - & {$[0.20]$} \\
\hline$N$ & 86849 & 85214 & 85724 & 84273 & 85063 & 83627 \\
\hline
\end{tabular}

${ }^{*} p<0.05,{ }^{* * *} p<0.01,{ }^{* * *} p<0.001$

Models (1) (3) and (5) are estimated excluding chronic conditions, while the remainder include chronic conditions. All models have been instrumented. FEES has been corrected for selection bias.

Other controls omitted for space: Hours worked, Born overseas, Smoker, Drinker, Has insurance, Year. 
Table D.3A: Including nurse visits without a doctor as a control variable, NZHS waves 2011/12-2015/16

\begin{tabular}{|c|c|c|c|c|c|c|c|c|}
\hline & \multicolumn{2}{|c|}{ FEES } & \multicolumn{2}{|c|}{ VISPROB } & \multicolumn{2}{|c|}{ VISNUM } & \multicolumn{2}{|c|}{ UNMET } \\
\hline & (1) & (2) & (3) & (4) & (5) & (6) & (7) & (8) \\
\hline Nurse visit & - & $-1.083^{3+2}$ & - & $0.478^{* * 2}$ & - & $0.880^{* * *}$ & - & $0.056^{* *}$ \\
\hline & - & {$[0.290]$} & - & {$[0.023]$} & - & {$[0.045]$} & - & {$[0.020]$} \\
\hline Female & 0.092 & 0.210 & $0.279^{* * * *}$ & $0.235^{* * *}$ & $0.559^{* * * *}$ & $0.471^{* * *}$ & $0.281^{* * *}$ & $0.275^{* * *}$ \\
\hline & {$[0.298]$} & {$[0.300]$} & {$[0.019]$} & {$[0.019]$} & {$[0.042]$} & {$[0.042]$} & {$[0.019]$} & {$[0.020]$} \\
\hline Age (base: 25-44) & & & & & & & & \\
\hline $18-24$ & $-4.085^{* * *}$ & $-4.071^{* * * *}$ & $0.067^{*}$ & $0.067^{*}$ & 0.138 & 0.133 & $-0.147^{* * *}$ & $-0.145^{*+1}$ \\
\hline & {$[0.671]$} & {$[0.671]$} & {$[0.031]$} & {$[0.031]$} & {$[0.071]$} & {$[0.070]$} & {$[0.031]$} & [0.031] \\
\hline $45-64$ & -0.682 & -0.566 & $0.160^{* * *}$ & $0.139^{* * *}$ & $0.147^{* * *}$ & $0.095^{*}$ & $-0.419^{* * * *}$ & $-0.424^{* *+}$ \\
\hline & {$[0.352]$} & {$[0.352]$} & {$[0.020]$} & {$[0.020]$} & {$[0.044]$} & {$[0.044]$} & {$[0.022]$} & {$[0.022]$} \\
\hline $65-79$ & $-1.243^{* *}$ & $-0.958^{*}$ & $0.626^{* * *}$ & $0.538^{* * *}$ & $0.668^{* * *}$ & $0.494^{* * *}$ & $-1.029^{* * *}$ & $-1.042^{*+1}$ \\
\hline & {$[0.453]$} & {$[0.454]$} & {$[0.033]$} & {$[0.034]$} & {$[0.069]$} & {$[0.070]$} & {$[0.035]$} & {$[0.036]$} \\
\hline $80+$ & -0.276 & -0.077 & $0.962^{* * *}$ & $0.912^{* * *}$ & $1.018^{* * *}$ & $0.894^{* * *}$ & $-1.530^{* * * *}$ & $-1.537^{*+*}$ \\
\hline & {$[0.652]$} & {$[0.650]$} & {$[0.057]$} & {$[0.059]$} & {$[0.100]$} & {$[0.101]$} & {$[0.060]$} & {$[0.060]$} \\
\hline Ethnicity (base: NZ European & & & & & & & & \\
\hline Māori & $-6.134^{* * * *}$ & $-6.217^{* * * *}$ & $-0.207^{* * * *}$ & $-0.202^{* * *}$ & 0.017 & 0.036 & $0.116^{* * * *}$ & $0.115^{* * *}$ \\
\hline & {$[0.386]$} & {$[0.387]$} & {$[0.024]$} & {$[0.025]$} & {$[0.070]$} & {$[0.069]$} & {$[0.023]$} & {$[0.023]$} \\
\hline Pacific & $-10.322^{* * *}$ & $-10.428^{* * *}$ & -0.067 & -0.037 & 0.073 & 0.142 & $0.081^{*}$ & $0.085^{*}$ \\
\hline & {$[0.632]$} & {$[0.633]$} & {$[0.042]$} & {$[0.043]$} & {$[0.105]$} & {$[0.104]$} & {$[0.041]$} & [0.041] \\
\hline Asian & $-5.204^{* * *}$ & $-5.326^{* * *}$ & $-0.122^{* * *}$ & $-0.079^{*}$ & $-0.367^{* * *}$ & $-0.273^{* * *}$ & $-0.259^{* * *}$ & $-0.255^{*+1}$ \\
\hline & {$[0.695]$} & {$[0.698]$} & {$[0.034]$} & {$[0.034]$} & {$[0.067]$} & {$[0.066]$} & {$[0.041]$} & {$[0.042]$} \\
\hline Qualifications (base: none) & & & & & & & & \\
\hline Secondary & 0.728 & 0.742 & 0.012 & 0.006 & -0.062 & -0.075 & 0.037 & 0.038 \\
\hline & {$[0.440]$} & {$[0.441]$} & {$[0.028]$} & {$[0.028]$} & [0.065] & {$[0.064]$} & {$[0.027]$} & [0.027] \\
\hline Vocational & $1.043^{* *}$ & $1.080^{* * * *}$ & $0.052^{*}$ & 0.038 & 0.012 & -0.023 & 0.013 & 0.013 \\
\hline & {$[0.322]$} & {$[0.323]$} & {$[0.023]$} & {$[0.023]$} & {$[0.048]$} & {$[0.047]$} & {$[0.024]$} & [0.023] \\
\hline Undergraduate & $3.185^{* * *}$ & $3.215^{* * * *}$ & $0.134^{* * *}$ & $0.119^{* * * *}$ & 0.084 & 0.044 & -0.014 & -0.014 \\
\hline & {$[0.530]$} & {$[0.526]$} & {$[0.029]$} & {$[0.029]$} & [0.059] & {$[0.058]$} & {$[0.032]$} & [0.032] \\
\hline Postgraduate & $2.199^{* * *}$ & $2.259^{* * *}$ & $0.094^{*}$ & $0.079^{*}$ & 0.032 & -0.012 & -0.014 & -0.013 \\
\hline & {$[0.581]$} & {$[0.581]$} & {$[0.037]$} & {$[0.038]$} & {$[0.067]$} & {$[0.066]$} & {$[0.042]$} & [0.041] \\
\hline Household income (base: loss & & & & & & & & \\
\hline$\$ 20,000)$ & & & & & & & & \\
\hline$\$ 20,001$ to $\$ 30,000$ & 0.766 & 0.773 & $0.092^{*}$ & 0.088 & 0.084 & 0.047 & -0.034 & -0.039 \\
\hline & [0.494] & {$[0.492]$} & {$[0.046]$} & {$[0.047]$} & {$[0.117]$} & {$[0.116]$} & {$[0.040]$} & {$[0.040]$} \\
\hline$\$ 30,001$ to $\$ 50,000$ & 0.544 & 0.565 & $0.145^{* * *}$ & $0.139^{* * *}$ & -0.003 & -0.041 & $-0.208^{* * * *}$ & $-0.213^{* *+}$ \\
\hline & {$[0.513]$} & {$[0.512]$} & {$[0.041]$} & {$[0.042]$} & {$[0.103]$} & {$[0.102]$} & {$[0.037]$} & [0.037] \\
\hline$\$ 50,001$ to $\$ 70,000$ & 1.007 & 1.009 & $0.148^{* * * *}$ & $0.143^{* * * *}$ & -0.185 & $-0.214^{*}$ & $-0.330^{* * * *}$ & $-0.333^{* * *}$ \\
\hline & {$[0.565]$} & {$[0.562]$} & {$[0.043]$} & {$[0.043]$} & {$[0.103]$} & {$[0.102]$} & {$[0.039]$} & {$[0.039]$} \\
\hline$\$ 70,001$ to $\$ 100,000$ & $1.357^{*}$ & $1.377^{*}$ & $0.190^{* * * *}$ & $0.183^{* * *}$ & -0.104 & -0.140 & $-0.481^{* * * *}$ & $-0.486^{* *+}$ \\
\hline & {$[0.588]$} & {$[0.587]$} & [0.044] & {$[0.045]$} & {$[0.102]$} & {$[0.101]$} & {$[0.040]$} & {$[0.040]$} \\
\hline$\$ 100,001$ and above & $2.215^{* * * *}$ & $2.197^{* * * *}$ & $0.227^{* * * *}$ & $0.229^{* * *}$ & -0.090 & -0.103 & $-0.717^{* * *}$ & $-0.723^{*+1}$ \\
\hline & {$[0.602]$} & {$[0.600]$} & {$[0.044]$} & {$[0.044]$} & {$[0.102]$} & {$[0.102]$} & {$[0.043]$} & [0.043] \\
\hline Don't know/refused & 0.163 & 0.109 & 0.062 & 0.069 & -0.157 & -0.154 & $-0.307^{* * * *}$ & $-0.310^{*+4}$ \\
\hline & {$[0.490]$} & {$[0.487]$} & {$[0.038]$} & {$[0.038]$} & [0.095] & [0.095] & {$[0.035]$} & {$[0.035]$} \\
\hline Has usual practice & $-12.815^{* * *}$ & $-12.547^{* * *}$ & $1.198^{* * * *}$ & $1.155^{* * * *}$ & $1.313^{* * * *}$ & $1.200^{* * *}$ & 0.021 & 0.014 \\
\hline & {$[2.028]$} & {$[2.034]$} & {$[0.038]$} & {$[0.037]$} & {$[0.064]$} & {$[0.063]$} & {$[0.041]$} & [0.041] \\
\hline NZDep Quintile (base: NZDep & & & & & & & & \\
\hline NZDep 2 & $-1.639^{* *}$ & $-1.687^{* *}$ & 0.035 & 0.035 & 0.005 & 0.008 & 0.068 & 0.072 \\
\hline & {$[0.598]$} & {$[0.596]$} & {$[0.031]$} & {$[0.031]$} & {$[0.061]$} & {$[0.061]$} & {$[0.039]$} & {$[0.038]$} \\
\hline NZDep 3 & $-3.269^{* * * *}$ & $-3.274^{* * *}$ & -0.041 & -0.044 & -0.066 & -0.066 & $0.101^{* *}$ & $0.106^{* *}$ \\
\hline & {$[0.562]$} & {$[0.563]$} & {$[0.031]$} & {$[0.031]$} & {$[0.061]$} & {$[0.061]$} & {$[0.038]$} & {$[0.037]$} \\
\hline NZDep 4 & $-5.563^{* * *}$ & $-5.562^{* * *}$ & 0.010 & 0.003 & 0.060 & 0.052 & $0.127^{* * *}$ & $0.128^{* * *}$ \\
\hline & {$[0.584]$} & {$[0.585]$} & {$[0.031]$} & {$[0.032]$} & {$[0.066]$} & {$[0.065]$} & {$[0.037]$} & {$[0.037]$} \\
\hline NZDep 5 & $-8.689^{* * * *}$ & $-8.726^{* * *}$ & -0.002 & -0.003 & $0.230^{* *}$ & $0.236^{* *}$ & $0.125^{* *}$ & $0.128^{* * * *}$ \\
\hline & {$[0.605]$} & {$[0.608]$} & {$[0.032]$} & {$[0.033]$} & {$[0.072]$} & {$[0.072]$} & {$[0.038]$} & {$[0.038]$} \\
\hline Public hospital & -0.406 & -0.344 & $0.310^{* * *}$ & $0.289^{* * *}$ & $1.080^{* * *}$ & $1.040^{* * *}$ & $0.208^{* * *}$ & $0.204^{* * *}$ \\
\hline & {$[0.343]$} & {$[0.337]$} & {$[0.028]$} & {$[0.028]$} & {$[0.059]$} & {$[0.058]$} & {$[0.022]$} & {$[0.022]$} \\
\hline Private hospital & $1.209^{* * *}$ & $1.317^{* *}$ & $0.284^{* * *}$ & $0.272^{* * * *}$ & $0.678^{* * * *}$ & $0.642^{* * * *}$ & -0.044 & -0.046 \\
\hline & {$[0.446]$} & {$[0.446]$} & {$[0.053]$} & {$[0.053]$} & {$[0.111]$} & {$[0.111]$} & {$[0.042]$} & [0.042] \\
\hline Specialist & - & - & $0.459^{* * * *}$ & $0.440^{* * * *}$ & $1.049^{* * * *}$ & $0.998^{* * *}$ & 0.015 & 0.013 \\
\hline & - & - & {$[0.029]$} & {$[0.030]$} & {$[0.058]$} & {$[0.057]$} & {$[0.023]$} & {$[0.023]$} \\
\hline Self-rated health & $4.368^{* * *}$ & $4.180^{* * * *}$ & $-0.370^{* * *}$ & $-0.351^{* * *}$ & $-1.605^{* * *}$ & $-1.537^{* * *}$ & $-0.209^{* * *}$ & $-0.208^{* *+}$ \\
\hline & {$[0.631]$} & {$[0.631]$} & {$[0.048]$} & [0.049] & {$[0.121]$} & {$[0.121]$} & {$[0.010]$} & {$[0.010]$} \\
\hline Chronic conditions (base: no c & & & & & & & & \\
\hline 1 condition & $0.760^{*}$ & $0.761^{*}$ & $0.151^{* * *}$ & $0.141^{* * *}$ & $0.264^{* * *}$ & $0.242^{* * *}$ & $0.046^{*}$ & $0.047^{*}$ \\
\hline & {$[0.324]$} & {$[0.324]$} & {$[0.023]$} & {$[0.024]$} & {$[0.048]$} & {$[0.047]$} & {$[0.022]$} & {$[0.022]$} \\
\hline$\geq 2$ conditions & 0.307 & 0.301 & $0.111^{* * * *}$ & $0.099^{* * * *}$ & $0.402^{* * * *}$ & $0.371^{* * * *}$ & $0.084^{* * *}$ & $0.083^{* *}$ \\
\hline & {$[0.404]$} & {$[0.397]$} & {$[0.030]$} & {$[0.030]$} & {$[0.063]$} & {$[0.063]$} & {$[0.025]$} & {$[0.025]$} \\
\hline Depressed & $3.455^{* * *}$ & $3.357^{* * * *}$ & 0.123 & 0.134 & $0.791^{* * * *}$ & $0.835^{* * * *}$ & $0.376^{* * *}$ & $0.376^{* * * *}$ \\
\hline & {$[0.904]$} & {$[0.906]$} & {$[0.070]$} & {$[0.069]$} & {$[0.201]$} & {$[0.199]$} & {$[0.045]$} & {$[0.045]$} \\
\hline Year (base: 2011/12) & & & & & & & & \\
\hline $2012 / 13$ & -0.882 & -0.885 & 0.015 & 0.019 & $0.150^{*}$ & $0.150^{*}$ & 0.028 & 0.030 \\
\hline & {$[0.546]$} & {$[0.547]$} & {$[0.029]$} & {$[0.029]$} & {$[0.064]$} & {$[0.064]$} & {$[0.032]$} & [0.033] \\
\hline $2013 / 14$ & -0.291 & -0.318 & -0.002 & 0.001 & 0.058 & 0.055 & 0.052 & 0.054 \\
\hline & {$[0.540]$} & {$[0.539]$} & {$[0.029]$} & {$[0.029]$} & {$[0.058]$} & {$[0.058]$} & {$[0.033]$} & [0.033] \\
\hline $2014 / 15$ & 0.541 & 0.506 & -0.006 & 0.006 & -0.045 & -0.026 & 0.025 & 0.023 \\
\hline & {$[0.552]$} & {$[0.554]$} & {$[0.029]$} & {$[0.029]$} & {$[0.062]$} & {$[0.061]$} & {$[0.033]$} & [0.032] \\
\hline $2015 / 16$ & $1.298^{*}$ & $1.297^{*}$ & $-0.075^{* *}$ & $-0.075^{* *}$ & $-0.301^{* * * *}$ & $-0.300^{* * * *}$ & 0.033 & 0.034 \\
\hline & {$[0.539]$} & {$[0.540]$} & {$[0.028]$} & {$[0.029]$} & {$[0.059]$} & {$[0.059]$} & {$[0.031]$} & {$[0.032]$} \\
\hline $\bar{N}$ & 60878 & 60715 & 60687 & 60551 & 60504 & 60369 & 60756 & 60615 \\
\hline
\end{tabular}


Table D.3B: Determinants of nurse \& GP

utilization

\begin{tabular}{lcc}
\hline & NURSE & GP \\
\hline Female & $0.306^{* * *}$ & $0.279^{* * *}$ \\
& {$[0.016]$} & {$[0.019]$}
\end{tabular}

Age (base: 25-44)

$\begin{array}{lcc}18-24 & 0.011 & 0.067^{*} \\ 45-64 & {[0.030]} & {[0.031]} \\ & 0.194^{* * *} & 0.160^{* * *} \\ 65-79 & {[0.018]} & {[0.020]} \\ & 0.554^{* * *} & 0.626^{* * *} \\ 80+ & {[0.026]} & {[0.033]} \\ & 0.390^{* * *} & 0.962^{* * *} \\ & {[0.035]} & {[0.057]}\end{array}$

Ethnicity (base: NZ

European/ Other)

$\begin{array}{lcc}\text { Māori } & -0.052^{*} & -0.207^{* * *} \\ & {[0.021]} & {[0.024]} \\ \text { Pacific } & -0.246^{* * * *} & -0.067 \\ & {[0.038]} & {[0.042]} \\ \text { Asian } & -0.416^{* * *} & -0.122^{* * *} \\ & {[0.033]} & {[0.034]}\end{array}$

Qualifications (base: none)

Secondary

Vocational

Undergraduate

Postgraduate

Household income (base:

loss or up to $\$ 20,000$ )

$\begin{array}{lll}\$ 20,001 \text { to } \$ 30,000 & 0.119^{* * *} & 0.092^{*} \\ & {[0.034]} & {[0.046]} \\ \$ 30,001 \text { to } \$ 50,000 & 0.141^{* * *} & 0.145^{* * *} \\ & {[0.034]} & {[0.041]} \\ \$ 50,001 \text { to } \$ 70,000 & 0.112^{* *} & 0.148^{* * *} \\ & {[0.036]} & {[0.043]} \\ \$ 70,001 \text { to } \$ 100,000 & 0.134^{* * *} & 0.190^{* * *} \\ & {[0.037]} & {[0.044]}\end{array}$

Table D.3B: Continued

\begin{tabular}{|c|c|c|}
\hline & NURSE & GP \\
\hline \multirow[t]{2}{*}{$\$ 100,001$ and above } & 0.058 & $0.227^{* * *}$ \\
\hline & {$[0.038]$} & [0.044] \\
\hline \multirow[t]{2}{*}{ Don't know/ refused } & -0.000 & 0.062 \\
\hline & [0.032] & {$[0.038]$} \\
\hline \multirow[t]{2}{*}{ Has usual practice } & $0.646^{* * *}$ & $1.198^{* * *}$ \\
\hline & [0.046] & {$[0.038]$} \\
\hline \multicolumn{3}{|l|}{ NZDep Quintile (base: } \\
\hline \multicolumn{3}{|l|}{ NZDep 1) } \\
\hline \multirow[t]{2}{*}{ NZDep 2} & -0.004 & 0.035 \\
\hline & [0.029] & [0.031] \\
\hline \multirow[t]{2}{*}{ NZDep 3} & 0.012 & -0.041 \\
\hline & [0.029] & {$[0.031]$} \\
\hline \multirow[t]{2}{*}{ NZDep 4} & 0.034 & 0.010 \\
\hline & {$[0.028]$} & [0.031] \\
\hline \multirow[t]{2}{*}{ NZDep 5} & -0.001 & -0.002 \\
\hline & [0.029] & [0.032] \\
\hline \multirow[t]{2}{*}{ Public hospital } & $0.138^{* * *}$ & $0.310^{* * *}$ \\
\hline & [0.021] & {$[0.028]$} \\
\hline \multirow[t]{2}{*}{ Private hospital } & $0.098^{* *}$ & $0.284^{* * *}$ \\
\hline & {$[0.033]$} & {$[0.053]$} \\
\hline \multirow[t]{2}{*}{ Specialist } & $0.174^{* * *}$ & $0.459^{* * *}$ \\
\hline & [0.021] & [0.029] \\
\hline \multirow[t]{2}{*}{ Self-rated health } & $-0.213^{* * * *}$ & $-0.370^{* * * *}$ \\
\hline & {$[0.040]$} & {$[0.048]$} \\
\hline \multicolumn{3}{|c|}{ Chronic conditions (base: } \\
\hline \multicolumn{3}{|l|}{ no conditions) } \\
\hline \multirow[t]{2}{*}{1 condition } & $0.080^{* * * *}$ & $0.151^{* * *}$ \\
\hline & [0.019] & {$[0.023]$} \\
\hline \multirow[t]{2}{*}{$\geq 2$ conditions } & $0.104^{* * *}$ & $0.111^{* * *}$ \\
\hline & {$[0.024]$} & {$[0.030]$} \\
\hline \multirow[t]{2}{*}{ Depressed } & $-0.112^{*}$ & 0.123 \\
\hline & {$[0.052]$} & {$[0.070]$} \\
\hline$N$ & 60623 & 60687 \\
\hline
\end{tabular}

Standard errors in brackets

${ }^{*} p<0.05,{ }^{* *} p<0.01,{ }^{* * *} p<0.001$

Data come from NZHS waves 2011/12-2015/16

Other controls omitted for space: Hours worked, Born overseas, Smoker, Drinker, Has insurance, Year. 
Table D.4A: Kleibergen-Paap F-Tests for weak instruments

\begin{tabular}{llll}
\hline & FEES & VISPROB & VISNUM \\
\hline Obesity & $F(3,9022)=523.46$ & $F(3,9021)=505.61$ & $F(3,9020)=341.33$ \\
Sutton & $F(2,9023)=714.47$ & $F(2,9022)=686.01$ & $F(2,9021)=447.27$ \\
WHO & $F(1,9024)=1598.89$ & $F(1,9023)=1541.69$ & $F(1,9022)=1063.50$ \\
\hline
\end{tabular}

All tests were significant at the $\mathrm{p}>0.0001$ level.

Data come from NZHS waves 2002/03-2015/16 
Table D.4B: Instrument specifications, NZHS waves 2002/03-2015/16

\begin{tabular}{|c|c|c|c|c|c|c|c|c|c|}
\hline & \multicolumn{3}{|c|}{ FEES } & \multicolumn{3}{|c|}{ VISPROB } & \multicolumn{3}{|c|}{ VISNUM } \\
\hline & OBESITY & SUTTON & WHO & OBESITY & SUTTON & WHO & OBESITY & SUTTON & WHO \\
\hline \multirow[t]{2}{*}{ Female } & 0.015 & -0.063 & -0.026 & $0.270^{* * * *}$ & $0.273^{* * * *}$ & $0.271^{* * *}$ & $0.562^{* * *}$ & $0.566^{* * *}$ & $0.563^{* * *}$ \\
\hline & {$[0.273]$} & {$[0.276]$} & {$[0.274]$} & {$[0.016]$} & {$[0.016]$} & {$[0.016]$} & {$[0.037]$} & {$[0.037]$} & {$[0.037]$} \\
\hline \multicolumn{10}{|l|}{ Age (base: 25-44) } \\
\hline \multirow[t]{2}{*}{$18-24$} & $-4.605^{* * *}$ & $-4.665^{* * *}$ & $-4.638^{* * *}$ & $0.087^{* * *}$ & $0.089^{* * *}$ & $0.088^{* * *}$ & $0.158^{*}$ & $0.161^{* *}$ & $0.159^{*}$ \\
\hline & {$[0.606]$} & {$[0.604]$} & {$[0.603]$} & {$[0.026]$} & {$[0.026]$} & {$[0.026]$} & {$[0.062]$} & {$[0.062]$} & {$[0.062]$} \\
\hline \multirow[t]{2}{*}{$45-64$} & $-1.282^{* * *}$ & $-1.260^{* * *}$ & $-1.270^{* * *}$ & $0.148^{* * *}$ & $0.147^{* * *}$ & $0.147^{* * *}$ & $0.176^{* * *}$ & $0.176^{* * *}$ & $0.176^{* * *}$ \\
\hline & {$[0.311]$} & {$[0.312]$} & {$[0.311]$} & {$[0.017]$} & {$[0.017]$} & {$[0.017]$} & {$[0.038]$} & {$[0.038]$} & {$[0.038]$} \\
\hline \multirow[t]{2}{*}{$65-79$} & $-1.926^{* * *}$ & $-1.990^{* * *}$ & $-1.957^{* * *}$ & $0.618^{* * *}$ & $0.619^{* * *}$ & $0.618^{* * *}$ & $0.646^{* * *}$ & $0.651^{* * *}$ & $0.648^{* * *}$ \\
\hline & {$[0.398]$} & {$[0.401]$} & {$[0.400]$} & {$[0.029]$} & [0.029] & {$[0.029]$} & {$[0.061]$} & {$[0.062]$} & {$[0.061]$} \\
\hline \multirow[t]{2}{*}{$80+$} & -0.976 & -0.996 & -0.983 & $0.922^{* * *}$ & $0.918^{* * *}$ & $0.921^{* * *}$ & $1.073^{* * *}$ & $1.075^{* * *}$ & $1.073^{* * *}$ \\
\hline & {$[0.554]$} & {$[0.557]$} & {$[0.556]$} & {$[0.050]$} & {$[0.050]$} & {$[0.050]$} & {$[0.095]$} & {$[0.096]$} & {$[0.095]$} \\
\hline Ethnicity (base: NZ European/ O & & & & & & & & & \\
\hline Māori & $-6.216^{* * *}$ & $-6.113^{* * *}$ & $-6.161^{* * *}$ & $-0.210^{* * *}$ & $-0.214^{* * *}$ & $-0.212^{* * * *}$ & 0.013 & 0.007 & 0.011 \\
\hline & {$[0.347]$} & {$[0.354]$} & {$[0.348]$} & {$[0.021]$} & {$[0.021]$} & {$[0.021]$} & {$[0.060]$} & {$[0.062]$} & {$[0.061]$} \\
\hline Pacific & $-10.660^{* * *}$ & $-10.606^{* * *}$ & $-10.633^{* * *}$ & -0.062 & -0.065 & -0.063 & 0.130 & 0.126 & 0.128 \\
\hline & {$[0.553]$} & [0.557] & [0.554] & {$[0.036]$} & {$[0.036]$} & {$[0.036]$} & {$[0.088]$} & {$[0.088]$} & {$[0.088]$} \\
\hline Asian & $-4.169^{* * *}$ & $-4.102^{* * *}$ & $-4.140^{* * *}$ & $-0.139^{* * *}$ & $-0.141^{* * *}$ & $-0.140^{* * *}$ & $-0.349^{* * *}$ & $-0.352^{* * *}$ & $-0.350^{* * *}$ \\
\hline & {$[0.651]$} & {$[0.656]$} & {$[0.652]$} & {$[0.029]$} & {$[0.029]$} & {$[0.029]$} & [0.059] & {$[0.060]$} & {$[0.060]$} \\
\hline Qualifications (base: none) & & & & & & & & & \\
\hline Secondary & 0.623 & 0.620 & 0.621 & 0.035 & 0.035 & 0.035 & -0.064 & -0.064 & -0.064 \\
\hline & {$[0.354]$} & {$[0.355]$} & {$[0.355]$} & {$[0.023]$} & {$[0.023]$} & {$[0.023]$} & {$[0.054]$} & {$[0.054]$} & {$[0.054]$} \\
\hline Vocational & $1.256^{* * *}$ & $1.212^{* * * *}$ & $1.234^{* * *}$ & $0.062^{* *}$ & $0.064^{* *}$ & $0.063^{* *}$ & -0.020 & -0.018 & -0.019 \\
\hline & {$[0.288]$} & [0.290] & [0.289] & {$[0.020]$} & {$[0.020]$} & {$[0.020]$} & [0.043] & {$[0.044]$} & {$[0.044]$} \\
\hline Undergraduate & $2.950^{* * * *}$ & $2.875^{* * *}$ & $2.912^{* * *}$ & $0.137^{* * *}$ & $0.140^{* * *}$ & $0.138^{* * *}$ & 0.051 & 0.055 & 0.052 \\
\hline & {$[0.503]$} & {$[0.505]$} & {$[0.502]$} & {$[0.026]$} & {$[0.026]$} & {$[0.026]$} & {$[0.053]$} & {$[0.054]$} & {$[0.054]$} \\
\hline Postgraduate & $2.037^{* * *}$ & $1.956^{* * *}$ & $1.996^{* * *}$ & $0.122^{* * *}$ & $0.126^{* * *}$ & $0.124^{* * *}$ & 0.030 & 0.034 & 0.031 \\
\hline & {$[0.544]$} & {$[0.547]$} & {$[0.544]$} & {$[0.033]$} & {$[0.033]$} & {$[0.033]$} & {$[0.061]$} & {$[0.062]$} & {$[0.061]$} \\
\hline Household income (base: Loss or & & & & & & & & & \\
\hline$\$ 20,000)$ & & & & & & & & & \\
\hline$\$ 20,001$ to $\$ 30,000$ & 0.303 & 0.242 & 0.269 & $0.099^{* *}$ & $0.101^{* *}$ & $0.100^{* *}$ & 0.067 & 0.070 & 0.068 \\
\hline & {$[0.480]$} & [0.483] & {$[0.480]$} & {$[0.038]$} & {$[0.038]$} & {$[0.038]$} & {$[0.096]$} & {$[0.096]$} & {$[0.096]$} \\
\hline$\$ 30,001$ to $\$ 50,000$ & 0.562 & 0.446 & 0.498 & $0.137^{* * *}$ & $0.142^{* * *}$ & $0.139^{* * *}$ & -0.058 & -0.052 & -0.056 \\
\hline & {$[0.483]$} & {$[0.492]$} & {$[0.488]$} & {$[0.035]$} & {$[0.035]$} & {$[0.035]$} & {$[0.087]$} & {$[0.087]$} & {$[0.087]$} \\
\hline$\$ 50,001$ to $\$ 70,000$ & 1.034 & 0.880 & 0.953 & $0.144^{* * *}$ & $0.151^{* * * *}$ & $0.147^{* * *}$ & $-0.196^{*}$ & $-0.188^{*}$ & $-0.193^{*}$ \\
\hline & {$[0.547]$} & {$[0.560]$} & {$[0.553]$} & {$[0.037]$} & {$[0.037]$} & {$[0.037]$} & {$[0.088]$} & [0.089] & {$[0.088]$} \\
\hline$\$ 70,001$ to $\$ 100,000$ & $2.090^{* * *}$ & $1.926^{* * * *}$ & $2.001^{* * * *}$ & $0.192^{* * *}$ & $0.199^{* * * *}$ & $0.195^{* * *}$ & -0.136 & -0.127 & -0.133 \\
\hline & {$[0.567]$} & {$[0.579]$} & {$[0.573]$} & {$[0.038]$} & {$[0.038]$} & {$[0.038]$} & {$[0.088]$} & {$[0.089]$} & {$[0.088]$} \\
\hline$\$ 100,001$ and above & $3.444^{* * *}$ & $3.250^{* * * *}$ & $3.338^{* * *}$ & $0.236^{* * *}$ & $0.244^{* * *}$ & $0.239^{* * *}$ & -0.070 & -0.060 & -0.066 \\
\hline & {$[0.591]$} & {$[0.607]$} & {$[0.599]$} & {$[0.038]$} & {$[0.038]$} & {$[0.038]$} & {$[0.090]$} & {$[0.091]$} & {$[0.090]$} \\
\hline Don't know/refused & 0.528 & 0.453 & 0.486 & 0.054 & 0.057 & 0.055 & -0.153 & -0.149 & -0.151 \\
\hline & {$[0.474]$} & {$[0.479]$} & {$[0.477]$} & {$[0.033]$} & {$[0.033]$} & {$[0.033]$} & {$[0.083]$} & {$[0.083]$} & {$[0.083]$} \\
\hline Has usual practice & $-10.961^{* * *}$ & $-10.869^{* * *}$ & $-10.921^{* * *}$ & $1.164^{* * *}$ & $1.153^{* * * *}$ & $1.160^{* * *}$ & $1.351^{* * *}$ & $1.347^{* * * *}$ & $1.349^{* * * *}$ \\
\hline & {$[1.605]$} & {$[1.603]$} & {$[1.602]$} & {$[0.032]$} & {$[0.033]$} & {$[0.032]$} & {$[0.054]$} & {$[0.055]$} & {$[0.054]$} \\
\hline NZDep Quintile (base: NZDep 1) & & & & & & & & & \\
\hline NZDep 2 & $-1.528^{* *}$ & $-1.490^{* *}$ & $-1.508^{* *}$ & 0.042 & 0.039 & 0.041 & 0.065 & 0.063 & 0.064 \\
\hline & {$[0.509]$} & {$[0.510]$} & {$[0.510]$} & {$[0.026]$} & {$[0.026]$} & {$[0.026]$} & {$[0.052]$} & {$[0.052]$} & {$[0.052]$} \\
\hline NZDep 3 & $-3.445^{* * * *}$ & $-3.376^{* * *}$ & $-3.412^{* * *}$ & -0.023 & -0.027 & -0.024 & 0.005 & 0.001 & 0.004 \\
\hline & {$[0.483]$} & {$[0.486]$} & {$[0.484]$} & {$[0.027]$} & {$[0.026]$} & {$[0.026]$} & {$[0.051]$} & {$[0.052]$} & {$[0.052]$} \\
\hline NZDep 4 & $-5.292^{* * *}$ & $-5.187^{* * *}$ & $-5.238^{* * *}$ & 0.017 & 0.011 & 0.015 & 0.107 & 0.101 & 0.105 \\
\hline & {$[0.503]$} & {$[0.508]$} & {$[0.504]$} & {$[0.027]$} & {$[0.027]$} & {$[0.027]$} & {$[0.056]$} & {$[0.057]$} & {$[0.056]$} \\
\hline NZDep 5 (most deprived) & $-8.708^{* * *}$ & $-8.588^{* * * *}$ & $-8.647^{* * *}$ & 0.022 & 0.015 & 0.019 & $0.262^{* * *}$ & $0.255^{* * *}$ & $0.259^{* * *}$ \\
\hline & {$[0.538]$} & {$[0.545]$} & {$[0.542]$} & {$[0.028]$} & {$[0.028]$} & {$[0.028]$} & {$[0.062]$} & {$[0.063]$} & {$[0.062]$} \\
\hline Public hospital & $-1.050^{* *}$ & $-0.826^{*}$ & $-0.934^{* *}$ & $0.311^{* * *}$ & $0.300^{* * *}$ & $0.307^{* * *}$ & $1.100^{* * *}$ & $1.091^{* * *}$ & $1.097^{* * *}$ \\
\hline & {$[0.352]$} & {$[0.376]$} & [0.357] & {$[0.025]$} & {$[0.025]$} & {$[0.025]$} & {$[0.053]$} & {$[0.055]$} & [0.054] \\
\hline Private hospital & $1.080^{* *}$ & $1.137^{* *}$ & $1.108^{* *}$ & $0.307^{* * *}$ & $0.306^{* * *}$ & $0.307^{* * *}$ & $0.641^{* * * *}$ & $0.643^{* * *}$ & $0.642^{* * *}$ \\
\hline & [0.399] & [0.402] & {$[0.400]$} & {$[0.046]$} & {$[0.046]$} & {$[0.046]$} & {$[0.095]$} & {$[0.095]$} & {$[0.095]$} \\
\hline Specialist & - & - & - & $0.474^{* * *}$ & $0.463^{* * *}$ & $0.470^{* * * *}$ & $1.123^{* * * *}$ & $1.115^{* * *}$ & $1.120^{* * *}$ \\
\hline & - & - & - & {$[0.026]$} & {$[0.026]$} & {$[0.026]$} & {$[0.051]$} & {$[0.054]$} & {$[0.052]$} \\
\hline Self-rated health & $3.903^{* * *}$ & $4.597^{* * *}$ & $4.266^{* * *}$ & $-0.388^{* * *}$ & $-0.421^{* * *}$ & $-0.400^{* * * *}$ & $-1.551^{* * *}$ & $-1.587^{* * *}$ & $-1.565^{* * *}$ \\
\hline & {$[0.800]$} & {$[0.887]$} & {$[0.806]$} & [0.044] & {$[0.045]$} & {$[0.043]$} & {$[0.110]$} & {$[0.125]$} & [0.113] \\
\hline Chronic conditions (base: no con & & & & & & & & & \\
\hline 1 condition & 0.534 & $0.649^{*}$ & $0.595^{*}$ & $0.144^{* * * *}$ & $0.138^{* * *}$ & $0.142^{* * *}$ & $0.281^{* * *}$ & $0.276^{* * *}$ & $0.279^{* * *}$ \\
\hline & [0.295] & {$[0.302]$} & [0.297] & {$[0.020]$} & {$[0.020]$} & {$[0.020]$} & {$[0.041]$} & {$[0.042]$} & {$[0.041]$} \\
\hline$\geq 2$ conditions & 0.088 & 0.303 & 0.203 & $0.135^{* * *}$ & $0.125^{* * *}$ & $0.131^{* * *}$ & $0.534^{* * *}$ & $0.524^{* * *}$ & $0.530^{* * *}$ \\
\hline & {$[0.400]$} & {$[0.416]$} & {$[0.402]$} & {$[0.028]$} & {$[0.028]$} & {$[0.028]$} & {$[0.060]$} & {$[0.063]$} & {$[0.061]$} \\
\hline Depressed & $3.464^{* * *}$ & $3.986^{* * * *}$ & $3.740^{* * *}$ & 0.084 & 0.058 & 0.074 & $0.950^{* * *}$ & $0.924^{* * *}$ & $0.940^{* * *}$ \\
\hline & {$[0.906]$} & {$[0.961]$} & {$[0.904]$} & {$[0.063]$} & {$[0.064]$} & {$[0.063]$} & {$[0.196]$} & {$[0.199]$} & {$[0.195]$} \\
\hline $\bar{N}$ & 85214 & 85214 & 85214 & 84273 & 84273 & 84273 & 83627 & 83627 & 83627 \\
\hline
\end{tabular}

${ }^{*} p<0.05,{ }^{* *} p<0.01,{ }^{* * *} p<0.001$

In the Sutton specification, BMI was normalised by its 2002/03 mean value

Other controls omitted for space: Hours worked, Born overseas, Smoker, Drinker, Has insurance, Year. 
Table D.5A: Kleibergen-Paap F-Tests for weak instruments

\begin{tabular}{llll}
\hline \multicolumn{2}{c}{ FEE } & VISPROB & VISNUM \\
\hline Diastolic & $\mathrm{F}(1,5317)=161.45$ & $\mathrm{~F}(1,5316)=159.40$ & $\mathrm{~F}(1,5315)=157.99$ \\
Systolic & $\mathrm{F}(1,5317)=38.69$ & $\mathrm{~F}(1,5316)=39.58$ & $\mathrm{~F}(1,5315)=38.82$ \\
Heartrate & $\mathrm{F}(1,5317)=231.50$ & $\mathrm{~F}(1,5316)=227.89$ & $\mathrm{~F}(1,5315)=238.87$ \\
Obesity & $\mathrm{F}(3,5315)=375.87$ & $\mathrm{~F}(3,5315)=371.23$ & $\mathrm{~F}(3,5313)=363.92$ \\
\hline
\end{tabular}

All tests were significant at the $\mathrm{p}>0.0001$ level.

Data come from NZHS waves 2012/13-2015/16 
Table D.5B: Alternative instruments, NZHS waves 2012/13 - 2015/16

\begin{tabular}{|c|c|c|c|c|c|c|c|c|c|c|c|c|}
\hline & \multicolumn{4}{|c|}{ FEES } & \multicolumn{4}{|c|}{ VISPROB } & \multicolumn{4}{|c|}{ VISNUM } \\
\hline & (1) & (2) & (3) & (4) & (5) & (6) & (7) & (8) & (9) & (10) & (11) & (12) \\
\hline & Obese & Diastolic & Systolic & Heart & Obese & Diastolic & Systolic & Heart & Obese & Diastolic & Systolic & Heart \\
\hline \multirow[t]{2}{*}{ Female } & 0.349 & 0.354 & 0.584 & 0.245 & $0.290^{* * *}$ & $0.242^{* * *}$ & $0.200^{* * *}$ & $0.256^{* * *}$ & $0.556^{* * *}$ & $0.470^{* * *}$ & $0.433^{* * *}$ & $0.571^{* * * *}$ \\
\hline & {$[0.324]$} & {$[0.372]$} & {$[0.393]$} & {$[0.362]$} & {$[0.020]$} & [0.029] & {$[0.055]$} & {$[0.026]$} & {$[0.046]$} & {$[0.053]$} & {$[0.076]$} & {$[0.051]$} \\
\hline \multicolumn{13}{|l|}{ Age (base: 25-44) } \\
\hline \multirow[t]{2}{*}{$18-24$} & $-4.628^{* * *}$ & $-4.610^{* * *}$ & $-4.304^{* * *}$ & $-4.730^{* * *}$ & 0.065 & 0.007 & -0.024 & 0.020 & $0.156^{*}$ & 0.052 & 0.009 & 0.173 \\
\hline & {$[0.735]$} & {$[0.790]$} & {$[0.802]$} & {$[0.768]$} & {$[0.034]$} & [0.038] & [0.047] & [0.037] & [0.079] & {$[0.085]$} & {$[0.105]$} & {$[0.088]$} \\
\hline \multirow[t]{2}{*}{$45-64$} & $-0.844^{*}$ & $-0.840^{*}$ & $-0.895^{*}$ & $-0.812^{*}$ & $0.158^{* * *}$ & $0.165^{* * *}$ & $0.157^{* * *}$ & $0.165^{* * *}$ & $0.154^{* *}$ & $0.165^{* * *}$ & $0.170^{* * *}$ & $0.152^{* *}$ \\
\hline & {$[0.385]$} & {$[0.385]$} & [0.387] & {$[0.390]$} & {$[0.022]$} & {$[0.022]$} & [0.024] & [0.023] & [0.049] & {$[0.048]$} & {$[0.049]$} & {$[0.050]$} \\
\hline $65-79$ & $-1.564^{* *}$ & $-1.560^{* *}$ & $-1.251^{*}$ & $-1.699^{* *}$ & $0.636^{* * *}$ & $0.564^{* * *}$ & $0.489^{* * *}$ & $0.588^{* * *}$ & $0.684^{* * *}$ & $0.552^{* * *}$ & $0.495^{* * *}$ & $0.708^{* * *}$ \\
\hline & {$[0.507]$} & {$[0.575]$} & [0.578] & {$[0.547]$} & {$[0.037]$} & [0.053] & [0.102] & {$[0.046]$} & {$[0.077]$} & {$[0.088]$} & {$[0.118]$} & {$[0.087]$} \\
\hline $80+$ & -0.621 & -0.601 & -0.400 & -0.693 & $0.970^{* * *}$ & $0.928^{* * *}$ & $0.843^{* * *}$ & $0.952^{* * *}$ & $1.105^{* * *}$ & $1.017^{* * *}$ & $0.980^{* * *}$ & $1.120^{* * *}$ \\
\hline & {$[0.748]$} & {$[0.756]$} & {$[0.779]$} & {$[0.757]$} & {$[0.064]$} & {$[0.074]$} & [0.127] & [0.068] & [0.111] & [0.113] & {$[0.124]$} & [0.113] \\
\hline Ethnicity (base: NZ European/ Ot & & & & & & & & & & & & \\
\hline Māori & $-6.190^{* * *}$ & $-6.189^{* * * * *}$ & $-6.535^{* * * *}$ & $-6.048^{* * * *}$ & $-0.229^{* * *}$ & $-0.157^{* * *}$ & -0.108 & $-0.175^{* * *}$ & 0.024 & 0.155 & 0.210 & 0.003 \\
\hline & {$[0.438]$} & {$[0.529]$} & {$[0.572]$} & {$[0.498]$} & {$[0.026]$} & {$[0.036]$} & {$[0.060]$} & {$[0.033]$} & [0.077] & [0.091] & [0.118] & [0.085] \\
\hline Pacific & $-10.359^{* * *}$ & $-10.367^{* * *}$ & $-10.615^{5 * *}$ & $-10.260^{* * *}$ & -0.081 & -0.028 & 0.002 & -0.040 & 0.014 & 0.117 & 0.158 & 0.005 \\
\hline & {$[0.676]$} & {$[0.702]$} & {$[0.714]$} & {$[0.692]$} & {$[0.047]$} & [0.049] & [0.055] & [0.049] & {$[0.119]$} & [0.117] & {$[0.130]$} & [0.124] \\
\hline Asian & $-5.394^{* * *}$ & $-5.361^{* * *}$ & $-5.531^{* * *}$ & $-5.280^{* * *}$ & $-0.125^{* * *}$ & $-0.084^{*}$ & -0.059 & $-0.094^{*}$ & $-0.354^{* * *}$ & $-0.285^{* * *}$ & $-0.256^{* *}$ & $-0.364^{* * *}$ \\
\hline & {$[0.727]$} & {$[0.732]$} & {$[0.748]$} & {$[0.734]$} & {$[0.037]$} & {$[0.040]$} & [0.046] & [0.039] & {$[0.074]$} & {$[0.072]$} & [0.080] & [0.077] \\
\hline Qualification (base: none) & & & & & & & & & & & & \\
\hline Secondary & 0.871 & 0.875 & 0.769 & 0.924 & 0.024 & 0.045 & 0.053 & 0.041 & -0.059 & -0.023 & -0.008 & -0.065 \\
\hline & [0.478] & {$[0.486]$} & {$[0.482]$} & [0.491] & [0.030] & [0.030] & [0.030] & [0.031] & {$[0.070]$} & {$[0.071]$} & [0.073] & [0.072] \\
\hline Vocational & $1.288^{* * *}$ & $1.285^{* * *}$ & $1.393^{* * *}$ & $1.237^{* * *}$ & $0.074^{* *}$ & 0.049 & 0.033 & $0.055^{*}$ & 0.028 & -0.019 & -0.038 & 0.035 \\
\hline & [0.353] & {$[0.358]$} & {$[0.373]$} & {$[0.362]$} & {$[0.025]$} & [0.027] & [0.031] & {$[0.026]$} & {$[0.053]$} & {$[0.054]$} & [0.063] & {$[0.054]$} \\
\hline Undergraduate & $3.197^{* * *}$ & $3.192^{* * *}$ & $3.432^{* * *}$ & $3.084^{* * *}$ & $0.149^{* * *}$ & $0.097^{* *}$ & 0.064 & $0.110^{* *}$ & 0.114 & 0.021 & -0.017 & 0.129 \\
\hline & [0.582] & [0.601] & {$[0.638]$} & {$[0.581]$} & [0.031] & [0.036] & [0.049] & [0.034] & {$[0.066]$} & [0.072] & [0.092] & [0.069] \\
\hline Postgraduate & $2.444^{* * * *}$ & $2.444^{* * *}$ & $2.732^{* * * *}$ & $2.315^{* * *}$ & $0.104^{*}$ & 0.040 & 0.004 & 0.055 & 0.064 & -0.050 & -0.098 & 0.082 \\
\hline & {$[0.619]$} & {$[0.655]$} & {$[0.680]$} & {$[0.650]$} & [0.041] & {$[0.045]$} & {$[0.055]$} & {$[0.043]$} & {$[0.074]$} & {$[0.080]$} & {$[0.106]$} & {$[0.078]$} \\
\hline Household income (base: loss or & & & & & & & & & & & & \\
\hline$\$ 20,000)$ & & & & & & & & & & & & \\
\hline$\$ 20,001$ to $\$ 30,000$ & 0.875 & 0.860 & 1.094 & 0.760 & 0.080 & 0.034 & 0.008 & 0.045 & 0.151 & 0.061 & 0.028 & 0.155 \\
\hline & {$[0.543]$} & {$[0.573]$} & {$[0.585]$} & {$[0.578]$} & {$[0.051]$} & {$[0.053]$} & {$[0.058]$} & {$[0.053]$} & [0.129] & [0.129] & [0.142] & {$[0.132]$} \\
\hline$\$ 30,001$ to $\$ 50,000$ & 0.660 & 0.639 & 0.997 & 0.484 & $0.133^{* *}$ & 0.061 & 0.020 & 0.078 & 0.009 & -0.124 & -0.177 & 0.023 \\
\hline & {$[0.567]$} & [0.609] & [0.675] & [0.615] & {$[0.046]$} & {$[0.052]$} & {$[0.064]$} & {$[0.050]$} & {$[0.111]$} & {$[0.115]$} & [0.144] & {$[0.118]$} \\
\hline$\$ 50,001$ to $\$ 70,000$ & $1.278^{*}$ & 1.257 & $1.761^{*}$ & 1.039 & $0.142^{* *}$ & 0.041 & -0.014 & 0.064 & -0.153 & $-0.338^{* *}$ & $-0.413^{*}$ & -0.130 \\
\hline & [0.604] & [0.702] & [0.784] & [0.701] & {$[0.047]$} & {$[0.057]$} & [0.077] & {$[0.054]$} & {$[0.111]$} & {$[0.122]$} & [0.168] & {$[0.122]$} \\
\hline$\$ 70,001$ to $\$ 100,000$ & $1.998^{* *}$ & $1.982^{* *}$ & $2.485^{* *}$ & $1.772^{*}$ & $0.193^{* * *}$ & 0.090 & 0.031 & $0.115^{*}$ & -0.075 & $-0.265^{*}$ & $-0.341^{*}$ & -0.053 \\
\hline & {$[0.651]$} & [0.743] & [0.808] & {$[0.722]$} & {$[0.049]$} & [0.059] & [0.081] & [0.057] & [0.109] & {$[0.120]$} & [0.171] & {$[0.122]$} \\
\hline$\$ 100,001$ and above & $2.251^{* * *}$ & $2.234^{* *}$ & $2.830^{* *}$ & $1.980^{*}$ & $0.237^{* * *}$ & 0.113 & 0.042 & $0.143^{*}$ & -0.052 & $-0.279^{*}$ & -0.371 & -0.023 \\
\hline & {$[0.651]$} & {$[0.816]$} & {$[0.900]$} & [0.772] & {$[0.048]$} & {$[0.062]$} & [0.093] & [0.059] & {$[0.111]$} & {$[0.127]$} & [0.191] & {$[0.127]$} \\
\hline Don't know/refused & 0.678 & 0.663 & 0.881 & 0.570 & 0.047 & 0.002 & -0.021 & 0.012 & -0.109 & -0.194 & -0.227 & -0.102 \\
\hline & {$[0.556]$} & {$[0.580]$} & {$[0.594]$} & {$[0.580]$} & {$[0.042]$} & {$[0.045]$} & {$[0.048]$} & {$[0.044]$} & {$[0.104]$} & {$[0.103]$} & [0.119] & {$[0.106]$} \\
\hline Has usual practice & $-12.151^{* * *}$ & $-12.126^{* * *}$ & $-12.397^{* * *}$ & $-11.995^{* * *}$ & $1.198^{* * *}$ & $1.245^{* * * *}$ & $1.189^{* * *}$ & $1.253^{* * * *}$ & $1.301^{* * *}$ & $1.376^{* * *}$ & $1.408^{* * *}$ & $1.289^{* * * *}$ \\
\hline & [2.177] & {$[2.171]$} & [2.188] & [2.192] & [0.044] & {$[0.043]$} & {$[0.100]$} & [0.040] & [0.074] & {$[0.070]$} & [0.083] & {$[0.076]$} \\
\hline NZDep Quintile (base: NZDep 1) & & & & & & & & & & & & \\
\hline NZDep 2 & $-1.430^{*}$ & $-1.441^{*}$ & $-1.523^{*}$ & $-1.406^{*}$ & 0.036 & 0.053 & 0.060 & 0.050 & -0.030 & 0.003 & 0.017 & -0.035 \\
\hline & {$[0.665]$} & {$[0.667]$} & {$[0.670]$} & {$[0.669]$} & [0.035] & [0.035] & {$[0.034]$} & {$[0.035]$} & {$[0.068]$} & {$[0.066]$} & {$[0.069]$} & {$[0.070]$} \\
\hline NZDep 3 & $-3.221^{* * *}$ & $-3.229^{* * *}$ & $-3.469^{* * *}$ & $-3.120^{* * *}$ & -0.027 & 0.024 & 0.049 & 0.012 & -0.100 & -0.010 & 0.028 & -0.114 \\
\hline & {$[0.632]$} & {$[0.657]$} & {$[0.678]$} & {$[0.654]$} & {$[0.034]$} & {$[0.037]$} & [0.043] & {$[0.036]$} & [0.069] & {$[0.074]$} & [0.092] & {$[0.075]$} \\
\hline NZDep 4 & $-5.625^{* * *}$ & $-5.641^{* * *}$ & $-5.922^{* * *}$ & $-5.513^{* * *}$ & 0.040 & $0.099^{* *}$ & $0.125^{* *}$ & $0.086^{*}$ & 0.051 & 0.157 & 0.202 & 0.032 \\
\hline & {$[0.649]$} & {$[0.677]$} & {$[0.708]$} & {$[0.675]$} & {$[0.035]$} & {$[0.038]$} & {$[0.041]$} & {$[0.037]$} & {$[0.073]$} & {$[0.081]$} & {$[0.105]$} & {$[0.082]$} \\
\hline NZDep 5 (most deprived) & $-8.803^{* * *}$ & $-8.820^{* * * *}$ & $-9.174^{* * *}$ & $-8.656^{* * *}$ & 0.025 & $0.101^{*}$ & $0.135^{* *}$ & $0.085^{*}$ & $0.245^{* *}$ & $0.383^{* * *}$ & $0.440^{* * * *}$ & $0.225^{*}$ \\
\hline & {$[0.668]$} & {$[0.707]$} & [0.749] & {$[0.706]$} & {$[0.035]$} & {$[0.040]$} & {$[0.048]$} & [0.039] & {$[0.081]$} & {$[0.091]$} & [0.122] & {$[0.092]$} \\
\hline Public hospital & -0.241 & -0.221 & -0.940 & 0.102 & $0.280^{* * *}$ & $0.384^{* * * *}$ & $0.414^{* * *}$ & $0.366^{* * *}$ & $1.004^{* * *}$ & $1.188^{* * *}$ & $1.264^{* * *}$ & $0.975^{* * *}$ \\
\hline & {$[0.377]$} & [0.652] & [0.819] & [0.604] & {$[0.031]$} & {$[0.034]$} & [0.035] & {$[0.034]$} & {$[0.063]$} & {$[0.088]$} & {$[0.144]$} & {$[0.079]$} \\
\hline Private hospital & $1.399^{* *}$ & $1.396^{* *}$ & $1.302^{* *}$ & $1.438^{* *}$ & $0.282^{* * *}$ & $0.251^{* * *}$ & $0.219^{* *}$ & $0.261^{* * *}$ & $0.655^{* * *}$ & $0.600^{* * * *}$ & $0.577^{* * *}$ & $0.663^{* * *}$ \\
\hline & {$[0.491]$} & [0.496] & [0.488] & {$[0.501]$} & {$[0.060]$} & {$[0.062]$} & {$[0.070]$} & {$[0.062]$} & {$[0.127]$} & {$[0.128]$} & [0.131] & {$[0.126]$} \\
\hline Specialist & - & - & - & - & $0.459^{* * *}$ & $0.560^{* * *}$ & $0.576^{* * *}$ & $0.545^{* * *}$ & $1.156^{* * *}$ & $1.333^{* * *}$ & $1.407^{* * *}$ & $1.128^{* * *}$ \\
\hline & - & - & - & - & {$[0.033]$} & [0.033] & [0.027] & {$[0.035]$} & {$[0.065]$} & {$[0.088]$} & [0.137] & {$[0.078]$} \\
\hline Self-rated health & $4.389^{* * *}$ & $4.435^{*}$ & 2.183 & $5.441^{* * *}$ & $-0.401^{* * *}$ & 0.058 & 0.294 & -0.046 & $-1.604^{* * *}$ & $-0.788^{* *}$ & -0.448 & $-1.732^{* * *}$ \\
\hline & {$[0.688]$} & [1.830] & [2.341] & [1.611] & {$[0.052]$} & [0.139] & {$[0.256]$} & {$[0.121]$} & {$[0.133]$} & [0.299] & {$[0.576]$} & {$[0.260]$} \\
\hline Chronic conditions (base: no con & & & & & & & & & & & & \\
\hline 1 condition & $0.952^{* *}$ & $0.954^{*}$ & 0.617 & $1.108^{* *}$ & $0.136^{* * * *}$ & $0.200^{* * * *}$ & $0.220^{* * * *}$ & $0.188^{* * * *}$ & $0.215^{* * * *}$ & $0.328^{* * * *}$ & $0.376^{* * *}$ & $0.196^{* *}$ \\
\hline & {$[0.357]$} & {$[0.438]$} & {$[0.494]$} & {$[0.413]$} & {$[0.026]$} & {$[0.028]$} & {$[0.030]$} & {$[0.029]$} & {$[0.053]$} & {$[0.063]$} & {$[0.094]$} & {$[0.064]$} \\
\hline$\geq 2$ conditions & 0.506 & 0.498 & -0.066 & 0.761 & $0.097^{* *}$ & $0.205^{* * *}$ & $0.249^{* * *}$ & $0.183^{* * *}$ & $0.411^{* * *}$ & $0.604^{* * *}$ & $0.684^{* * *}$ & $0.383^{* * *}$ \\
\hline & {$[0.443]$} & {$[0.651]$} & {$[0.713]$} & {$[0.579]$} & [0.032] & {$[0.042]$} & {$[0.052]$} & {$[0.041]$} & {$[0.069]$} & {$[0.088]$} & {$[0.140]$} & {$[0.087]$} \\
\hline Depressed & $3.605^{* * *}$ & $3.648^{*}$ & 1.907 & $4.420^{* *}$ & 0.081 & $0.427^{* * * *}$ & $0.581^{* * *}$ & $0.355^{* *}$ & $0.851^{* * *}$ & $1.463^{* * *}$ & $1.720^{* * * *}$ & $0.749^{* *}$ \\
\hline & {$[1.052]$} & {$[1.721]$} & [2.063] & {$[1.532]$} & {$[0.080]$} & [0.119] & {$[0.172]$} & [0.109] & {$[0.233]$} & {$[0.314]$} & {$[0.501]$} & {$[0.282]$} \\
\hline $\bar{N}$ & 49296 & 49296 & 49296 & 49296 & 49091 & 49085 & 49085 & 49085 & 48946 & 48941 & 48941 & 48941 \\
\hline
\end{tabular}




\section{References}

1. King A. The Primary Health Care Strategy. Wellington: Ministry of Health; 2001.

2. World Health Organisation. Alma Ata Declaration. Geneva: World Health Organisation; 1978.

3. Cumming J, McDonald J, Barr C, Martin G, Gerring Z, Daubé J. New Zealand health system review. Health System in Transition. Manila: World Health Organization; 2014.

4. Starfield B, Shi L, Macinko J. Contribution of primary care to health systems and health. The Milbank Quarterly. 2005;83(3):457-502.

5. Schoen C, Osborn R, Doty MM, Bishop M, Peugh J, Murukutla N. Toward higherperformance health systems: Adults' health care experiences in seven countries, 2007. Health Aff. 2007;26(6):w717-w34.

6. Kringos DS, Boerma WG, Hutchinson A, van der Zee J, Groenewegen PP. The breadth of primary care: A systematic literature review of its core dimensions. BMC Health Services Research. 2010;10(1):65.

7. Cumming J, Gribben B. Evaluation of the Primary Health Care Strategy: Practice data analysis 2001-2005. Wellington: Health Services Research Centre, Victoria University of Wellington; 2007.

8. Raymont A. Cost barriers to health care: Provisional analysis from the New Zealand Health Survey 2002/03. Wellington: Health Services Research Centre, Victoria University of Wellington; 2004.

9. Crengle S. Māori primary care services. Wellington: National Health Committee; 1999. 10. Sarfati D, Scott K, Haslett S, Johnston G, Hodges I. Taking the pulse: The 1996/97 New Zealand Health Survey. Wellington: Ministry of Health; 1999.

11. Smith J. Critical analysis of the implementation of the Primary Health Care Strategy implementation and framing of issues for the next phase. Wellington: Ministry of Health; 2009.

12. Cumming J, Mays N. New Zealand's Primary Health Care Strategy: Early effects of the new financing and payment system for general practice and future challenges. Health Economics, Policy and Law. 2011;6(1):1-21.

13. Paris V, Hewlett E, Auraaen A, Alexa J, Lisa S. Health care coverage in OECD countries in 2012. Paris, France; 2016 Contract No.: 88.

14. New Zealand National Party. Policy 2017: Health. Wellington: New Zealand National Party; 2017. 
15. New Zealand Labour Party. Reducing GP Fees. Wellington. 2018.

\section{http://www.labour.org.nz/gp_fees}

16. Taylor C. Primary care welcomes health review but GPs worried about sustainability. New Zealand Doctor. 2018.

17. New Zealand Government. Draft terms of reference: Review of New Zealand health and disability sector. Wellington; 2018.

18. Manning WG, Newhouse JP, Duan N, Keeler EB, Leibowitz A. Health insurance and the demand for medical care: Evidence from a randomized experiment. The American Economic Review. 1987:251-77.

19. Newhouse JP. Free for all? Lessons from the RAND health insurance experiment. Harvard University Press; 1993.

20. Nolan A, Smith S. The effect of differential eligibility for free GP services on GP utilisation in Ireland. Social Science \& Medicine. 2012;74(10):1644-51.

21. Socías ME, Koehoorn M, Shoveller J. Gender inequalities in access to health care among adults living in British Columbia, Canada. Women's Health Issues. 2016;26(1):74-9.

22. Marshall EG. Do young adults have unmet healthcare needs? J Adolesc Health. 2011;49(5):490-7.

23. Cumming J, Stillman S, Liang Y, Poland M, Hannis G. The determinants of GP visits in New Zealand. Australian and New Zealand Journal of Public Health. 2010;34(5):451-7.

24. Devaux M. Income-related inequalities and inequities in health care services utilisation in 18 selected OECD countries. European Journal of Health Economics. 2013;16(1):21-33. doi:10.1007/s10198-013-0546-4).

25. Spleen AM, Lengerich EJ, Camacho FT, Vanderpool RC. Health care avoidance among rural populations: Results from a nationally representative survey. Journal of Rural Health. 2014;30(1):79-88. doi:10.1111/jrh.12032.

26. Jatrana S, Crampton P. Primary health care in New Zealand: Who has access? Health Policy. 2009;93(1):1-10.

27. Cumming J, Stillman S, Poland M. Who pays what for primary health care? Patterns and determinants of the fees paid by patients in a mixed public-private financing model.

Wellington: Motu; 2009.

28. Cumming J, Mays N, Gribben B. Reforming primary health care: Is New Zealand's primary health care strategy achieving its early goals? Australia and New Zealand Health Policy. 2008;5(1):24. doi:10.1186/1743-8462-5-24. 
29. Downs A. From theory to practice: The promise of primary care in New Zealand. Wellington: Fulbright New Zealand; 2017.

30. Milne BJ, Parker K, McLay J, Von Randow M, Lay-Yee R, Hider P et al. Primary health care access and ambulatory sensitive hospitalizations in New Zealand. The Journal of Ambulatory Care Management. 2015;38(2):178-87.

31. Sutton M, Carr-Hill R, Gravelle H, Rice N. Do measures of self-reported morbidity bias the estimation of the determinants of health care utilisation? Social Science \& Medicine. 1999;49(7):867-78.

32. Bago d'Uva T, Lindeboom M, O'Donnell O, Van Doorslaer E. Education - related inequity in healthcare with heterogeneous reporting of health. Journal of the Royal Statistical Society: Series A (Statistics in Society). 2011;174(3):639-64.

33. Granger CW. Investigating causal relations by econometric models and cross-spectral methods. Econometrica. 1969:424-38.

34. Heckman JJ. Sample selection bias as a specification error (with an application to the estimation of labor supply functions). Cambridge, MA: National Bureau of Economic Research; 1977.

35. Chen J, Vargas - Bustamante A, Mortensen K, Thomas SB. Using quantile regression to examine health care expenditures during the great recession. Health Services Research. 2014;49(2):705-30.

36. Grossman M. On the concept of health capital and the demand for health. Journal of Political Economy. 1972;80(2):223-55.

37. Malcolm L. Inequities in access to and utilisation of primary medical care services for Māori and low income New Zealanders. New Zealand Medical Journal. 1996;109(1030):3568.

38. Ministry of Health. Annual Data Explorer 2016/17: New Zealand Health Survey. Ministry of Health, Wellington. 2017. https://minhealthnz.shinyapps.io/nz-health-survey2016-17-annual-update.

39. Gauld R. Questions about New Zealand's health system in 2013, its 75th anniversary year. New Zealand Medical Journal. 2013;126(1380).

40. McGuigan T. A health service for New Zealand. Wellington: Department of Health; 1975.

41. Whitehead D, Gauld R. Revolving doors: New Zealand's health reforms-the continuing saga. Journal of Social Policy. 2010;39:663. 
42. Upton S. Your health and the public health: A statement of government health policy. Wellington: Department of Health; 1991.

43. Malcolm L. Primary-care reform in New Zealand: Key contrasts with Australia. In: Bloom A, editor. Health Reform in Australia and New Zealand. Melbourne: Oxford University Press; 2000. p. 183-200.

44. Quin P. New Zealand health system reforms: Parliamentary Library research paper (No. 09/03). Wellington: NZ Parliamentary Library; 2009.

45. Coster G, McAvoy P. Health reforms: A New Zealand perspective. The British Journal of General Practice. 1996;46(408):391.

46. Davis P, Gribben B, Lee RL, McAvoy B. The impact of the new subsidy regime in general practice in New Zealand. Health Policy. 1994;29(1):113-25.

47. Gribben B. The community services card and utilisation of general practitioner services. New Zealand Medical Journal. 1996;109(1018):103-5.

48. Scott C, Fougere G, Marwick J. Choices for health care: Report of the Health Benefits Review. Wellington: Health Benefits Review; 1986.

49. Crampton P. Third sector primary health care. Wellington: National Advisory Committee on Health and Disability; 1999.

50. Cumming J. Funding population-based primary health care in New Zealand. Wellington: National Advisory Committee on Health and Disability; 1999.

51. Tukuitonga C. Primary Healthcare for Pacific People in New Zealand: Discussion paper for the National Health Committee. Wellington: National Health Committee, National Advisory Committee on Health and Disability; 1999.

52. Health Funding Authority. The next five years in general practice. Auckland: Health Funding Authority, Northern Office; 1998.

53. King A. The future shape of primary health care: A discussion document. Wellington: Ministry of Health; 2000.

54. King A. The New Zealand Health Strategy. Wellington: Ministry of Health; 2000.

55. Coleman J. The New Zealand Health Strategy: Future direction. Wellington: Ministry of Health; 2016.

56. Ministry of Social Development. New Zealand Disability Strategy, 2016-2026.

Wellington: Ministry of Social Development; 2016.

57. Ministry of Social Development. New Zealand Disability Strategy. Wellington: Ministry of Social Development; 2001. 
58. Ministry of Health. The guide to He Korowai Oranga: Māori Health Strategy.

Wellington: Ministry of Health; 2014.

59. Ministry of Health. He Korowai Oranga: Māori Health Strategy. Wellington: Ministry of Health; 2002.

60. Barnett P, Smith J, Cumming J. The roles and functions of Primary Health Organisations. Wellington: Health Services Research Centre, Victoria University of Wellington; 2009.

61. Ministry of Health. Capitation rates. Ministry of Health, Wellington. 2017.

https://www.health.govt.nz/our-work/primary-health-care/primary-health-care-subsidies-andservices/capitation-rates. Accessed 2 Feb 2018.

62. Berwick DM. Payment by capitation and the quality of care. Mass Medical Soc; 1996.

63. National Health Committee. Improving health for New Zealanders by investing in primary health care. Wellington: National Health Committee; 2000.

64. Hodgson P. Primary health - Low fees are good but what's next? (Address to the Dunedin School of Medicine). Beehive, Wellington. 2006.

https://www.beehive.govt.nz/speech/primary-health-\%E2\%80\%93-low-fees-are-good-whatsnext. Accessed 12 March 2018.

65. Ministry of Health. Very Low Cost Access scheme. 2018.

https://www.health.govt.nz/our-work/primary-health-care/primary-health-care-subsidies-andservices/very-low-cost-access-scheme. Accessed Feb 022019.

66. Ministry of Health. Services to improve access. Ministry of Health, Wellington. 2014. https://www.health.govt.nz/our-work/primary-health-care/primary-health-care-subsidies-andservices/services-improve-access.

67. Ministry of Health. Health promotion for primary health care. 2017.

https://www.health.govt.nz/our-work/primary-health-care/primary-health-care-subsidies-andservices/health-promotion-primary-health-care

68. Ministry of Health. Care Plus: An overview. In: Health Mo, editor. Wellington: Ministry of Health; 2004.

69. Perera R, McDonald J, Cumming J, Goodhead A. Primary Health Organisations: The first year (July 2002-June 2003) from the PHO perspective. Wellington: Health Services Research Centre, Victoria University of Wellington; 2003.

70. Ministry of Health. Summary of responses to 'The future shape of primary health care: A discussion document'. Wellington: Ministry of Health; 2000. 
71. Keene L, Bagshaw P, Nicholls MG, Rosenberg B, Frampton CM, Powell I. Funding New Zealand's public healthcare system: Time for an honest appraisal and public debate. New Zealand Medical Journal. 2016;129:10-20.

72. Carville O. Unmet need 'a national disgrace'. The Press. 2014.

73. Bagshaw P. Re: The clinical consequences of underfunding elective healthcare: A second red flag warning. New Zealand Medical Journal. 2016;129(1440):135.

74. Lawn JE, Rohde J, Rifkin S, Were M, Paul VK, Chopra M. Alma-Ata 30 years on: revolutionary, relevant, and time to revitalise. Lancet. 2008;372(9642):917-27.

75. World Health Organisation. Primary health care: 25 years after Alma-Ata. Cairo: Regional Office for the Eastern Mediterranean; 2003.

76. Macinko J, Starfield B, Shi L. The contribution of primary care systems to health outcomes within Organization for Economic Cooperation and Development (OECD) countries, 1970-1998. Health Services Research. 2003;38(3):831-65.

77. Hsieh VC-R, Wu JC-1, Wu T-N, Chiang T-1. Universal coverage for primary health care is a wise investment: evidence from 102 low-and middle-income countries. Asia Pacific Journal of Public Health. 2015;27(2):NP877-NP86.

78. Starfield B. State of the art in research on equity in health. Journal of Health Politics, Policy and Law. 2006;31(1):11-32.

79. Basu J, Clancy C. Racial disparity, primary care, and specialty referral. Health services research. 2001;36(6 Pt 2):64.

80. Shi L, Regan J, Politzer RM, Luo J. Community health centers and racial/ethnic disparities in healthy life. Int J Health Serv. 2001;31(3):567-82.

81. Shi L, Starfield B. Primary care, income inequality, and self-rated health in the United States: A mixed-level analysis. Int J Health Serv. 2000;30(3):541-55.

82. Starfield B, Shi L. Policy relevant determinants of health: An international perspective. Health Policy. 2002;60(3):201-18.

83. Welch WP, Miller ME, Welch HG, Fisher ES, Wennberg JE. Geographic variation in expenditures for physicians' services in the United States. N Engl J Med. 1993;328(9):621-7. 84. Ansari Z, Laditka JN, Laditka SB. Access to health care and hospitalization for ambulatory care sensitive conditions. Medical care research and review. 2006;63(6):719-41. 85. Russell LB. Prevention's potential for slowing the growth of medical spending. Washington, DC: National Coalition on Health Care. 2007.

86. Jaen CR, Stange KC, Nutting PA. Competing demands of primary care: a model for the delivery of clinical preventive services. Journal of Family Practice. 1994;38(2):166-74. 
87. Shaw E, Howard J, Clark E, Etz R, Arya R, Tallia A. Decision-making processes of patients who use the emergency department for primary care needs. Journal of Health Care for the Poor and Underserved. 2013;24(3):1288-305. doi:10.1353/hpu.2013.0140.

88. Cowling TE, Cecil EV, Soljak MA, Lee JT, Millett C, Majeed A et al. Access to primary care and visits to emergency departments in England: A cross-sectional, population-based study. PLoS One. 2013;8(6):e66699. doi:10.1371/journal.pone.0066699.

89. Kringos DS, Boerma W, van der Zee J, Groenewegen P. Europe's strong primary care systems are linked to better population health but also to higher health spending. Health Aff. 2013;32(4):686-94.

90. Levesque J-F, Harris MF, Russell G. Patient-centred access to health care:

Conceptualising access at the interface of health systems and populations. Int J Equity Health. 2013;12(1):18.

91. Frenk J, White KL. The concept and measurement of accessibility. Health services research: An anthology. vol 534. Washington, DC: Pan American Health Organization; 1992. p. $842-55$.

92. Donabedian A. Aspects of medical care administration: Specifying requirements for health care. Harvard University Press; 1973.

93. Salkever DS. Accessibility and the demand for preventive care. Social Science \& Medicine. 1976;10(9-10):469-75.

94. Penchansky R, Thomas JW. The concept of access: Definition and relationship to consumer satisfaction. Medical Care. 1981;19(2):127-40.

95. Mooney GH. Equity in health care: Confronting the confusion. Effective Health Care. 1983;1(4):179-85.

96. Andersen RM. A behavioral model of families' use of health services. Chicago, IL:

Centre for Health Administration Studies, University of Chicago; 1968.

97. Phelps CE. Health economics. Addison-Wesley Reading, MA; 1997.

98. Torrance GW, Thomas WH, Sackett DL. A utility maximization model for evaluation of health care programs. Health Services Research. 1972;7(2):118.

99. Shengelia B, Tandon A, Adams OB, Murray CJ. Access, utilization, quality, and effective coverage: An integrated conceptual framework and measurement strategy. Social Science \& Medicine. 2005;61(1):97-109.

100. Becker GS. Human capital and the personal distribution of income: An analytical approach. vol 1. Institute of Public Administration; 1967. 
101. Berman P, Kendall C, Bhattacharyya K. The household production of health: Integrating social science perspectives on micro-level health determinants. Social Science \& Medicine. 1994;38(2):205-15.

102. Grossman M. The relationship between health and schooling: What's new? Nordic Journal of Health Economics. 2015;3(1):7-17.

103. Kowalski A. Censored quantile instrumental variable estimates of the price elasticity of expenditure on medical care. Journal of Business \& Economic Statistics. 2016;34(1):107-17. 104. Seesaengnom D, Parackal S, Ho E, editors. Utilisation of and barriers to accessing primary health care services in New Zealand: A cross-sectional survey of Thai adults living in Auckland. Social Environment, Migration, and Health Proceedings of the Fifth International Asian and Ethnic Minority Health and Wellbeing Conference; 2012. 105. Parslow R, Jorm A, Christensen H, Jacomb P, Rodgers B. Gender differences in factors affecting use of health services: An analysis of a community study of middle-aged and older Australians. Social Science \& Medicine. 2004;59(10):2121-9.

106. Green CA, Pope CR. Gender, psychosocial factors and the use of medical services: A longitudinal analysis. Social Science \& Medicine. 1999;48(10):1363-72.

107. Spitzer DL. Engendering health disparities. Canadian Journal of Public Health. 2005;96(2):s78-s96.

108. Vaidya V, Partha G, Karmakar M. Gender differences in utilization of preventive care services in the United States. Journal of Women's Health. 2012;21(2):140-5.

109. Idler EL. Discussion: Gender differences in self-rated health, in mortality, and in the relationship between the two. The Gerontologist. 2003;43(3):372-5.

110. Levesque J-F, Pineault R, Hamel M, Roberge D, Kapetanakis C, Simard B et al. Emerging organisational models of primary healthcare and unmet needs for care: Insights from a population-based survey in Quebec province. BMC Family Practice. 2012;13(1):66. 111. Bryant T, Leaver C, Dunn J. Unmet healthcare need, gender, and health inequalities in Canada. Health policy. 2009;91(1):24-32.

112. Hou F, Chen J. Unmet needs for health care. Health Reports. 2002;13(2):23.

113. Law M, Wilson K, Eyles J, Elliott S, Jerrett M, Moffat T et al. Meeting health need, accessing health care: the role of neighbourhood. Health \& Place. 2005;11(4):367-77. 114. Dunlop S, Coyte PC, McIsaac W. Socio-economic status and the utilisation of physicians' services: results from the Canadian National Population Health Survey. Social Science \& Medicine. 2000;51(1):123-33.

115. Nabalamba A, Millar WJ. Going to the doctor. Health Reports. 2007;18(1):23. 
116. Seiffge-Krenke I. Adolescents' health: A developmental perspective. Mahwah, NJ: Lawrence Erlbaum Associates Publishers; 1998.

117. Roter D, Lipkin Jr M, Korsgaard A. Sex differences in patients' and physicians' communication during primary care medical visits. Medical Care. 1991;29(11):1083-93. 118. Marshall EG. Universal health care?: Access to primary care and missed health care of young adult Canadians: University of British Columbia; 2007.

119. Hoogendijk EO, Muntinga ME, van Leeuwen KM, van der Horst HE, Deeg DJ, Frijters DH et al. Self-perceived met and unmet care needs of frail older adults in primary care. Archives of Gerontology and Geriatrics. 2014;58(1):37-42. 120. Scott KM, Marwick JC, Crampton PR. Utilization of general practitioner services in New Zealand and its relationship with income, ethnicity and government subsidy. Health services management research. 2003;16(1):45-55.

121. Ministry of Health. A portrait of health: Key results of the 2002/03 New Zealand Health Survey. Wellington: Ministry of Health; 2004.

122. Anderson LM, Scrimshaw SC, Fullilove MT, Fielding JE, Normand J. Culturally competent healthcare systems: A systematic review. American journal of preventive medicine. 2003;24(3):68-79.

123. Napier AD, Ancarno C, Butler B, Calabrese J, Chater A, Chatterjee H et al. Culture and health. The Lancet. 2014;384(9954):1607-39.

124. Barer M. Why are some people healthy and others not? Routledge; 2017.

125. Came H, Doole C, McKenna B, McCreanor T. Institutional racism in public health contracting: Findings of a nationwide survey from New Zealand. Social Science \& Medicine. 2018;199:132-9.

126. Te Morenga L, Pekepo C, Corrigan C, Matoe L, Mules R, Goodwin D et al. Codesigning an mHealth tool in the New Zealand Māori community with a "Kaupapa Māori" approach. AlterNative: An International Journal of Indigenous Peoples. 2018;14(1):90-9. 127. Te Karu L, Bryant L, Harwood M, Arroll B. Achieving health equity in Aotearoa New Zealand: The contribution of medicines optimisation. Journal of Primary Health Care. 2018;10(1):11-5.

128. La Vecchia C, Negri E, Pagano R, Decarli A. Education, prevalence of disease, and frequency of health care utilisation. The 1983 Italian National Health Survey. Journal of Epidemiology \& Community Health. 1987;41(2):161-5. 
129. Diaz E, Calderon-Larranaga A, Prado-Torres A, Poblador-Plou B, Gimeno-Feliu LA. How do immigrants use primary health care services? A register-based study in Norway. Eur J Public Health. 2015;25(1):72-8. doi:10.1093/eurpub/cku123.

130. Calderón-Larrañaga A, Gimeno-Feliu LA, Macipe-Costa R, Poblador-Plou B, Bordonaba-Bosque D, Prados-Torres A. Primary care utilisation patterns among an urban immigrant population in the Spanish National Health System. BMC Public Health. 2011;11(1):432.

131. Gushulak B. Healthier on arrival? Further insight into the "healthy immigrant effect". Canadian Medical Association Journal. 2007;176(10):1439-40.

132. Starfield B, Shi L. The medical home, access to care, and insurance: A review of evidence. Pediatrics. 2004;113(Supplement 4):1493-8.

133. Bindman AB, Grumbach K, Osmond D, Vranizan K, Stewart AL. Primary care and receipt of preventive services. Journal of General Internal Medicine. 1996;11(5):269-76. 134. Scott KM, Sarfati D, Tobias MI, Haslett SJ. A challenge to the cross-cultural validity of the SF-36 health survey: Factor structure in Māori, Pacific and New Zealand European ethnic groups. Social Science \& Medicine. 2000;51(11):1655-64.

135. Farag M, NandaKumar A, Wallack S, Hodgkin D, Gaumer G, Erbil C. The income elasticity of health care spending in developing and developed countries. International Journal of Health Care Finance and Economics. 2012;12(2):145-62.

136. Sen A. Is health care a luxury? New evidence from OECD data. International Journal of Health Care Finance and Economics. 2005;5(2):147-64.

137. Pearson AL, Pearce J, Kingham S. Deprived yet healthy: Neighbourhood-level resilience in New Zealand. Social Science \& Medicine. 2013;91:238-45.

138. Chan WC, Wright C, Riddell T, Wells S, Kerr AJ, Gala G et al. Ethnic and socioeconomic disparities in the prevalence of cardiovascular disease in New Zealand. New Zealand Medical Journal. 2008;121(1285).

139. Liljas B. The demand for health with uncertainty and insurance. J Health Econ. 1998;17(2):153-70.

140. Fergusson D, Horwood L, Shannon F. Medical insurance and childhood general practitioner contacts. The New Zealand medical journal. 1989;102(880):609-10.

141. Finkelstein A, Gentzkow M, Williams H. Sources of geographic variation in health care: Evidence from patient migration. Quarterly Journal of Economics. 2016;131(4):1681-726. doi:10.1093/qje/qjw023. 
142. Jedidi K, Zhang ZJ. Augmenting conjoint analysis to estimate consumer reservation price. Management Science. 2002;48(10):1350-68.

143. Stock JH, Watson MW. Introduction to econometrics: Global edition. Boston, MA: Pearson Education; 2012.

144. Wooldridge JM. Introductory econometrics: A modern approach. Cengage Learning; 2013.

145. World Health Organisation. Obesity: Preventing and managing the global epidemic. Geneva: World Health Organisation; 2000. Report No.: 894.

146. Bhaskaran K, Douglas I, Forbes H, dos-Santos-Silva I, Leon DA, Smeeth L. Body-mass index and risk of 22 specific cancers: A population-based cohort study of $5 \cdot 24$ million UK adults. The Lancet. 2014;384(9945):755-65.

147. Jensen MD, Ryan DH, Apovian CM, Ard JD, Comuzzie AG, Donato KA et al. 2013 AHA/ACC/TOS guideline for the management of overweight and obesity in adults: A report of the American College of Cardiology/American Heart Association Task Force on Practice Guidelines and The Obesity Society. J Am Coll Cardiol. 2014;63(25 Part B):2985-3023. 148. National Heart L, and Blood Institute. Managing overweight and obesity in adults: Systematic evidence review from the Obesity Expert Panel, 2013. Washington, DC: US Department of Health and Human Services; 2013.

149. Puhani P. The Heckman correction for sample selection and its critique. Journal of Economic Surveys. 2000;14(1):53-68.

150. Hefford M, Crampton P, Foley J. Reducing health disparities through primary care reform: The New Zealand experiment. Health Policy. 2005;72(1):9-23.

151. Ministry of Health. Methodology report 2015/16: New Zealand Health Survey. Wellington: Ministry of Health; 2016.

152. Korn EL, Graubard BI. Analysis of health surveys. Toronto: John Wiley \& Sons, Inc.; 1999.

153. Ministry of Health. New Zealand Health Survey methodology report: 2012. Wellington: Ministry of Health; 2012.

154. Ministry of Health. Methodology report for the 2006/07 New Zealand Health

Survey. Wellington: Ministry of Health; 2008.

155. Ministry of Health. New Zealand Health Survey methodology report 2012/13.

Wellington: Ministry of Health; 2013.

156. Ministry of Health. Methodology report 2013/14: New Zealand Health 
Survey. Wellington: Ministry of Health; 2014.

157. Ministry of Health. Methodology report 2014/15: New Zealand Health Survey.

Wellington: Ministry of Health; 2015.

158. Wilkinson TJ, Sainsbury R. The association between mortality, morbidity and age in

New Zealand's oldest old. The International Journal of Aging and Human Development. 1998;46(4):333-43.

159. Guay M, Dubois M-F, Corrada M, Lapointe-Garant M-P, Kawas C. Exponential increases in the prevalence of disability in the oldest old: A Canadian national survey. Gerontology. 2014;60(5):395-401.

160. Bolin K, Jacobson L, Lindgren B. The family as the health producer-when spouses act strategically. J Health Econ. 2002;21(3):475-95.

161. Jacobson L. The family as producer of health — an extended Grossman model. J Health Econ. 2000;19(5):611-37.

162. Babor TF, Higgins-Biddle J, Saunders J, Monteiro M. The Alcohol Use Disorders Identification Test-Guidelines for use in Primary Care. Geneva, Switzerland: World Health Organization; 2001.

163. Jatrana S, Crampton P, Norris P. Ethnic differences in access to prescription medication because of cost in New Zealand. Journal of Epidemiology \& Community Health. 2010:jech. 2009.099101.

164. Rubin DB. Inference and missing data. Biometrika. 1976;63(3):581-92.

165. Little RJ, Rubin DB. The analysis of social science data with missing values.

Sociological Methods \& Research. 1989;18(2-3):292-326.

166. Little RJ, Rubin DB. Bayes and multiple imputation. Statistical Analysis with Missing Data, Second Edition. 2002:200-20.

167. Little RJ. Regression with missing X's: A review. Journal of the American Statistical Association. 1992;87(420):1227-37.

168. Little RJ, Schenker N. Missing data. Handbook of statistical modeling for the social and behavioral sciences. New York: Springer; 1995. p. 39-75.

169. Little TD, Jorgensen TD, Lang KM, Moore EWG. On the joys of missing data. Journal of Pediatric Psychology. 2013;39(2):151-62.

170. Heeringa SG, Little RJ, Raghunathan TE. Multivariate imputation of coarsened survey data on household wealth. In: Groves RM, Dillman DA, Eltinge JL, Little RJ, editors. Survey non-response. New York: John Wiley \& Sons; 2002. p. 357-72. 
171. Acock AC. Working with missing values. Journal of Marriage and family. 2005;67(4):1012-28.

172. Abrevaya J, Donald SG. A GMM approach for dealing with missing data on regressors and instruments. Unpublished manuscript. 2011.

173. Roodman D. Estimating fully observed recursive mixed-process models with cmp. Stata Journal. 2011;11(2):159-206.

174. Stock JH, Wright JH, Yogo M. A survey of weak instruments and weak identification in generalized method of moments. Journal of Business \& Economic Statistics. 2002;20(4):51829.

175. Poi BP. Jackknife instrumental variables estimation in Stata. Stata Journal. 2006;6(3):364-76.

176. Flores-Lagunes A. Finite sample evidence of IV estimators under weak instruments. Journal of Applied Econometrics. 2007;22(3):677-94.

177. Staiger DO, Stock JH. Instrumental variables regression with weak instruments. Econometrica. 1997;65:557-86.

178. Stock JH, Yogo M. Testing for weak instruments in linear IV regression. Cambridge, MA: National Bureau of Economic Research; 2002.

179. Ministry of Health. Tatau Kahukura Māori Health Chart Book 2015. Wellington: Ministry of Health; 2015.

180. Ministry of Health. Nurses and their work in primary health care. Wellington; 2005. 181. Angrist JD, Pischke J-S. Mostly harmless econometrics: An empiricist's companion. Princeton University Press; 2008.

182. Howell BE. Funding populations and paying providers: The role of financial risk in the New Zealand Primary Health Care Strategy. Wellington: Victoria University of Wellington; 2016.

183. Taylor C. Primary care keeps Budget hopes in check as Govt faces tough choices. New Zealand Doctor. 2018.

184. Brown R. Sapere reasonable fees method 'not keeping up with GP costs'. 2018. 185. Love T, Blick G. Primary care funding - a discussion paper. Wellington: Sapere Research Group; 2014.

186. Primary Care Working Group. Primary Care Working Group on general practice sustainability: Report to the Minister of Health. Wellington; 2015.

187. Howden-Chapman P. Home truths: Confronting New Zealand's housing crisis. Wellington: Bridget Williams Books; 2015. 
188. Goodyear RK, Fabian A. Housing in Auckland: Trends in housing from the Census of Population and Dwellings 1991 to 2013. Wellington: Statistics New Zealand; 2014. 189. Ministry of Health. Health loss in New Zealand 1990-2013. Wellington: Ministry of Health; 2016.

190. Ministry of Health. Mortality: Historical summary 1948-2015. Wellington. 2018. https://www.health.govt.nz/publication/mortality-historical-summary-1948-2015.

191. Ministry of Health. Reducing rheumatic fever. Ministry of Health, Wellington. 2018. https://www.health.govt.nz/our-work/diseases-and-conditions/rheumatic-fever/reducingrheumatic-fever.

192. Ministry of Health. Publicly funded hospital discharges - 1 July 2014 to 30 June 2015.

Ministry of Health, Wellington. 2017. https://www.health.govt.nz/publication/publiclyfunded-hospital-discharges-1-july-2014-30-june-2015.

193. Goodin RE, Le Grand J. Not only the poor: The middle classes and the welfare state. London: Routledge; 2018.

194. Royal New Zealand College of General Practitioners. General practice fact sheet. Wellington2014.

195. Taylor C. Q\&A: 'Scrap it!' Malloy draws line in sand over vexed VLCA debate. New Zealand Doctor. 2017.

196. Brabyn L, Barnett R. Population need and geographical access to general practitioners in rural New Zealand. The New Zealand Medical Journal (Online). 2004;117(1199).

197. Goins RT, Williams KA, Carter MW, Spencer SM, Solovieva T. Perceived barriers to health care access among rural older adults: A qualitative study. The Journal of Rural Health. 2005;21(3):206-13.

198. Breidert C, Hahsler M, Reutterer T. A review of methods for measuring willingness-topay. Innovative Marketing. 2006;2(4):8-32.

199. Baum CF, Schaffer ME, Stillman S. Instrumental variables and GMM: Estimation and testing. Stata journal. 2003;3(1):1-31. 